\title{
Periodicity and Accretion Taxation: Norms and Implementation
}

\author{
Jeff Strnad $†$
}

\section{CONTENTS}

I. Accretion Taxation and Periodicity: IntroducTORY CONCEPTS

A. Tax Periodicity and Continuous Taxation: An Example

B. The Need for Normative Analysis

II. ACCREtion Taxation Norms 1832

A. Wealth-Related Norms 1832

1. Taxing Intangible Benefits from Holding Wealth 1833

a. Introduction 1833

b. The Intangible Benefits Justification Implies Continuous Accretion Taxation

c. Adding Risk, Inflation, and a Positive Riskless Rate of Return 1840

d. Increasing Marginal Tax Rates 1843

2. Accretion Taxation as a Second Best Wealth $\operatorname{Tax}$

3. The Cost of Deviations from the Ideal Under Wealth-Related Norms

a. The Cost of Deviations Under the Intangible Benefits Justification

b. The Cost of Deviations Under the Second Best Justification

c. Conclusions

B. Tax Neutrality

† John B. Milliken Professor of Taxation, University of Southern California, and Associate Professor of Law and Economics, California Institute of Technology. I am grateful for comments received in workshops at Boalt Law School, the Harvard Seminar on Current Research in Taxation, the University of Southern California Law Center and the Yale Law School and for substantial helpful comments received outside of the workshop context from Bill Andrews, Joe Bankman, Boris Bittker, Mike Graetz, Tom Griffith, Dan Halperin, Henry Hansmann, Louis Kaplow, Bill Klein, Ed McCaffery, Roberta Romano, Dan Rubinfeld, Alan Schwartz and Al Warren. All errors are my own responsibility. The numerical simulations in this Article were made possible by a grant from the University of Southern California Faculty Research and Innovation Fund. 
1. The Samuelson Result

1853

2. Periodicity Implications of the Samuelson Result 1857

C. The Haig-Simons Ideal

1860

III. The Normative Costs of the Accounting Period CHOICE

A. Asset Path Information and Administrative Costs 1863

1. Asset Path Information 1863

2. Administrative Costs

1866

B. Asset Riskiness, Strategic Trading, and Transaction

Costs

1868

1. Bridge Process Technology

1868

2. Riskiness and Strategic Trading

1874

C. Samuelson Neutrality and the Timing Option

1879

D. The Normative Costs of the Timing Option

1882

IV. Policy Implications

1884

A. Timing Option Distortions: Attempts at Control Under Current Law

1885

1. The Limitation on Capital Losses

1885

a. Timing Option Distortions and the Capital Gains Provisions

1885

b. Reforming the Limitation on Capital Losses and the Efficacy of the Limitation as Reformed

2. Restrictions on Losses from Wash Sales

3. Conclusions

B. Designing an Accretion Tax

1. Approximation Techniques and Their Limitations

2. Frequent Assessment

3. Directions for Future Research

1901

V. Conclusions

1903

Appendix: Periodic and Continuous Taxation in a

RISKLESS OR RISK-Neutral SETTING

I. The Pre-Tax Asset Paths

II. Linear and Exponential Approximations for PreTAX PathS

III. AFter-TaX Interest Rates

IV. Computing the Equivalent Tax at a Given Time 1907

V. Computing After-Tax Present Value 
Much of the modern tax policy debate has centered on two paradigmatic tax treatments: cash flow taxation and accretion taxation. ${ }^{1}$ For an investment, cash flow taxation calls for deducting investment costs when they are paid and taking cash receipts into income when they are received. In contrast, accretion taxation calls for taxing changes in the value of the investment even if the investor is simply holding the investment and neither paying out nor receiving any cash flows. In tax terminology, accretion taxation subjects losses and gains to taxation even though they are "unrealized." In contrast, the cash flow method taxes gains and losses only if they are "realized" by sale of the investment or by the receipt or payment of cash flows.

Theorists have debated the merits of cash flow taxation and accretion taxation under the assumption that there are no problems in implementing either tax. ${ }^{2}$ However, implementing the two taxes raises some difficult issues, and these issues have spawned an extensive literature. ${ }^{3}$ One set of implementation problems is particularly serious for accretion taxation: how to tax unrealized changes in wealth. ${ }^{4}$ These changes are not accompanied by a sale or other event that creates a record of the magnitude of the changes. As a result, policymakers must address the question of "periodicity," how often changes in value should be assessed and taxed. Advocates of accretion taxation usually assume that annual assessment is ideal and then struggle with the problem of estimating the annual wealth changes associated with various assets. ${ }^{5}$

There are several problems with this approach. The most serious is that policy proposals for implementing accretion taxation are not linked clearly or carefully to the norms that motivate choice of the accretion approach in the first place. Unless reference is made to these norms, it is

1. The accretion taxation treatment has been identified with "the income tax" while the cash flow treatment has been identified with "the consumption tax." The literature is massive. See, e.g., Balcer, The Taxation of Capital Gains: Samuelson's Fundamental Principle, 38 PuB. Fin. 1, 1-2 (1983) (citing sources).

The argument for identifying cash flow taxation with a consumption tax is straightforward. Income is either invested or consumed. The cash flow tax allows a deduction for investment. This deduction exempts investment from the tax base so that only consumption is taxed.

2. See, e.g., Andrews, Faimess and the Personal Incone Tax: A Reply to Professor IVarren, 88 Harv. L. Rev. 947 (1975); Kelman, Time Preference and Tax Equity, 35 Stan. L. Rev. 649 (1983); Warren, Faimess and a Consumption-Type or Cash Flow Personal Income Tax, 88 HaRv. L. REv. 931 (1975) [hereinafter Warren 1975]; Warren, Would a Consumption Tax Be Fairer Than an Income Tax?, 89 YALE L.J. 1081 (1980) [hereinafter Warren 1980].

3. Sep, e.g., Andrews, A Consumption-Type or Cash Flow Personal Income Tax, 87 HaRv. L. Rev. 1113 (1974); Graetz, Expendilure Tax Design, in What Should BE Taxed, Income or Expenditure? 161 (J. Pechman ed. 1980).

4. One prominent critic of accretion taxation has termed the problems associated with the realization requirement "the Achilles heel" of that method of taxation. See Andrews, The Achilles' Heel of the Comprehensize Income Tax, in Restructuring The Federal TAX SysTEM 278, 280 (1986).

5. See, eg., Halperin, Interest in Disguise: Taxing the "Time Value of Money," 95 YALE L.J. 506 (1986); Shakow, Taxation Without Realization: A Proposal for Accrual Taxation, 134 U. PA. L. REv. 1111 (1986); Slawson, Taxing as Ordinary Income the Appreciation of Publicly Held Stock, 76 YAle L.J. 623 (1967); Note, Realizing Appreciation Without Sale: Accrual Taxation of Capital Gains on Marketable Securities, 34 STAN. L. REv. 857 (1982). 
unclear how much is lost when various approximations to accretion treatment are used. One must know, for example, how much worse it is to tax certain assets every five years or only at death rather than annually. With that knowledge, a policymaker can compare the benefits of frequent assessment with the costs to the government and to taxpayers. The costs of assessment will be termed "administrative costs" while the losses that result from falling short of a norm because of less frequent assessment will be termed "normative costs."

There is a second basic problem: Why is annual assessment presumed to be ideal? In a medieval agricultural economy, tax compliance might have required collection at the time of the annual harvest. But today there is no obvious reason to assess taxes annually. ${ }^{6}$ Indeed, some parts of the tax system do not operate on an annual basis. For example, estimated tax payments are made every three months. Choice of an annual assessment period as ideal should be justified rather than presumed.

One intriguing possibility is that assessment might be made at periods much longer than the ideal period without losing much of the benefit of taxing at ideal intervals. This would be accomplished by altering the tax imposed for the longer period to approximate the tax that would have been due if taxation had been imposed repeatedly at the end of each ideal interval. Such a tax would replicate an ideal accretion tax closely even though assessment is made only once every several years or even once in a lifetime. Thus administrative costs could be reduced without an offsetting increase in normative costs.

In addressing these issues, this Article begins by considering four norms that have motivated scholars and policymakers to favor accretion taxation. The first norm is that intangible benefits from holding wealth should be taxed. The second norm is that the tax system should address disparities in wealth as well as disparities in consumption. For many, the ability of accretion taxation to satisfy these two "wealth-related" norms is what makes it fairer than cash flow taxation. The third norm is tax neutrality based on the "Samuelson principle." This norm is satisfied if the value of each investment is the same in the hands of investors who àre taxed at

6. One argument for assessing taxes annually is that business accounting is often done on an annual basis. Allowing the tax accounts to be annualized might save administrative resources for businesses and thus lower tax compliance costs. The businesses would be able to cumulate both their tax and financial accounts at the same time and thus avoid some duplication of effort. The problem with this argument is that corporate profits, the financial accounting analog of taxable income, are typically reported quarterly to the shareholders. Presumably, the same administrative advantages of cumulating both tax and financial accounts simultaneously at year end would exist if there were quarterly tax assessments coinciding with the quarterly profit reports to shareholders.

Of course, if there are strong normative reasons for assessing taxes over a period that does not coincide with any business accounting period, these reasons may override any saving in administrative costs that might accrue from matching the tax assessment period to the financial accounting period. In addition, businesses might be able to adjust the financial accounting period to match the desired tax accounting period. 
different rates. This means that there is no scope for tax motivated deals between taxpayers in different brackets. Tax motivated deals tend to distort the allocation of investment between different projects and may have adverse distributional consequences. The fourth norm is the "HaigSimons ideal." Under this norm, tax should be levied on consumption plus the change in wealth over each accounting period."

Although the results in this Article reflect on the usefulness and coherence of these norms, the Article will not discuss which of the norms, or what mixture of them, is most desirable as a foundation for accretion taxation. I have chosen these norms because they are the main justifications that scholars and policymakers have put forward in advocating accretion taxation. The focus here will be on two other tasks.

The first task is to determine the most basic implications of each norm for periodicity issues. To accomplish this task two questions need answers. First, what is the ideal periodicity under each norm? Second, how costly is any particular deviation from that ideal under the norm? If the answers to these two questions are clear, then the policymaker or scholar can measure the normative costs of choosing a particular periodicity.

The second task involves tax implementation. Given a structure of normative costs, what can one say about the choice of accounting period under the tax laws? This task needs to be distinguished from a complementary effort that has been the focus of much of the literature: the implications of administrative costs for implementation of an accretion tax. ${ }^{8}$ This Article focuses almost exclusively on the normative cost side of the inquiry. A few polar cases of very high and very low administrative cost are examined to illustrate the policy implications of the normative cost results, but no attempt is made to make fine distinctions based on administrative costs.

Part II sets out the major results on the implications of the norms. Only the two wealth-related norms speak to the ideal periodicity for accretion taxation. Both of these norms suggest that continuous taxation of wealth changes is ideal. That is, the accounting period should be infinitesimally short, and wealth changes should be taxed the instant they occur: Unfortunately, it is not easy under either of the wealth-related norms to quantify the comparative loss due to different deviations from continuous taxation. This makes it difficult to compare normative costs to the administrative cost of implementation under these norms.

Tax neutrality based on the Samuelson principle does not support any

7. These four norms can be characterized at least roughly in terms of the traditional categories of equity and efficiency. The wealth-related theories and the Haig-Simons ideal are motivated primarily by equity considerations, while tax neutrality involves efficiency. See R. TREsch, Public FinanCE: A NORMative TheORY 265-71 (1981) (discussing equity rationale for Haig-Simons ideal); infra text accompanying note 106 (connecting tax neutrality goal to efficiency objective).

8. See Shakow, supra note 5; Note, supra note 5. 
particular frequency of taxation, but it does imply that the frequency that is chosen should be applied to all assets. The Samuelson principle is a consistency requirement; it does not determine the choice of the basic accounting period for the tax system. In fact, the Samuelson principle supports a consistently applied cash flow tax as well as an accretion tax of any given periodicity.

The Haig-Simons ideal does not help in determining the proper period for accretion taxation. If one fixes the periodicity of an accretion tax, the tax will fail to meet the Haig-Simons ideal for any other accounting period. Attempts to define a tax that will satisfy the doctrine independent of the accounting period suggest the use of cash flow taxation rather than an accretion tax of any periodicity.

The wealth distribution and tax neutrality norms suggest that continuous taxation is ideal and that it is important to apply this ideal consistently across different assets. Using these guidelines, Parts III and IV study implementation and policy issues. ${ }^{\circ}$ Part III examines the normative costs of choosing periodic rather than continuous taxation. Two major conclusions emerge. First, the normative costs of taxing wealth changes periodically increase with the volatility of the assets. This suggests that the greatest effort at frequent assessment under an accretion tax should be aimed at the most volatile assets. ${ }^{10}$

Second, the degree to which volatility makes frequent assessment important depends on how costly it is to trade the asset and on the treatment of tax losses. If investors can obtain the tax benefits associated with taking losses early by trading at low cost, then the normative cost of having a long accounting period for risky assets is substantially higher. This is true for both of the wealth-related norms and also for the norm based on the Samuelson principle. Allowing early loss taking dilutes the wealth tax aspects of accretion taxation. It also allows some assets to be taxed with different periodicity than others at the option of the taxpayer. This inconsistent treatment across assets leads to violations of the Samuelson principle.

Part IV explores the tax policy implications of the results in Parts II and III using two main lines of inquiry. One line of inquiry explores the possibility of controlling the problem of early loss taking by using existing techniques in U.S. law. In particular, one might use either the capital asset versus ordinary asset distinction already in the code or the wash sale provisions of the code that prevent loss taking followed by repurchase of

9. Some readers may not be interested in Part II's extended demonstration that a continuous tax is optimal and that consistency is important. These readers may proceed directly to Parts III and IV, which can be read independently of Part II.

10. In contrast, the current system permits long delays in assessment for many classes of risky assets while expending great effort to assess some low volatility assets frequently. See infra text accompanying notes 223-26. 
the same asset. Part IV shows that these two approaches have serious weaknesses.

With this result in hand, Part IV takes up the second main line of inquiry: the implications of the results in Parts II and III for the general question of how to design an accretion tax. There are two easy cases. Where transaction costs are low and market data is readily available, frequent assessment seems the best tax treatment. Frequent assessment minimizes the potential gains from early loss taking and similar trading strategies that are viable when transaction costs are low. Frequent assessment also provides a good approximation of continuous taxation. Where transactions costs are high, early loss taking and other trading strategies are not profitable for taxpayers. In this case, it is possible to approximate continuous taxation well by tax rules that are based only on the purchase price, final value and holding period of the asset.

Cases that do not fall into these two categories are more difficult. There are technical problems involved in approximating continuous taxation. Furthermore, the wealth distribution norms that underlie the choice of continuous taxation as an ideal do not provide a clear picture of how serious a given deviation from continuous taxation is. As a result, it is difficult to know how to strike a balance between the administrative costs of frequent assessment and the normative costs that will result from deviating from continuous taxation.

Since the length of the accounting period is an important conceptual issue for an income tax system, resolving these problems would be valuable even if the deviations from continuous taxation under current law were modest. But Part IV also indicates that these deviations are often large and distributed unevenly across different types of assets. This raises serious equity and efficiency concerns about the current system.

To get a feeling for the magnitudes involved, it is necessary to isolate phenomena associated with asset riskiness from more conventional phenomena. Two aspects of the current tax treatment of risky investments are troubling. First, the current system allows the taxpayer to delay taxation of any gain over the purchase price of an asset by holding rather than selling the asset. This is the "conventional" concern about deferral. Second, there are potential gains for taxpayers from strategic trading. The taxpayer can take losses when they occur and defer the matching gains that occur if the asset moves back up to the original purchase price. This second aspect is peculiar to risky assets and is the focus of considerable attention in Parts III and IV.

For many investments, this second aspect is significant as well as the first aspect. Consider a twenty-five year investment in a typical common stock by an individual in the $30 \%$ bracket. Allowing taxes on gains over the purchase price to be delayed until sale instead of being taxed continuously for this investment is equivalent to granting a $7.1 \%$ investment tax 
credit when the stock is purchased. ${ }^{11}$ The ability to trade strategically is equivalent to allowing an additional investment tax credit of $3.5 \%$ when the stock is purchased. ${ }^{12}$ This second advantage does not exist for low risk assets since these assets are unlikely to move below their purchase price in value. Thus, strategic trading effects potentially bias investment significantly toward riskier assets.

The results in Part IV are important for addressing many detailed policy problems as well as for the overall design of an accretion tax. Whenever the taxpayer can delay realization, the approach taken in the law needs to be sensitive to asset riskiness, transaction costs and the possibilities for strategic trading. Part IV discusses potential ex post solutions, such as attributing cumulated income to past periods, in terms of these three important factors. This discussion should be valuable for scholars and policymakers faced with tax policy problems that arise from the ability of the taxpayer to delay realization. ${ }^{13}$

Prior to the derivation and discussion of the results in Parts II, III and IV, Part I introduces key concepts through an example. Part V summarizes the major conclusions reached in the Article. Finally, an Appendix describes the derivation and computation of many of the numerical examples presented throughout the Article. ${ }^{14}$

11. The method for arriving at the $7.1 \%$ figure is as follows. The average stock market asset has earned an average return of $11.4 \%$ annually over the years from 1926-1981 compared to an average nominal riskless rate of $3.1 \%$ over the same period. See infra note 148 . An investment of $\$ 100$ for 25 years at an annual rate of $11.4 \%$ would be worth $\$ 1486.38$ at the end of the 25 years. The net gain is $\$ 1386.38$. Applying a $30 \%$ tax rate to this net gain yields a tax of $\$ 415.91$. This is the tax that would be applied under current law when the asset is sold at the end of the 25 year period.

With a nominal riskless rate of $3.1 \%$, the after-tax interest rate for the $30 \%$ bracket taxpayer is $70 \%$ of the $3.1 \%$. Using this after-tax interest rate, the continuous tax on the average path of the asset transiated into a tax at the end of the 25 years would be $\$ 492.15$. The method for computing a continuous tax as an equivalent tax at a point in time is discussed infra at text accompanying notes 21-22 and in Part IV of Appendix A.

To translate the $\$ 76.24$ difference between the $\$ 492.15$ and the $\$ 415.91$ into tax credit terms, note that each $\$ 1$ of investment will yield $\$ 14.86$ after 25 years. A $30 \%$ tax will reduce the $\$ 13.86$ gain to $\$ 9.70$ so that a $\$ 1$ investment will produce $\$ 10.70$ after tax. Thus, about $\$ 7.1$ of additional investment is needed to cover the $\$ 76.24$ additional tax.

This $7.1 \%$ result is an approximation. For example, the average of the taxes over all possible asset price paths is not exactly equal to the tax on the average path computed here. But an exact computation probably would not change the result very much.

12. See infra note 191; text accompanying notes $190-92$. The $3.5 \%$ benefit from strategic trading is independent of the $7.1 \%$ benefit from deferral. The strategic trading gain does not include any of the benefit due to deferring gains over the initial purchase price. See infra note 191. Thus the $7.1 \%$ and $3.5 \%$ benefits sum to a total benefit of $10.6 \%$.

13. A reader who is primarily interested in applying the results of Part IV to detailed policy issues may skip the extended normative discussion in Part II and proceed directly to Parts III and IV.

14. The Appendix relies mostly on algebra and a tiny bit of elementary calculus. This Appendix suffices to explain the computations that generate Figures 1 and 3, Tables I-IV, Tables X-XI, part of Table XIII, and Table XIV.

Much more sophisticated mathematics is required to generate Figure 2, Tables VII-IX and the remainder of Table XIII. This mathematics is described in Appendix B of the working paper version of this Article. See J. Strnad, Periodicity and Accretion Taxation: Norms and Implementation 182-210 (California Institute of Technology Social Science Working Paper No. 721, 1990) (Appen$\operatorname{dix} B$ ). The derivation of Table XII is not described in the Appendix or in the working paper because the numbers in that Table follow directly from the work of others. 


\section{Accretion Taxation and Periodicity: INTRODUCTORY CONCEPTS}

Before discussing either the four norms supporting accretion taxation or tax implementation using those norms, I first introduce some concepts and definitions and illustrate the key role of the norms in the choice of a period for taxation. Section A of this Part describes continuous taxation, defines the period and frequency of a tax, and shows how periodicity affects the wealth position of an investor. This is done through a simple example that serves as a reference point throughout the Article. Section B then motivates the normative discussion that follows in Part II by illustrating the central role of normative analysis in deciding periodicity issues.

\section{A. Tax Periodicity and Continuous Taxation: An Example}

Consider an investment consisting of two riskless cash flows: a cost of $\$ 100$ at the beginning of year one and revenue of $\$ 144$ at the end of year two. ${ }^{16}$ For convenience, "time 0 " is the point in time when the investment begins, "time 1 " is the end of the first year and "time 2 " is the end of the second year. Suppose that the instantaneous pre-tax riskless interest rate will be constant and certain during the two years in the life of the invest-

15. There are two different senses in which an investment can be "riskless." First, the cash flows from the investment and their timing may be known with certainty. Second, the time path of the value of the asset may be known with certainty.

These two conditions are not equivalent. To see this, suppose that cash flows are certain. The asset value path may still be uncertain. The reason for this is that asset value depends on the behavior of other investment opportunities in the economy. These opportunities may vary over time in a way that affects the value of the asset. If interest rates increase, for example, this would diminish the value of a positive riskless cash flow to be received in the future. See infra note 137 (example). The risk of interest rate changes makes the asset value path uncertain.

The term "riskless interest rate" means the rate of return available in the economy for an investment that has fixed, and therefore riskless, cash flows. A period must be specified for this rate. For example, a one year riskless interest rate is the rate one can earn by investing now in exchange for a riskless cash flow payout one year from now. This rate may vary over time, but it represents the rate on an investment that is riskless in the first sense: riskless cash flows. This investment may fluctuate in value and therefore is not riskless in the second sense. 
ment. ${ }^{16}$ This implies that the path of the pre-tax value of the investment during the two years is certain. ${ }^{17}$

Suppose the constant instantaneous pre-tax riskless rate is $10 \%$ on an annual basis. Then the investment is "profitable" in the sense that it earns $20 \%$ pre-tax over two years while the pre-tax market rate of return is $10 \%$. An investment of $\$ 100$ at time 0 that earns $10 \%$ would yield $\$ 121$ at time 2 instead of $\$ 144 .{ }^{18}$ Assuming that the investor could costlessly convince others that the cash flow at time 2 will be $\$ 144$ and will be riskless, the market value of the investment would be almost exactly $\$ 119 .{ }^{10}$ This is because $\$ 119$ growing at $10 \%$ per year for two years will yield $\$ 144$. Since the right to the $\$ 144$ cash flow at time 2 is riskless, owning that right must yield the same rate of return as similar riskless investments.

It is easy to represent the pre-tax path of the value of the investment graphically. The value jumps $\$ 19$ at time 0 from the cost of $\$ 100$ and then increases exponentially from $\$ 119$ to $\$ 144$ over the two years in the time interval. This jump in value and subsequent exponential increase is portrayed as the line connecting boxes in Figure 1.

16. Part I of the Appendix infra explains what an instantaneous interest rate is. Suppose that the constant instantaneous rate is $r$. Assuming that this instantaneous rate is certain over the two periods eliminates any uncertainty that might arise from potential changes in interest rates during the two periods. This makes the value path of an investment consisting entirely of riskless cash flows certain over the two periods. See supra note 15 (not only riskless cash flow but also constant interest rates required for path to be certain).

It also fixes the term structure of interest rates for riskless borrowing and lending contracts that will commence and terminate during the two periods. A loan of $\$ \mathrm{X}$ for time t during the period will require a repayment of $\$ \mathrm{Xe}^{\mathrm{rt}}$ at the end of the loan. The per period rate on the loan will be $\mathrm{e}^{r}-1$. This will be true independent of the loan period. As a result, a two-period loan made at the beginning of the first period will be equivalent to a loan for the first period followed by a loan for the second period made at the end of the first period.

This property is called the "expectation hypothesis" in the literature on the term structure of interest rates. See R. Brealey \& S. Myers, Principles of Corporate Finance 476-77 (2d ed. 1984). Economic theory does not imply this property, and the actual term structure of interest rates usually does not exhibit the property. Typically, long-term loans require higher interest rates than an equivalent series of short term loans. See id. at 473-80. The text uses an example that obeys the expectation hypothesis only for simplicity.

17. Since interest rates for intraperiod investments are certain, there is no risk that the opportunity cost of the investment will change. Combined with the fact that the investment has riskless cash flows, this yields an investment value path that is certain. See supra notes 15-16.

The after-tax value that an investor perceives may differ from the pre-tax value. Furthermore, even if the pre-tax value path is certain, the after-tax value path may be uncertain for taxpayers facing uncertainty as to what tax rate or tax rules will be applied to the realized and unrealized returns from the asset. In the example, it is assumed that each investor faces a constant and certain marginal tax rate during the two year interval. As a result, each investor will perceive the path of the after-tax value of the investment to be certain.

18. It grows $10 \%$ (from $\$ 100$ to $\$ 110$ ) in the first time period and grows $10 \%$ (from $\$ 110$ to $\$ 121)$ in the second time period.

19. More precisely, the market value would be $144 /(1.1)^{2}=\$ 119.0083$.

The assumption that the investor can convince potential buyers that the $\$ 144$ will be received risklessly at time 2 is nontrivial. There is an extensive literature on the costs of conveying such information to the market. For a discussion of recent work in the area, see Ambarish, John \& Williams, Efficient Signalling with Ditidends and Investments, 42 J. Fin. 321 (1987). 


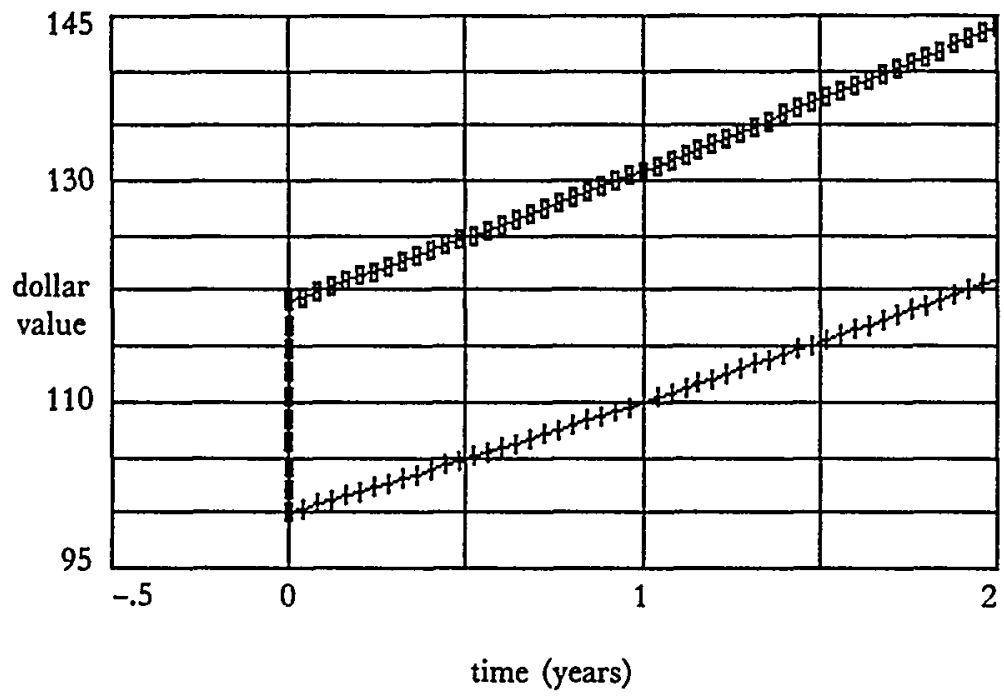

Figure 1

The "spike" increase of $\$ 19$ at time 0 is a profit in excess of the market rate of return. This type of profit is called "pure profit" or "economic profit." In contrast, the exponential increase from $\$ 119$ to $\$ 144$ represents receipt of the market rate of return. This is just the required rate of return on capital and can be called the "normal profit." If the investor had earned only the normal profit on the investment of $\$ 100$, the return at time 2 would have been $\$ 121$ instead of $\$ 144$. The path for this investment is represented by the line connecting plus signs in Figure 1.

Before carrying this example further, it is necessary to establish terminology describing the periodicity of an accretion tax. A natural approach is to say that an accretion tax has "a period of $n$ " if the tax is assessed at the end of every $n$ time units. Here we use a year as the unit time interval, so that a tax with "a period of $n$ " is simply a tax assessed at the end of every $n$ years. An annual accretion tax therefore would be an accretion tax with a period of one. A tax assessed and collected each quarter, as is the case for some estimated tax payments under current U.S. tax law, is a tax with a period of one-quarter. ${ }^{20}$

The inverse of period is frequency. A tax with a period of $n$ has a frequency of $1 / \mathrm{n}$. The frequency is simply the number of times per year that taxes are assessed and collected. For example, quarterly assessment and collection of taxes has a frequency of 4 and a period of one-quarter.

20. The estimated tax system does not always require the assessment and collection of the total tax accrued each quarter. The taxpayer can operate under various safe-harbor conventions. For example, if the sum of four equal estimated tax payments for a year equals or exceeds the previous year's tax liability, the taxpayer will not be subject to any penalty even if these estimated tax payments fall far short of the actual tax liability accrued during each quarter. See I.R.C. $\$ 6654$ (d)(1)(B)(ii) (1989). 
Suppose that we assess and collect a tax with period $\mathrm{n}$ and that we allow $\mathbf{n}$ to become extremely small. The frequency of the assessment and collection of taxes will then become extremely large. In the limit, the period will be zero and the frequency will be infinite. This limit is "continuous taxation." At every instant of time the government assesses and collects taxes.

Now consider three accretion taxes: an accretion tax with period one (the annual accretion tax), an accretion tax with period two, and the continuous accretion tax. An accretion tax with period one would tax the accumulated gain at the end of each year and increase basis an amount equal to the gain that is taxed. In order to apply this tax to the investment here, one needs to know the market value of the investment at the end of one year. This is approximately $\$ 131 .^{21}$ The gain in the first year is therefore $\$ 31$ and this would be taxed at the end of the first year. During the second year the investment increases approximately $\$ 13$ in value, from $\$ 131$ to $\$ 144$. This increase of $\$ 13$ would be taxed at the end of the second year. Accretion taxation with period two would simply tax the entire gain of $\$ 44$ at the end of the second year.

Accretion taxation applied continuously is more complicated. Gains are taxed at every instant they occur. A continuous stream of taxes emerges from the continuous stream of increase in value. Basis increases by the amount of gain that is taxed. As a result, adjusted basis is always equal to market value. The taxpayer can sell the asset at any time without paying any additional taxes.

The three taxes require assessment and collection of taxes at different times during the life of the asset. The accretion tax with period two requires assessment and collection only at time 2 . The accretion tax with period one requires assessment and collection both at time 1 and at time 2 . The continuous accretion tax requires assessment and collection at every moment during the life of the investment.

"Tax assessment" consists of computing taxable income and the tax liability due on that taxable income while "tax collection" consists of actually collecting the taxes. In order to compare the three taxes, we need to translate tax collection to one common time while leaving the pattern of tax assessment under each tax treatment unchanged. One way to do this is to assume that all taxes will be paid at time 2 when the investment comes to an end. Tax liabilities or tax benefits assessed before time 2 are paid or credited with interest at time 2 . Where all taxpayers face the same constant marginal tax rate over the life of the investment, the appropriate interest rate is the common after-tax interest rate. This is the rate at which both the government and taxpayers can borrow and lend. ${ }^{22}$ Given a

21. The actual value at the end of one period is $\$ 144 /(1.1)=\$ 130.9091$.

22. The taxpayer as lender will receive the after-tax rate of return. If interest is deductible, the 
fixed pre-tax interest rate, the after-tax interest rate will depend on the periodicity of the accretion tax. ${ }^{23}$

The following table lists the annualized after-tax interest rate and the tax, collected entirely at time 2 , for the three different accretion taxes. ${ }^{24}$ The tax rate is $40 \%$.

\section{Table I}

assessment period

two years (biannual)
one year (annual)
continuous equivalent tax at time 2

17.60

18.34

19.10 annualized after-tax interest rate

$6.11 \%$

$6.00 \%$

$5.89 \%$

The biannual tax is easy to calculate. It consists of adding up the revenues and subtracting the costs that occur during the two years and multiplying by $40 \% .{ }^{25}$ This is the treatment that would occur under current law. There is no tax and no allowance for cost recovery until realization which occurs here when the cash payout of $\$ 144$ is made at the end of the investment.

Annual assessment and continuous assessment would tax unrealized gains in this case since realization does not occur until the end of the second year. These assessment periods result in a higher total tax, because gains are taxed earlier under these two methods. The pure profit of $\$ 19$ that occurs when the investment is made is taxed immediately under continuous assessment, at the end of one year under annual assessment, and at the end of two years under biannual assessment. ${ }^{26}$ The normal profits

taxpayer will borrow at the after-tax rate of interest. Taxes are reduced by the marginal tax rate times each interest payment.

When the government borrows money, it pays out interest but gets back the taxes on the interest paid. When the government lends money, it receives interest but must reduce tax receipts by the marginal tax rate times the amount of the receipts. This reduction is necessary because taxpayers can deduct the interest paid to the government. Thus, the government borrows and lends at the after-tax rate of interest.

23. This dependence is derived mathematically infra Part III of the Appendix. The dependence is also illustrated in Table I, infra text accompanying notes 24-25.

24. The annualized after-tax interest rate is the annual after-tax interest rate achieved by purchasing a zero coupon bond at the beginning of the tax assessment period that pays all principal and interest at the end of that period. For a continuous tax this after-tax interest rate is calculated by computing the pre-tax increase in value over the year and subtracting the accumulated value, with interest, of the taxes due on that increase. The Appendix, infra, describes in detail the derivation of the results in this Table as well as the results in Tables II-VI, Tables X-XI, part of Table XIII, and Table XIV. A separate working paper details the derivation of other numerical results in this Article. Set supra note 14 (separate roles of Appendix and working paper in supporting various numerical results).

25. Total revenues are $\$ 144$ and total cost is $\$ 100$ so that the tax is $0.40 \times \$ 44=\$ 17.60$.

26. If the investment begins precisely at time 0 , then the gain at time 0 occurs exactly at the end of the assessment period ending at time 0 . The results in the text apply strictly only in the case where the investment is made an infinitesimal amount of time after time 0 . Thus, the pure profit of $\$ 19$ occurs infinitesimally close to time 0 , but this profit is not taxable income in the assessment period that ends at time 0. 
earned on the $\$ 119$ in value that exists right after time 0 are taxed at the time they are earned under continuous assessment, are cumulated, without interest, and taxed at one-year intervals under annual assessment and are cumulated, without interest, and taxed at the end of the two years under biannual assessment. In this example, taxes are about $8 \%$ lower under biannual assessment and about $4 \%$ lower under annual assessment than under continuous assessment. ${ }^{27}$ Because after-tax interest rates have been used to bring taxes forward to a common time, these differences represent the different impacts of the different assessment periods on the taxpayer's time 2 wealth position. ${ }^{28}$

\section{B. The Need for Normative Analysis}

This Section considers a simple "reductionist" argument in favor of continuous taxation, that is, a tax accounting period of zero, over an accretion tax based on any non-zero period. This argument is not conclusive, but demonstrates the need for the deeper normative analysis provided in Part II. The argument is reductionist because it extends conventional reasoning in support of annual taxation to a claim that a continuous tax is ideal. The conventional reasoning is that an annual tax is desirable because the annual tax is better than a tax with a longer period at reflecting

This infinitesimal delay corresponds to the expected behavior of taxpayers. The delay shifts the tax on the gain of $\$ 19$ one assessment period later.

If the investment occurred exactly at time 0 so that the gain of $\$ 19$ was assessed at time 0 under all three taxes, then the "equivalent tax at time 2 " column in the table would read 18.56, 18.83 and 19.10 from top to bottom instead of $17.60,18.43$, and 19.10. The qualitative result of a higher $\operatorname{tax}$ corresponding to more frequent assessment would still be true, but the intuitive discussion in the text would be more complicated.

27. The result here is approximately linear in the assessment period: The deviation of an annual assessment system from continuous taxation is about half that of a biannual system. This linearity property is peculiar to this example and does not generalize. In most cases, doubling the assessment frequency does not halve the deviation from continuous taxation. This can be seen for exponentially increasing riskless assets from Table XIV, infra text accompanying notes 247-48.

The $4 \%$ and $8 \%$ deviations from continuous taxation may seem rather small. The example is not meant to illustrate typical deviations under current law. These are often much larger. See supra notes 11-12 and accompanying text (deviation of greater than $20 \%$ in absolute size of tax translates into deviation of greater than $10 \%$ in tax credit terms).

28. The example treats the pre-tax world as constant. Regardless of the assessment period, the pre-tax interest rate is $10 \%$ annually, and the investment costs $\$ 100$ at time 0 and yields $\$ 144$ at time 2. The implicit assumption here is that there are "no general equilibrium effects" of the tax regime. Varying the assessment period does not change any market price: the price of borrowing money, the price of purchasing the equipment necessary to undertake the investment, or the price of the goods produced by the investment.

This is a strong assumption. In general one would expect that changing the assessment period would have some effect on pre-tax prices. For example, shortening the assessment period causes a decrease in the after-tax interest rate as can be seen from the second column of Table I, supra text accompanying notes 24-25. This might lead individuals to lower their savings while firms attempt to increase investment based on a lower after-tax cost of borrowing. To equate supply with demand, the pre-tax interest rate would have to increase. Such an increase would decrease investment demand and simultaneously increase the supply of savings. The increase in the pre-tax interest rate might partially, or wholly, offset the increased tax rate inherent in more frequent assessment.

The potential impact of general equilibrium effects is considered carefully in the discussion of the norms in the next Part. See infra notes 111 \& 128; text accompanying notes 91-94, 110-11. 
the pattern of wealth changes that occur during the longer period. One can use the same argument to claim that a six month accounting period is superior to a year, that a one month accounting period is superior to six months, and so on. The chain of arguments ends in continuous taxation. Only a continuous tax avoids the pitfall common to all taxes that use a nonzero accounting period: These taxes focus only on the net wealth change during the accounting period while ignoring the pattern of wealth changes that occur within that accounting period.

An example illustrates this reasoning. Suppose that on January 1 of a particular year an asset is purchased for $\$ 100$. It increases in value steadily, reaching $\$ 200$ in value on July 1 , at exactly mid-year. Then the asset declines steadily until it is again worth $\$ 100$ at the end of the year. Under the traditional idea that one year should be the accounting period, no tax should be levied since there is no net change in value over the accounting period. However, if the same pattern of asset value occurred over two years, it would be a different matter. In that case, the peak of $\$ 200$ would be reached after one year, and then a loss of $\$ 100$ would occur in the second year. Failure to tax the $\$ 100$ gain at the end of the first year and to allow a $\$ 100$ deduction at the end of the second year would result in an unjustified interest free loan for the taxpayer. ${ }^{28}$ It is unclear, however, why the same conclusion would not apply if the same pattern of wealth changes occurred during a single year or any shorter period.

Only the tax accounting period of zero length inherent in a continuous tax eliminates the need to neglect the pattern of gains and losses during some time period. Under this tax, gains and losses that occur at different times do not offset each other. For an asset that increases in value and then decreases an equal amount, the tax on the increase will precede the tax on the decrease. Taking into account the time value of money, there will be a net tax altogether even though the wealth position of the taxpayer is the same at the end of the period as it was at the beginning. ${ }^{30}$

The strict respect for the temporal pattern of gains and losses under a continuous tax may seem like an attractive feature. But to justify choosing that tax in the face of potentially high administrative costs requires more work. It is important to know why strict respect for the temporal pattern of gains and losses is desirable, and what the social costs of deviating from

29. The logic here is that biannual assessment is flawed because it does not tax net annual gains at the end of each year. This allows an unjustified deferral of tax for one year. But the failure to consider the pattern of gains within any given year is not criticized. Indeed, taxing net gains over each year is implicitly assumed to be correct. This assumption is found even in some of the most excellent work on accretion taxation. See, e.g., Halperin, supra note 5, at 509-10 (annual tax comports with "economic substance," biannual tax does not); infra note 92 (praising Professor Halperin's article for its sophisticated analysis). But see Halperin, Commentan;, in Life Insurance Company Taxation: The Mutual versus Stock Differential 5-2 (1986) (suggesting in insurance taxation context that daily taxation might be superior to annual taxation).

30. A continuous tax cumulated and collected with interest at the end of the period on this asset value path would be positive. 
that strict respect are. The choice of period under an accretion tax needs to be decided on the basis of the norms that motivate choice of accretion taxation in the first place. The next Part addresses that task.

\section{Accretion TaXation Norms}

There are four primary norms that are cited in support of accretion taxation: that disparities in wealth should be reduced, that intangible benefits from holding wealth should be taxed, that the tax system should be "neutral," and that the system should conform to the Haig-Simons ideal. The first two norms lead to two "wealth-related" theories of accretion taxation. Section A discusses these two norms together. Sections B and C discuss the last two norms in turn.

The goal of this Part is to answer two major questions for each norm. First, what frequency of taxation is optimal under each norm? Second, what are the social costs of deviating from the optimal frequency under each norm ? $^{31}$

\section{A. Wealth-Related Norms}

Two wealth-related justifications for accretion taxation emerge from the literature. The first identifies certain intangible benefits from holding wealth and suggests that these benefits should be included in the tax base. The second focuses on a concern for the distribution of wealth. The core of this justification is the claim that accretion taxation is more effective than its rival, cash flow taxation, at reducing disparities in wealth. If political or administrative constraints mean that these two taxes are the only available alternatives, one might choose an accretion tax based on its impact on wealth distribution. In effect, under this second justification an accretion tax is favored as a "second best" alternative to a wealth tax.

Both supporters and critics of accretion taxation have claimed that these wealth-based justifications are the strongest arguments for using accretion taxation instead of a cash flow tax. ${ }^{32}$ This Section discusses each of the two justifications and their implications for periodicity. Subsection 1 discusses the intangible benefits justification and shows that under this justification a continuous tax is ideal. Subsection 2 shows that a continuous

31. Answering both of these questions will require extending somewhat the previous scholarly analysis of the norms, particularly the wealth-related norms. Although the central task in this Part is to discover the connection between the norms brought forward in the literature to justify an accretion tax and the optimal periodicity of that tax, it is hoped that the discussion of the norms themselves will be of independent interest.

It is also important to note that I do not intend to advocate any particular norm or the tax policy results that follow from it. Effective advocacy would require a much different and much more extensive article. The goal here is the more modest one of developing the mapping between accretion taxation norms and periodicity.

32. See, e.g., Andrews, supra note 3, at 1169; Andrews, supra note 2, at 957; Warren 1975, supra note 2, at 943, 946; Warren 1980, supra note 2, at 1122, 1124. 
tax is also ideal under the second best justification, but the case is much less clear than under the intangible benefits justification. Subsection 3 discusses the problem of assessing the seriousness of departures from continuous taxation under each of the justifications.

\section{Taxing Intangible Benefits from Holding Wealth \\ a. Introduction}

There are two different kinds of benefits that flow from wealth. First, wealth represents potential future tangible consumption. Second, there are intangible benefits that flow from holding wealth such as security, prestige, and power. ${ }^{33}$ Both supporters and critics of accretion taxation have noted that one important argument for using accretion taxation instead of a cash flow tax is that these intangible benefits should be in the tax base. $^{34}$

The reasoning for this position is as follows. A cash flow tax reaches the future tangible consumption aspect of wealth. It does this by taxing the tangible consumption that occurs when the wealth is liquidated and spent. The fact that this future tangible consumption will be taxed reduces the value of wealth accumulation at present. Under a regime of constant tax rates, taxing all future tangible consumption and bequests lowers the present value of all current wealth accumulation by exactly the tax rate. ${ }^{35}$ But this may not be sufficient if one believes that the added economic well-being from increases in wealth stems from intangible benefits as well as from the prospect of additional future tangible consumption.

Prominent commentators who take this position seem to assume that taxing wealth directly would be the best way to tax these intangible benefits. ${ }^{38}$ They point out several defects in using an accretion tax as a proxy for a wealth tax. ${ }^{37}$ First, an accretion tax simply taxes accumulation. It

33. Sit C. Shoup, Public Finance 352 (1969); Andrews, supra note 3, at 1169-70.

34. Sie H. Simons, Personal Income Taxation 96-97 (1938); Andrews, supra note 2, at 956; Warren 1980, supra note 2, at 1097.

35. Suppose, for example, that the taxpayer unexpectedly receives an award of $\$ 1100$ to be paid one year from now. Assume a $10 \%$ riskless interest rate. The present value of the award is $\$ 1000=$ $\$ 1100 /(1+.10)$. This is how much the taxpayer's wealth has increased now. Consider a cash flow tax at a rate of $40 \%$. The award will be only $\$ 660$ after tax. Since a cash flow tax preserves the pretax interest rate, see infra text accompanying notes $72-73$, the after-tax present value of the award is now $\$ 600=\$ 660 /(1+.10)$. The taxpayer's current increase in wealth, the present value of the award, has been reduced from $\$ 1000$ to $\$ 600$. The rate of reduction is exactly equal to the tax rate of $40 \%$.

This idea generalizes: If general equilibrium effects are ignored and tax rates are constant, the cash flow tax will reduce wealth increases over any given accounting period by exactly the tax rate. See Strnad, The Bankrupty of Conventional Tax Timing Wisdom Is Deeper than Semantics: A Rejoinder to Professors Kaplow and Warren, 39 STAN. L. REv. 389, 397-99 (1987).

36. The word "seem" is used here because the critique of accretion taxation as a wealth tax proxy occurs in the context of discussing both wealth-related justifications at the same time. The critique may be aimed primarily at the second justification, reducing disparities in wealth, rather than the one discussed here, taxing the intangible returns to wealth.

37. Sie Andrews, supra note 2, at 956-58; Warren 1980, supra note 2, at 1123. 
does not tax wealth as an independent base. Taxpayers who have similar wealth gains during an accounting period are taxed similarly under an accretion tax even though they may have very different total wealth holdings. Second, if marginal rates under an ideal wealth tax increase with the amount of wealth held by the taxpayer, an accretion tax is flawed because it applies rates based on the amount of wealth accumulation over the accounting period and not based on the stock of wealth held by the taxpayer. Third, an accretion tax does not reach wealth accumulation that has occurred before the tax was imposed.

These are all good points. They are especially potent when aimed at use of accretion taxation under the second wealth-related justification: reducing disparities in wealth. However, the case for using an accretion tax to reach the intangible benefits from wealth is stronger than the previous literature suggests. The next two Subsections discuss that case and show that the logic behind it implies continuous taxation as an ideal.

\section{b. The Intangible Benefits Justification Implies Continuous Accretion Taxation}

It is convenient to begin with a very simple economic and tax environment. ${ }^{38}$ All real and financial assets are riskless and earn a zero rate of return. There is no inflation. Consumption and bequests are taxed at a $40 \%$ rate, and there is no separate tax on accumulated wealth.

In this environment there are two motives to accumulate wealth. One motive is to transfer tangible consumption into the future. This transfer happens at a one-to-one rate since the riskless interest rate is zero. For each dollar's worth of tangible consumption given up presently, a person gains a dollar of tangible consumption in the future. A second motive is to enjoy the intangible benefits, such as prestige, power, and security, that flow from holding wealth. ${ }^{39}$ Suppose that for all individuals these intangible benefits consist of a proportional flow that is valued at $\$ w$ per $\$ 1$ of wealth per year. ${ }^{40}$

38. Later Subsections explore the ramifications of relaxing the drastic assumptions that delineate this simple environment. See infra text accompanying notes 56-71 and notes 56 \& 61 .

39. Some of these benefits are "priced," that is, the market value of each unit of wealth is larger because of the increased demand due to people who want the intangible benefits.

The degree to which the benefits are priced will be determined by market forces just as market forces in a real economy determine the riskless rate of return and the various premia for holding risky assets. If a society places a high value on the prestige benefits attached to material possessions, one would expect a significant price effect. Prestige-heightened demand for a limited supply of wealth will drive up the prices of the real assets that are a store of value.

To the extent that the supply of wealth is elastic, this effect will be diminished. But one would expect prestige and power to attach most easily to assets that are in inelastic supply. The very scarcity of these assets makes them impressive from the prestige standpoint and controlling them confers power.

40. After developing the argument for accretion taxation, the Article explores the consequences of modifying this proportionality assumption. See infra notes 56 and 61 .

Note also that no assumption is made concerning whether the proportional component is "priced." 
The amount $w$ is very much like imputed income. No cash flow corresponds to it. ${ }^{11}$ Unlike some varieties of imputed income, such as the imputed rental value of owner-occupied housing, w may be very hard to observe or estimate. The imputed rental value of housing can be estimated by observing the market rental amounts paid on comparable housing. No such straightforward method applies for the intangible return to wealth. ${ }^{42}$

Under consumption tax theory, ${ }^{43}$ there is a familiar theoretical solution for taxing proportional imputed returns. In particular, yield exemption treatment is often put forward as a method of taxation when an asset produces a flow of benefits that are not observable as cash flows. ${ }^{44}$ Under this method, no deduction is allowed for the initial investment and no tax

See supra note 39. For most tangible consumption items, the price of the item corresponds exactly to a common proportional benefit experienced by each individual. But this may not be true for the intangible benefits from wealth. See infra note 61 .

For the prestige element of the intangible benefits from wealth, there is an argument that proportionality may not be a bad assumption. The argument is based on the claim that perceived prestige rests primarily on local status as opposed to absolute status. Individuals care how they compare to a local group (defined by occupation, physical location, or similar factors) much more than to others with whom they have little contact. There is economic and even biological evidence for this position. Sep R. Frank, Choosing the Right Pond: Human Behavior and the Quest for Status (1985) (evidence from neurochemical studies of primates and from studies of internal wage structure of U.S. firms).

If prestige is a function of local status, then wealth increments may be as productive in generating an increase in prestige and power among low wealth individuals as among high wealth individuals. In Beverly Hills, a Ferrari costing $\$ 100,000$ sets one apart from the masses who own BMW's and Volvos. But, for low income individuals, a $\$ 1000$, five-year-old, American model may be the car that wins dates and impresses friends. The $\$ 1000$ in wealth required for the used American car may be as or more productive per dollar in generating prestige benefits as the $\$ 100,000$ required to buy the Ferrari.

41. It is important to note, however, that the flow $w$ is assumed to arise independent of the form that the wealth takes. Cash, bonds, diamonds, houses, art, and businesses all have a common proportional flow of intangible benefits.

In addition to this proportional flow that is common to all wealth, some forms of wealth produce an additional flow of imputed income. Owner-occupied housing, for example, produces a flow of physical shelter services. It is important not to confuse the special imputed income properties of some assets with the general intangible benefits from each dollar of wealth that are posited here. It is this general intangible benefit stream that drives the arguments in the text. Of course, asset-specific imputed income streams are also relevant for tax policy. See infra note 45.

42. The increase in asset prices due to demand for the intangible benefits that flow from wealth may result in a lower tangible return for financial assets. In the simple economy here, that means a lower riskless interest rate. However, the connection between the drop in that interest rate and the size of $w$ may be very complicated so that clear inferences about $w$ may be hard to come by.

At the very least, the relationship will depend on the supply conditions for real assets. If supply is inelastic, one might guess that the interest rate falls by exactly $w$. But even if this is the case, measuring $w$ by the drop in the riskless rate requires a knowledge of what the interest rate would have been in a world without demand for the intangible benefits from wealth.

43. The reader might wonder why consumption tax theory is being considered here when the goal is to ascertain the optimal frequency of accretion taxation. The rationale for this approach rests both on the results that flow from the approach and on history. When faced with the need to tax intangible benefits from wealth, the consumption tax theory implies a classical accretion tax. Furthermore, Henry Simons, the father of modern income tax theory, relied on related arguments to defend accretion taxation against consumption tax alternatives. See infra note 47 and accompanying text.

44. Andrews, supra note 3, at 1150, 1155-59; Graetz, supra note 3, at 184-87. The yield exemption method often goes by another name, "the prepayment approach." See, e.g., Fullerton, Shoven \& Whalley, Replacing the U.S. Income Tax with a Progressize Consumption Tax, 20 J. PuB. Econ. 3, 6 (1983); Warren 1980, supra note 2, at 1102. 
is levied on any of the returns from the investment including the return of capital at the end. Considering only $w$, the proportional component of the intangible benefits of wealth, yield exemption treatment is equivalent to applying the cash flow method itself directly to the intangible flows. ${ }^{45}$ The cash flow method consists of allowing a deduction for the amount of investment, taxing $40 \%$ of the flow, $w$, each year, and taxing the return of capital when the investment is liquidated. ${ }^{46}$

Applying the yield exemption approach to a common proportional component of the intangible benefits from holding wealth yields precisely accretion taxation. ${ }^{47}$ To see this intuitively, consider the following example. Ms. $Y$ has earned $\$ 500,000$ that she wants to save by investing in a small business. ${ }^{48}$ Because the riskless rate is zero and there are no risky assets, businesses will produce no net tangible return in the form of positive net cash flow. Instead, the total cash returns plus the terminal value at the time of sale will be equal to the purchase price of the business. For simplicity, assume that the terminal value of each business under consideration is equal to its purchase price. In other words, these businesses do not pay out cash dividends. Operating them merely transfers a dollar from the present to the future. Nevertheless, owning a business will produce the intangible benefits of holding wealth.

45. The yield exemption approach was designed with assets that produce imputed income streams in mind. See supra note 44 (citing sources). Under a consumption tax, this class of assets can be singled out for yield exemption treatment while all other assets receive cash flow treatment.

The theory presented here rests on the assumption that all forms of wealth produce a significant proportional intangible return. This return is not asset-specific but flows from all assets. This requires that all assets and, as discussed in the next Subsection, all tangible returns from assets be treated under the yield exemption approach. The result is accretion taxation.

46. If an investment earns returns at a higher rate than the market rate, then yield exemption will result in a failure to tax the added value that results from the excess rate of return above the market rate. Cash flow taxation would reach this added value at exactly the tax rate if tax rates are held constant over time. See Strnad, Taxation of Income fram Capital: A Theoretical Reappraisal, 37 StaN. L. REv. 1023, 1069-71 (1985); Strnad, supra note 35, at 397-99. In this context where the return is in the form of intangible benefits, the excess of the actual rate of return over the "market" rate of return would be consumer surplus. The tax policy implications of this consumer surplus are discussed infra note 56.

47. The reasoning here puts the intangible benefits from wealth on the same footing as tangible consumption. See infra notes 56 \& 86 . It might seem that income tax theory is being subsumed by consumption tax theory. However, this view is similar to that taken by Henry Simons himself in his seminal work on income tax theory. Simons believed that the conventional accretion method is superior to the cash flow approach because the accretion method taxes the priced portion of the intangible benefits from wealth. He argued that this priced portion is equivalent to spending on tangible consumption and therefore should be taxed. See H. Simons, supra note 34 , at 97.

What differentiates the theory in this Article from Simons' view is that the argument for accretion taxation here does not depend on whether or not the intangible benefits from wealth are priced. Sef supra note 40 (no assumption made that intangible benefits are priced). In fact, a cash flow tax may" do a good job of taxing the priced portion. See infra text accompanying notes 52-54.

48. Whether this $\$ 500,000$ is earned as wages, profits, or is simply a windfall does not affect the analysis. The reader is free to imagine that the earnings come from any one of those sources. The economic environment in this Section has no risky assets and the riskless rate is zero. No profits and windfalls should exist in such an environment. Nonetheless, the fact that the analysis is independent of the source of the $\$ 500,000$ means that the analysis carries over without modification to the next Subsection where the economy includes risky assets and a nonzero riskless rate. See infra text accompanying notes $56-57$. 
Suppose these intangible benefits are in the form of prestige. The larger the business, the more prestige that flows from owning and running it. If the tax system ignores intangible benefits, then only tangible forms of consumption and bequests will be taxed. In that case, Ms. $Y$ can buy a $\$ 500,000$ business. She will not be taxed on the $\$ 500,000$ until she sells the business and consumes the proceeds or until she dies and the business passes by bequest to her heirs. In contrast, under the yield exemption approach, Ms. $Y$ will have to pay $\$ 200,000$ in taxes on the $\$ 500,000$ at the time she buys the business. She will only be able to afford a $\$ 300,000$ business. Owning and operating this business will be less prestigious. In particular, the proportional component of Ms. $Y^{\prime}$ s prestige flow will be cut by exactly the tax rate of $40 \%$ each year. This follows because this component is a constant flow of $\$ \mathrm{w}$ per $\$ 1$ of wealth. ${ }^{49}$

Several important points emerge from this example. First, it is worth repeating that the derived tax treatment is accretion taxation. ${ }^{50} \mathrm{~A}$ portion of wealth gains are impounded when they occur. In contrast, a cash flow approach based only on tangible returns would delay taxation until the wealth is used for future consumption or bequests.

Second, the yield exemption approach works independent of the actual value of $w$, the proportional component of the intangible benefits that flow from holding wealth. ${ }^{51}$ The government does not have to know or estimate the magnitude of $w$. In the example, $40 \%$ of Ms. $Y^{\prime}$ s wealth is being impounded by the government between the time she earns it and the time

49. There is one possible complication that arises when prestige is the intangible benefit under consideration. Prestige benefits from wealth may depend on the history of a person's wealth position as well as the lez'l of wealth held at present. For example, suppose that becoming very wealthy results in a flow of $w$ in prestige per dollar of wealth but that subsequently losing that amount of wealth more than eradicates $w$. One is not only as poor as before but also has been disgraced by losing a great accumulation of wealth. This disgrace might result in an ongoing negatite flow of prestige.

Although there may be a significant systematic dependence of prestige benefits on wealth history, this dependence must be specified before studying the consequences for tax policy. It is not obvious to the author what form the dependence might take or even if it exists.

50. The claim that the treatment here is identical to accretion taxation is based on the conventional definition of an accretion tax. It is possible to construct a "meta-accretion" tax that would impound wealth gains when they occur and then also add a periodic wealth tax as a surcharge levied on the intangible benefits that flow from the portion of wealth that was not impounded. This metaaccretion tax therefore would consist of the conventional accretion tax combined with a wealth tax.

There is an analogy between the meta-accretion tax and the conventional accretion tax. Just as the conventional accretion tax is levied on wealth increments and on the subsequent tangible returns to the remaining wealth, the meta-accretion tax is levied on wealth increments and on the subsequent intangible returns to the remaining wealth.

Despite this analogy, the previous work that raises the intangible benefits from wealth as a justification for accretion taxation does not advocate a meta-accretion tax. See H. SimoNS, supra note 34, at 95-97; Andrews, supra note 2, at 956; Warren 1980, supra note 2, at 1097. Working within this tradition, it seems sufficient to consider justifications for the conventional accretion tax.

51. Professor Andrews has noted that one of the big advantages of consumption taxation is that the yield exemption approach can be used to tax a flow of imputed income from particular assets such as owner-occupied housing or consumer durables without knowing or observing the magnitude of the flow. See Andrews, supra note 3, at 1150, 1155-59. Here the approach is being applied to all changes in wealth in order to tax the unobservable intangible benefits that flow from all forms of wealth. 
she consumes it. This denies her $40 \%$ of the value of the flow $w$ because this flow is proportional to the amount of wealth that she holds. ${ }^{52}$

Third, the theory here depends critically on the assumption that holding wealth confers a proportional intangible return independent of the net present value of the individual's tangible future returns. In the example, if a cash flow tax on tangible consumption and bequests is applied, Ms. Y's $\$ 500,000$ will have a net present value of only $\$ 300,000$. The reason for this is that there will be $\$ 200,000$ of tax at some future time. This will occur when she dies and the $\$ 500,000$ passes by bequest or when she withdraws it from saving and spends it on consumption. The present value of this $\$ 200,000$ tax is $\$ 200,000$ since the riskless interest rate is zero.

If the proportional component of the intangible benefits from wealth flows only from the net present value of future tangible returns, then this component is reduced proportionately by the tax rate under a cash flow tax on tangible consumption and bequests. There is no need for an accretion tax. That need arises only if intangible benefits flow from having control in the interim over the $\$ 200,000$ that will be paid in future tax. ${ }^{.3}$ The example suggests the possibility that interim control would confer such benefits by pointing out that Ms. $Y$ could own a larger and therefore more prestigious business. ${ }^{54}$

52. Note that with a zero riskless interest rate, the $\$ 200,000$ that is impounded is exactly the amount of tax that Ms. $Y$ would have paid under a cash flow tax when tangible consumption or a bequest occurred in the future. Cash flow taxation that ignores the intangible benefits from wealth would allow Ms. $Y$ to consume $\$ 300,000$ in tangible benefits at any time or to leave $\$ 300,000$ as a bequest. This is also true under yield exemption. The added feature under the yield exemption approach is that Ms. $Y$ cannot hold the full $\$ 500,000$ until the time of tangible consumption or bequest. This cuts off the intangible benefits that would have flowed from the $\$ 200,000$ that is taxed immediately under the yield exemption approach. The intangible benefits that are eliminated include $40 \%$ of the flow $w$ that would have accrued from holding the full $\$ 500,000$.

53. If this phenomenon occurs, special problems will arise for the tax treatment of liabilities. When the taxpayer borrows and invests the proceeds, the taxpayer can enjoy the benefits of holding wealth without an increase in net worth. One million dollars of borrowed funds that are invested will produce intangible benefits of the same magnitude as one million dollars of wages or profits received and saved.

The conventional wisdom concerning borrowing is that because it does not represent an increase in net worth, no tax should be due based on receiving the proceeds of a loan. See Andrews, supra note 3, at 1137. This treatment clearly will allow intangible benefits to be earned tax free. For example, in the riskless world presented in the text, the taxpayer can borrow $\$ 1000$ and invest the proceeds. The proceeds will not be taxed upon receipt and no deduction will be allowed on repayment. But in the meantime the taxpayer enjoys the ongoing stream of intangible benefits from holding $\$ 1000$ in wealth.

Applying cash flow treatment to loans provides only a partial cure. Under this treatment proceeds are taxed and there is a deduction on repayment. This reduces the amount of the borrowing by the tax rate and reduces the proportional stream of intangible benefits by the same amount. But in the riskless world of the text, the taxpayer could simply increase the amount of borrowing (securing it by the investments made with the proceeds) to offset any tax.

The intangible benefits theory may require even harsher treatment of borrowing than under a cash flow tax. It certainly seems clear that the conventional approach under income taxation is much too lenient.

I do not explore the tax treatment of borrowing further here. Determining the best treatment for borrowing is an important task but would require an extensive discussion.

54. It is important to note that the argument here depends on there being a proportional intangi- 
A fourth point implicit in the example is that the case for accretion taxation does not depend on there being a time value of money. In this simple example, the accretion approach emerges as superior to cash flow taxation based on tangible returns even though the riskless interest rate is zero. That cash flow approach fails to tax the intangible benefits from wealth while the accretion tax reaches these benefits.

Under traditional theory accretion taxation is equivalent to cash flow taxation when the riskless rate is zero. ${ }^{85}$ The different result here arises from the goal of taxing intangible as well as tangible benefits from wealth. The traditional view is true if only tangible returns are considered. Consider Ms. Y's $\$ 500,000$ in earnings. The cash flow tax delays the tax of $\$ 200,000$ until consumption or bequest occurs while the accretion approach levies the $\$ 200,000$ tax immediately. But the delay under the cash flow tax does not confer any tangible financial benefit on Ms. $Y$. Since interest rates are zero, she cannot profit by investing the $\$ 200,000$ and having more tangible wealth at the time of consumption or bequest.

Finally, and most important for the purposes of this Article, the example shows that a continuous tax is ideal. If the government delays impounding $40 \%$ of Ms. Y's wealth increase beyond the time she earns it, she will be able to realize intangible benefits tax free during the period of delay. Thus, if the government waits a year to tax away $\$ 200,000$ of the $\$ 500,000$, then Ms. $Y$ will receive the full intangible benefit from holding the $\$ 500,000$ during that year. ${ }^{56}$

ble benefit from holding all wealth. The amount of this benefit would be independent of the form of wealth held. Holding $\$ 200,000$ in cash, diamonds, or a business would result in the same proportional level of benefits.

It might seem that diamonds and the business would be more prestigious assets. But the prices of these assets in equilibrium should reflect this extra prestige value. In equilibrium, intangible benefits such as prestige will be the same for bare financial assets like cash as for glittery assets such as diamonds because people will know that $\$ 200,000$ in cash could be turned into $\$ 200,000$ in diamonds if the owner so wished.

In the simple economic environment set out in the text, prestige price premiums can coexist with a zero tangible rate of return on all assets. Suppose that tastes concerning what is prestigious remain fixed and that assets do not physically deteriorate. A single diamond with no industrial utility may be worth \$200,000 because of its special prestige value. If that prestige value will be the same in the future as at present, the $\$ 200,000$ value will persist and the diamond will be equivalent to bonds (carning a $0 \%$ rate in the economy in the text) or cash as a store of value.

55. See Warren 1980, supra note 2, at 1102-07 (different treatment of riskless rate is key difference between consumption tax and income tax).

56. In this Subsection we have relied on the assumption that every individual experiences the same proportional flow of intangible benefits from wealth. See supra text accompanying note 40 . An important question is whether relaxing this assumption will affect the result that an accretion tax should be continuous rather than periodic.

At first glance, considering nonproportionality for the intangible benefits from wealth raises no new issues. The problem of nonproportional benefits also exists for tangible consumption. A person buys tangible goods because the person finds them at least as valuable as the market price. The market price represents a common proportional benefit experienced by all consumers. But a consumer may value the first few units purchased at grealer than the market price. The excess value on these units is "consumer surplus." Consumer surplus is a nonproportional component of the benefits from tangible consumption.

It is also possible that the first few units are valued at less than their market price. Later units, 


\section{c. Adding Risk, Inflation, and a Positive Riskless Rate of Return}

Suppose that the example is made richer by adding inflation, by adding a non-zero riskless rate and by allowing some assets to be risky. These new conditions imply that the value of assets plus their tangible returns will no longer be constant. This Subsection demonstrates that the main results from the previous Section still will apply: accretion taxation will tax the proportional component of the intangible benefits that flow from wealth at the applicable tax rate, and a continuous tax is ideal. One caveat to this conclusion does arise, however. A non-zero riskless rate implies that there will be an efficiency cost to the use of an accretion tax. This trade-off may prompt choice of a periodic rather than a continuous accretion tax.

Consider adding risky assets while holding both the riskless rate and the inflation rate at zero. This means that asset values will fluctuate. Returning to the example, suppose that Ms. $Y$ buys her business for the $\$ 300,000$ in after-tax proceeds that remains from her $\$ 500,000$ but that one year later the value of the business jumps to $\$ 400,000$ from $\$ 300,000$. This increase in wealth begins producing intangible benefits. The proportional component of the benefits amounts to $w$ per dollar of wealth per year. In order to tax this component, the same yield exemption approach suffices: tax the increase in wealth up front to compensate for the fact that the stream $w$ is not observable and thus must go untaxed. Once again, a continuous tax is best. If taxation is delayed, the proportional component of the intangible benefits will go untaxed in the interim.

Continuing with the assumption of no inflation, a similar analysis would apply to interest payments under a non-zero riskless rate. These payments increase wealth and the intangible benefits that flow from it.

Adding inflation does not change the conclusion that a continuous tax is

however, are valued at so much more than the market price that the individual buys the first few units in order to tap the high surplus that results from high consumption. This individual will still have consumer surplus if the value to the individual of the aggregate consumption exceeds the aggregate purchase price.

The traditional tax policy approach toward consumer surplus is to ignore it. Consumer surplus is not included in the tax base. See Strnad, supra note 46, at 1092-98; Kelman, supra note 2, at 657 n.23, 679-80; Warren 1980, subra note 2, at 1095-97. If one believes the same policy should apply when "surplus" intangible benefits from wealth are considered, the analysis in the text which focuses on the proportional component of the intangible benefits is complete.

But even if one believes that "surplus" intangible benefits from wealth should be taxed, the result in the text in favor of continuous taxation still stands. An accretion tax that is continuous rather than periodic is better at taxing both the proportional element and the surplus element of intangible benefits from wealth. A periodic accretion tax delays taxing wealth increases until the end of the assessment period. During the period of the delay, the taxpayer receives both the proportional component of the intangible benefits from wealth and any surplus component tax free. Under a continuous accretion tax, there is no delay. See supra text accompanying notes 55-56.

It appears, then, that the proportionality assumption is innocuous. If we also drop the assumption of a zero riskless interest rate, however, this conclusion becomes less certain. See infra note 61 (violation of proportionality assumption may lead to favoring periodic accretion tax over continuous accretion tax if riskless interest rate is positive). 
best. Intangible benefits are almost certainly a function of real rather than -nominal wealth. ${ }^{57}$ Assuming that is the case, the intangible benefits justification calls for indexation of basis for all assets. Intangible benefits change only in response to real gains and losses, and only real gains and losses should be taxed to reach the intangible benefits that flow from them. But these gains and losses should be taxed when they occur to avoid tax free enjoyment of the intangible benefit stream.

Introducing a positive riskless rate does add another policy aspect for consideration. Under accretion taxation, the tax portion of a person's wealth is impounded before the person consumes or bequeaths the aftertax proceeds. This tax portion would have earned the riskless rate of interest. As a result, the person's potential future consumption and bequests will fall by more than the tax rate. Since present consumption is reduced by the tax rate, there will be a bias against future consumption and bequests. The following example illustrates this bias and the inefficiency that follows from it.

Consider Ms. $Y$ once again. Upon receiving the $\$ 500,000$ in earnings, she could immediately consume $\$ 300,000$ after tax, given a $40 \%$ tax rate. Suppose instead that she invests the $\$ 500,000$ in a riskless business that would appreciate at a rate of $10 \%$ in one year. At the end of the year she will consume the after-tax proceeds. Under a $40 \%$ cash flow tax focused on tangible benefits only, she will have $\$ 550,000$ times $60 \%$ or $\$ 330,000$ in consumption. Giving up $\$ 300,000$ in consumption at the beginning of the year yields $\$ 330,000$ in consumption at the end. Her potential aftertax consumption increases by the pre-tax interest rate of $10 \%$. This pretax interest rate is exactly the rate at which the economy can transform present consumption goods into future consumption goods.

Under accretion taxation, Ms. $Y$ starts with $\$ 300,000$ and earns $\$ 18,000$ in interest after tax to yield $\$ 318,000$. She loses the $\$ 12,000$ in after-tax interest that she would have earned on the $\$ 200,000$ that is taxed up front under accretion taxation. Giving up $\$ 300,000$ in consumption yields only $\$ 318,000$ after one year, a $6 \%$ increase. There is a gap between the pre-tax rate of interest, $10 \%$, and the after-tax rate of $6 \%$. The economy can transform present consumption goods into future consumption goods at that pre-tax $10 \%$ rate, but Ms. $Y$ can only transfer present consumption to future consumption at the $6 \%$ after-tax rate. For the economy's productive resources to be used efficiently, Ms. $Y$ should base her decision between future and present consumption on the ability of the economy to transform one into the other. Instead she bases her

57. Consider paper money, that has high nominal value but very little real value. This money is not a source of security because it will not provide either physical goods such as food and shelter or a leisurely lifestyle in the future. Since most people will not be impressed by large holdings of a worthless paper asset, the money also is not a source of prestige. 
decision on a tax-distorted price that values future goods too low relative to current goods. ${ }^{58}$

In a world with a positive riskless rate, an accretion tax reaches the intangible returns from wealth at the cost of distorting the price at which individuals choose between present and future consumption. ${ }^{59}$ As a result, the argument that a continuous accretion tax is superior to a periodic one of any period might fail. Increasing the period of taxation tends to decrease the gap between the pre-tax and after-tax riskless rate. ${ }^{80}$ One might choose to deviate from continuous taxation in favor of some fixed period in order to balance the goal of taxing intangible benefits from wealth against the goal of not distorting the cost of future consumption relative to present consumption. ${ }^{61}$

58. It might appear that one can construct a similar argument for risky assets based on distortionary effects on the expected rate of return. If investors are risk averse, this expected rate of return should exceed the riskless rate to compensate for risk. However, there is an argument that taxing risky assets does not create efficiency problems. When the government taxes a risky asset and allows full loss offsets, the government shares in the upside and downside of the asset at equal rates. The reduction in expected return caused by taxation is compensated for by a reduction in the riskiness of the returns. If the riskless rate is zero, then this compensation is exact. Otherwise, it is exact only up to a second order term. See Gordon, Taxation of Corporate Capital Incone: Tax Rezenues Versus Tax Distortions, 100 Q.J. EcoN. 1, 4-5 (1985) (raising and discussing basic phenomenon); J. Strnad, The Taxation of Risky Investments: An Asset Pricing Approach 33 (California Institute of Technology Social Science Working Paper No. 546, 1984) (discussing second order term); see also Warren 1980, supra note 2, at 1102-07 (exempting riskless return under accretion taxation makes accretion tax treatment of risky returns same as cash flow tax).

59. This is a classic trade-off: The focus of much of the legal literature has been on the conflict between wealth-related justifications for accretion taxation and the efficiency cost that it causes by distorting the relative price of present and future consumption. See supra note 2 (citing sources).

60. See Table I, supra text accompanying notes $24-25$. This effect may be partially or wholly offet by general equilibrium effects that alter the pre-tax riskless rate. See supra note 28.

61. Distorting the cost of future consumption relative to present consumption raises equity concerns as well as the efficiency concerns just discussed. For tangible consumption, the market price is the common proportional benefit experienced by everyone who buys the goods. See supra note 56; infra note 86 . But there is no guarantee that a person who accumulates wealth experiences any intangible benefits from the wealth. Holding wealth produces two distinct services simultaneously. It transfers consumption to the future and provides intangible benefits such as prestige and power. But some individuals may be interested only in transferring consumption to the future.

If the riskless rate is positive, an accretion tax tends to harm these individuals by increasing the cost of future consumption in terms of present consumption. This phenomenon raises an equity problem. Individuals interested only in transferring consumption to the future are harmed as innocent bystanders in an attempt to tax the intangible benefits that flow from wealth.

One way to address this equity problem is the same way that was suggested for addressing the corresponding efficiency problem: use an accretion tax that is periodic rather than continuous. This will tend to reduce the harm to those who accumulate wealth for future consumption. At the same time, however, it will allow others who value the intangible benefits from wealth to receive some of these benefits tax free.

If the equity problem arises from wealth differences rather than differences in preferences, then there are some viable approaches that may be superior to making accretion taxation periodic instead of continuous. Suppose, for example, that preferences are the same in the sense that each individual saves the first $\$ 500,000$ with future consumption in mind while any additional saving is motivated by a desire for prestige. A way to alleviate the equity problem in this world would be to allow tax free accumulation of $\$ 500,000$ while subjecting accumulation in excess of that amount to an accretion tax. The low-wealth individual who experiences no prestige benefits would be free from the tax penalty inherent in the accretion tax. This exemption scheme and its equity rationale have been suggested by Professor Andrews. See Andrews, supra note 2, at 958. 


\section{d. Increasing Marginal Tax Rates}

The case for continuous taxation may be weaker when tax rates are not proportional but vary substantially with income. If wealth is held for a long period of time, the stream of intangible benefits from that wealth will extend over many years. Accretion taxation reaches this stream by taxing each wealth increase when it first accrues instead of directly taxing the stream of benefits. This cuts off a proportion of all future intangible benefits. This proportion is equal to the tax rate that applies at the time of accrual. This tax rate may be a poor proxy for the future tax rates that would have applied to the flow of benefits. ${ }^{62}$ In particular, since the accretion method bunches the taxation of the stream of intangible benefits into an early year, the benefits may be taxed at too high a rate under a rate structure with increasing marginal rates. ${ }^{83}$

Despite this intuition, the exact interaction of accretion taxation and nonproportional tax rates is more complicated. The intuition is likely to be correct if the taxpayer earns most of his or her wealth in a few years early in life. In that case, rates will tend to be higher in the early, highearning years than they should be to serve as a proxy for the intangible benefits that flow during later years when taxable income will be much lower. However, this particular pattern of wealth accumulation may not be the most common one. ${ }^{64} \mathrm{~A}$ taxpayer may accumulate wealth steadily. In that case, using accretion taxation instead of a cash flow tax on intangible benefits may have very little impact on the tax rates that apply.

If accretion taxation does exacerbate the negative impact of nonproportional rates, one response is to use a long accounting period. A long accounting period reduces the probability that high accumulation episodes will be isolated into separate periods with very high rates applying. Thus, it will be less likely that wealth accumulation will be taxed at rates that are too high to provide a good proxy for the rates that would have applied to the intangible benefits from the wealth if they were taxed directly.

62. Consumption tax commentators have been careful to point out that yield exemption and cash flow taxation are not equivalent when marginal rates change over time. See Graetz, supra note 3, at 172-73; Warren 1980, supra note 2, at 1108. This makes "bunching" of income due to the yield exemption treatment of intangible benefits a potential problem.

63. With a tax rate structure consisting of increasing marginal rates, bunching of income creates a higher overall tax burden. A simple example illustrates this point. Suppose that the first $\$ 50,000$ of income is untaxed and that all income above $\$ 50,000$ is subject to a $50 \%$ rate. Assume that the riskless interest rate is zero so that there is no need to take into account the time value of money. Taxpayer $A$ makes $\$ 50,000$ in year one and $\$ 50,000$ in year two. This taxpayer will pay a total tax of zero. Taxpayer $B$ makes $\$ 100,000$ in year one and $\$ 0$ in year two. Despite having the same average income as taxpayer $A$, taxpayer $B$ pays a total tax of $\$ 25,000,25 \%$ of total income, while taxpayer $A$ pays nothing. The taxpayer with more volatile income is taxed more heavily.

This example generalizes. More volatile incomes are taxed more heavily under any rate structure with increasing marginal rates. See Moffitt \& Rothschild, Variable Earnings and Nonlinear Taxation, 22 J. HuMan Resources 405, 407 (1987). 71 .

64. For a discussion of evidence about the typical pattern of wealth accumulation, see infra note 
The problem with using a long accounting period is that it delays the tax on increases in wealth. This allows the taxpayer to reap tax-free intangible benefits from these wealth increments during the delay. The longer the period used for taxation, the greater the tax-free benefits will be. On the other hand, a longer period will result in more averaging of consumption and wealth accumulation episodes ${ }^{65}$ This approach results in an unresolved trade-off, but it suggests that departures from continuous taxation may be desirable.

There are ways to address nonproportional rate problems without departing from frequent taxation. Perhaps the most well-known method is Professor Vickrey's cumulative averaging approach. ${ }^{66}$ During each accounting period the taxpayer is taxed on cumulative taxable income over all accounting periods. Past tax payments are credited with interest. A separate tax table is used for each period of cumulation. ${ }^{67}$ As a result, rates may be adjusted so that the marginal rate that applies to the taxpayer is the marginal rate that would have applied on average under the current system of taxing period by period. ${ }^{68}$ This approach combined with a short assessment period would preserve the advantages of the yield exemption approach for taxing the intangible benefits from wealth. Wealth increments would be taxed when they occur.

The rate adjustment in the Vickrey scheme is not a perfect solution to the problems that might arise under the accretion taxation approach. Suppose, for example, that $\mathrm{Mr}$. $Z$ makes large amounts of wage income as a young man. He accumulates a large stock of wealth and then retires. Assume that marginal tax rates increase between the level of Mr. Z's average income and the high levels of income in the early years. Then Mr. $Z$ will pay taxes at too high a rate on the early income. As time goes on, he will receive the excess taxes back with interest. However, he will never receive back the excess intangible benefits of wealth that were taken away. Too large a proportion of his wealth was impounded early in life. Gradually, the proportion impounded is reduced as he receives taxes paid previ-

65. It might appear that this problem could be avoided by relying on the distinction raised earlier between the time of assessment and the time of collection. See supra text accompanying notes 21-23. It is only at the time of collection that tax rates need to be applied. The government could collect infrequently and thus assure that there is significant averaging. At the same time, the government would assess changes in wealth continuously.

This method has a critical weakness. Since taxes on wealth changes would not be collected immediately, the government would have to add to the tax base a percentage return representing the intangible benefits that accrue to holding the wealth. This percentage may be very different from the market interest rate and may be hard to observe. This observability problem motivates use of an accretion tax in the first place. See supra note 51; text accompanying notes 44 \& 51.

66. See Vickrey, Tax Simplification Through Cumulative Averaging, 34 LAw \& ConTEMP. Probs. 736 (1969).

67. The cumulation period might begin at a certain age, for example, 18. If a taxpayer reached 18 in 1970 , then for the tax year 1988 the taxpayer would use a cumulation table for 19 years of income. For a clear example of this approach, see $i d$. at 738.

68. The cumulation tables would have to be specifically designed to achieve this result. See id. at 739. 
ously back with interest. But only in the final accounting period does the proportion become correct. In all the early periods, Mr. $Z$ lost more intangible benefits to the tax system than was warranted. ${ }^{68}$ The only way to correct this discrepancy would be to estimate the excess intangible benefits that were taken away from Mr. $Z$ in the early periods and to compensate him in later periods. But this solution involves estimating the level of the intangible benefits. The strength of the accretion taxation approach is that it avoids the need to observe or estimate the level of intangible benefits. ${ }^{70}$

Despite the imperfect nature of the Vickrey system, it is doubtful that using long accounting periods would be superior. The Vickrey system can average over very long time intervals, including the lifetime of the taxpayer. At the same time, the Vickrey system permits use of a short accounting period. A short accounting period avoids the tax free consumption of intangible benefits from wealth due to delays in taxing increases in wealth. Thus, compared to using a long accounting period, the Vickrey system performs at least as well as an averaging device but without allowing tax free consumption of intangible benefits. However, much more analysis would be required to make a strong claim for the overall superiority of the Vickrey scheme. ${ }^{71}$

69. If the rate structure is fixed over time, Mr. $Z$ will know in advance that he will receive excess taxes back with interest. Future tax relief has a present value. It might seem that this present value would offset the excess taxes in the early years. However, the argument that the intangible benefits theory supports accretion taxation rests on a presumption that those benefits come from holding wealth, not from the net present value of the individual's wealth position. See supra text accompanying notes 52-54. Under that presumption, excess taxation in early years combined with a return of the taxes with interest will deprive the taxpayer of intangible benefits in the interim.

70. Ser supra note 51 ; text accompanying notes $44 \& 51$.

71. The need for further analysis arises because the conclusion that the Vickery scheme performs at least as well as an averaging device is only true when intangible benefits are left out of the picture. Applying the Vickery scheme or a long accounting period may result in the same smoothing of tax rates during that accounting period, but the two methods will treat intangible benefits quite differently. The Vickery scheme smooths tax rates gradually over time while the use of a long accounting period accomplishes smoothing by applying a single rate at the end of the period. As indicated by the text example, the gradual correction inherent in the Vickery scheme may result in overtaxation of the intangible benefits from wealth if most wealth gains occur early in life. On the other hand, regardless of the exact pattern of saving, using a long accounting period would allow tax-free consumption of the intangible benefits during the delay between the time the wealth gains occur and the time of taxation at the end of the period. In the case of a concentration of wealth gains early in life, it is possible that the undertaxation due to this delay under a long accounting period is less serious than the overtaxation that would flow from the gradual adjustment of tax rates inherent in the Vickery scheme.

Suppose that this possibility represents reality so that a long accounting period is a superior approach in cases of high accumulation of wealth early in life. It still may be true that the Vickery scheme is superior as a general approach because it is superior for the typical pattern of saving. For example, under life cycle theories of saving, most accumulation will accur in high earning years in the middle of life. This accumulation provides resources for the low earning years during retirement. Vickrey's approach would work quite well for this saving pattern. Taxes on the high middle year incomes would be buffered by averaging with the low income levels in early years. If excessive taxation occurred at all, it would tend not to be as extreme as in the text example where almost all wealth accumulation occurred very early in life. This suggests that the Vickery scheme would be superior if most people are life cycle savers.

The Vickery scheme also will compare favorably to using long accounting periods if theoretical or empirical doubts about whether life cycle saving is typical turn out to be well-founded. In particular, it appears that saving for bequests (and concurrently for insurance in the face of an imperfect annuity 
In conclusion, it is doubtful that overtaxation from using an increasing marginal rate structure implies that a long accounting period should be used under accretion taxation. That rate structure overtaxes only if the accumulation of wealth is concentrated in a few periods of the taxpayer's lifetime rather than spread out more evenly. Furthermore, even if wealth accumulation does tend to be bunched, using the Vickrey scheme combined with a short accounting period may well be a solution that is superior to lengthening the accounting period.

\section{Accretion Taxation as a Second Best Wealth Tax}

The second wealth-related justification for accretion taxation is that it is a way of reducing disparities in wealth in the absence of a wealth tax. The idea is that, compared to a cash flow tax, accretion taxation reduces the rate at which an individual can accumulate wealth and therefore should dynamically reduce disparities in wealth. This theory is "second best" in nature. A wealth tax would provide a more satisfactory solution, but the choice is constrained to be between cash flow taxation and accretion taxation.

This justification extends fairly easily into an argument for continuous taxation. To see this, consider an example. Suppose the pre-tax riskless interest rate is $10 \%$ for a one-year riskless bond. A cash flow tax will leave the after-tax rate of return at $10 \%$. A person with a marginal rate of $40 \%$ buys a $\$ 1000$ bond and immediately receives a tax deduction worth $\$ 400 .{ }^{72}$ The net investment is therefore $\$ 600$. The bond returns $\$ 1100$ at the end of the year and $40 \%$ of this is taxed away, leaving $\$ 660$. The investor has earned $10 \%$ after tax. ${ }^{73}$

In contrast, an accretion tax with a one-year period cuts the after-tax rate of return to $6 \%$ for this individual. The net investment is the full $\$ 1000$, and the individual earns $\$ 60$ in interest after tax. Using a shorter period than one year results in an even lower after-tax rate of return. ${ }^{74}$ At

market) is a saving motive that is at least as important as saving for retirement. See, e.g., Kotlikoff \& Summers, The Role of Intergenerational Transfers in Aggregate Capital Accumulation, $89 \mathrm{~J}$. PoL. Econ. 706 (1981) (intergenerational transfers dwarf life-cycle savings in importance; saving occurs during all of life so that hump of saving predicted by life-cycle theory is absent); Kotlikoff, Intergenerational Transfers and Savings, in What Determines Savings? 69-81 (L. Kotlikoff ed. 1989). This motive would tend to clump wealth accumulation and high wealth levels more toward the end of life. As a result, averaging using either the Vickrey scheme or a long accounting period would not result in applying rates that are too high. The taxpayer would average his or her earnings using many early years of low income. If averaging resulted in using the wrong tax rate, the error would be in the direction of undertaxation. In this case, the Vickrey scheme would be superior to using accounting periods equal in length to the averaging length used in the scheme. The delay in taxing intangible benefits when the accounting period is long would exacerbate any undertaxation due to averaging.

72. See supra note 1 (deduction for investment allowed under cash flow tax).

73. This result is independent of the tax rate. With a $70 \%$ marginal tax rate instead of $40 \%$, for example, the net investment would be $\$ 300$ and the after-tax return would be $\$ 330$. Thus, the aftertax rate of return would still be $10 \%$.

74. See supra note 28; text accompanying notes 24-25 (after-tax interest rates lower for shorter assessment period). 
the extreme of continuous taxation the rate is reduced to $5.89 \%{ }^{75}$ Since the goal is to lower the after-tax rate of accumulation, a continuous tax will be superior to a tax of any finite period. ${ }^{76}$

This reasoning implicitly assumes that divergence of the wealth distribution from optimality will be reduced by any marginal reduction in the rate of accumulation. That assumption itself has some interesting tax policy implications. For example, the assumption may justify taxing nominal rather than real return if the nominal rate of return is higher than the real rate. Consider U.S. Treasury bills as an example. Over the past fiftyfive years, U.S. Treasury bills (short-term notes) have averaged a $3.5 \%$ nominal return but only a $0.4 \%$ real return. ${ }^{77}$ Taxing the nominal returns may have resulted in a better substitute for an absent wealth tax than taxing the real returns. ${ }^{78}$

An important point follows from this discussion of nominal versus real returns. It is not the cause of the level of nominal return but the actual level that is important in using the accretion tax as a proxy. ${ }^{79}$ If inflation were high enough, taxing nominal returns might even result in a much greater impact on accumulation than would be desirable under an ideal wealth $\operatorname{tax}^{80}$

75. Sit Table I, supra text accompanying notes 24-25.

76. This argument is subject to a strong caveat based on potential general equilibrium effects. Those effects are eliminated in the text example by taking the pre-tax rate of return to be $10 \%$ independent of the tax system. The pre-tax rate of return may differ under different tax systems and the ensuing effects may result in a very different picture under a wealth-related norm. See infra note 92; text accompanying notes 91-94.

77. There is a great deal of variance in the ex post real rate of return. During the 1940's and 1970 's, Treasury bills had a significant negative ex post real rate of return. During the 1926-34 period and during the 1980 's, bills had a large positive ex post real rate of return. See R. BREALEY \& S. Myers, Principles of Corporate Finance 546 (chart) (3d ed. 1988).

78. For risky assets the magnitude of the rate of return is less meaningful in determining the effectiveness of accretion taxation as a wealth tax proxy. When the government taxes the fluctuating portion of the return, it reduces the risk that the investor faces. If the riskless rate of return is zero and full loss offsets are available, then the risk reduction exactly compensates for the reduction in expected return ex ante on the asset. Even if the riskless rate is not zero, the reduction in risk largely offsets the reduction in return, and, to a large extent, the tax system does not reach the risky part of the return. See supra note 58.

Treasury bills may seem like a riskless asset. The United States government is unlikely to default, and the asset is so short-lived that capital losses from shifts in interest rates are likely to be minimal. For domestic investors, however, there is inflation risk in investing in Treasury bills. The current inflation rate is not observed. It takes time for data to be gathered and for inflation to be summarized in an index. If inflation rises faster than expected over a period of time, Treasury bills will tend to have too low a rate of return. This return compensates for expected inflation but not for actual inflation. The text discussion ignores this risk and treats Treasury bills as if they earned a very small real return plus the rate of inflation.

79. Some fairly complex economic phenomena may have a significant impact on the rate of return. During the 1980's, Treasury bills have had a significant positive ex post real return. One prominent international economist explains this on the basis of foreign capital flows. Foreigners who invested in the U.S. interest-bearing securities demanded a premium return to compensate for an anticipated decline in the dollar. This decline was expected to be more than would be justified simply by the U.S. domestic inflation rate. See McKinnon, Sound Dollar Tells Business: Think Long, Wall St. J., June 15, 1989, at A12, col. 4.

80. For example, under hyperinflation of say $9999 \%$ per year almost the entire real value of wealth would be received as "interest" on Treasury bills earning a zero rate of return. A chain of 
There is another complication that can be seen from the Treasury bill example. The inflation rate fluctuates, and the nominal rate on Treasury bills fluctuates with it. ${ }^{81}$ Thus, the degree to which an accretion tax operates as a good proxy for a wealth tax may vary sharply with economic conditions. Even if the tax system is indexed for inflation, the riskless rate of return may vary significantly over time. ${ }^{82}$

To make discussion straightforward, Parts III and IV of the Article assume that under current and currently foreseeable economic conditions, the reasoning behind the wealth taxation proxy justification holds up. That is, given those economic conditions, a marginal reduction in the after-tax rate of accumulation leads to a superior distribution of wealth. The additional reduction available from more frequent taxation is therefore desirable, and this makes continuous taxation ideal as a periodicity policy.

\section{The Cost of Deviations from the Ideal Under Wealth-Related Norms}

Under both of the wealth-related norms, the ideal assessment period for an accretion tax is the zero length accounting period typical of continuous taxation. In some cases, however, it will be difficult and costly to implement a continuous tax. ${ }^{83}$ Part IV studies a series of tax approaches that are less costly than an actual continuous tax but that fall short of an exact approximation of that tax. ${ }^{84}$

There is a normative question that must be addressed before beginning such a study. How serious are departures from exact continuous taxation? Unfortunately, there is no indication in the theoretical literature as to how to compare deviations of different sizes. ${ }^{85}$ Subsections $a$ and $b$ of this Sec-

Treasury bill investments starting with $\$ 1$ at the beginning of a year would have to earn $\$ 9999$ in interest to keep even with inflation. Of the terminal value of $\$ 10,000, \$ 9999$ would be in the tax base if basis were not indexed for inflation. This $\$ 9999$ might be taxed at a much higher rate than the ideal wealth tax rate on $\$ 10,000$.

81. The correlation between the inflation rate and the rate on Treasury bills is far from perfect. For example, although the Treasury bill rate has on average been equal to the rate of inflation, there have been long periods of time where the ex post real return on Treasury bills has been negative. See supra note 77 .

82. The most recent evidence suggests that the ex ante real riskless rate is not stable. It displays a unit root which implies that the time series for the ex ante real riskless rate is nonstationary. This behavior seems robust to the time period and to many other variables used in the statistical analysis. See Rose, Is the Real Interest Rate Stable?, 43 J. Fin. 1095 (1988).

A nonstationary variable does not tend to return to any particular average value but wanders around more or less at random. Thus, long runs of negative or positive real rates are to be expected if past is prologue. Qualitatively, these runs seem to characterize real ex post returns on U.S. Treasury bills. See supra note 77 . Furthermore, there is no reason for the average real rate over a long time period to be any particular value.

83. See infra text accompanying notes $140-43$.

84. See infra text accompanying notes $230-45$.

85. The literature that attempts to justify accretion taxation on the basis of wealth-related justifications does not have much to say about the cost of deviations. There is an historical reason for this phenomenon. The wealth distribution justifications for accretion taxation originated in the debate 
tion examine possible methods of determining the costs of deviations under each of the two wealth-related norms in turn. No easily applied method emerges for either norm. In light of this negative result, Subsection c discusses the strategy that will be used for studying implementation in Parts III and IV.

\section{a. The Cost of Deviations Under the Intangible Benefits Justification}

It is easy to construct a theory that specifies the cost of deviations under the intangible benefits justification. The accretion tax includes the proportional component of the intangible benefits in the tax base without requiring that the tax authorities observe the level of this component. A continuous accretion tax impounds a percentage of each wealth increment when the increment occurs. This eliminates that percentage of the proportional component of the intangible benefits from the investor's future stream of benefits. The percentage is equal to the tax rate.

If there is a delay in taxing wealth increments under an accretion approach, the taxpayer will consume the proportional component of the intangible benefits tax free during the period of delay. This deviation from continuous taxation is equivalent to allowing the taxpayer to receive tangible consumption on a tax free basis. ${ }^{86}$

The equivalence between the proportional component of intangible benefits from wealth and other consumption suggests that policymakers can use the existing normative framework of optimal income tax theory to evaluate deviations from continuous taxation. ${ }^{87}$ This theory specifies the

about the choice between accretion taxation and cash flow taxation. See, e.g., supra note 2 (citing sources). It served as a qualitative argument in favor of accretion taxation over its cash flow rival. No attempt was made to quantify the wealth-related justification advantages inherent in accretion taxation.

Some commentators point out that accretion taxation will necessarily remain an ideal rather than an actuality since implementation is difficult. See Andrews, supra note 3, at 1115-18, 1128-65; Andrews, sufera note 2, at 947. One of the most serious implementation problems is that it is hard to tax unrealized gains. See supra text accompanying note 4 . But there is no attempt in the literature to specify the costs of deviating from accretion taxation by assessing infrequently. There is only a sense that infrequent assessment does have some normative cost in terms of the wealth-related norms.

86. The equivalence is exact because taxing the market value of tangible consumption taxes only the proportional component of the benefit from that consumption. Consider oranges. Part of the benefits of buying and eating oranges is proportional and is "priced." In particular, oranges have a market price, and anyone who buys them anticipates benefits at least equal to the market price. The market price represents a proportional component that is common to all individuals. This proportional component goes into the tax base as consumption and is reduced by a percentage that is equal to the tax rate. No tax is levied on the benefit that the taxpayer experiences in excess of the market price. See supra note 56.

87. For an accessible discussion of optimal income tax theory see A. Atkinson \& J. STIGLITz, Lectures on Public Economics 394-423 (1980); Bankman \& Griffith, Social Welfare and the Rale Structure: A New' Look at Progressize Taxation, 75 Calif. L. Rev. 1905, 1945-65 (1987). Under that approach one chooses the income tax rate structure that maximizes a social welfare function. The form of the social welfare function captures social equity norms. For example, this function might be utilitarian, consisting of the sum of all person's utilities, or Rawlsian, consisting of the utility of the person with lowest utility. The approach takes into account the effect of tax rates on behavior such as how long or hard the person works. The central idea is to pick out the best attainable after- 
cost in terms of distributional goals of failing to tax a dollar of consumption for each taxpayer ${ }^{88}$ Generally, this cost will be higher for taxpayers in a higher bracket. ${ }^{89}$ In effect, optimal income tax theory provides a "weight" for each taxpayer that represents the distributional cost of failing to pay a dollar of tax. If a particular form of consumption is untaxed, the policymaker can compute a social cost for this policy by multiplying each taxpayer's weight times the unpaid taxes on the taxpayer's consumption and adding up the products for all taxpayers. Armed with this social cost, it is possible to evaluate changes in the policy by comparing the total improvement in social cost to the added administrative cost of implementing the policy.

Unfortunately, this approach is unlikely to be successful at evaluating deviations from continuous taxation. The approach does provide weights that allow policymakers to evaluate the distributional cost of failing to tax intangible benefits for each taxpayer. The problem is that applying the approach requires that the policymaker know the size of the proportional component of intangible benefits that flow from wealth. Then the weight for each taxpayer could be multiplied by the tax reduction from failing to tax the benefits received by the taxpayer. But the difficulties inherent in measuring the proportional component of the intangible benefits from wealth is the major motivation for using an accretion tax in the first place.

tax state given the social welfare norm. That norm permits precise evaluation of the relative seriousness of deviations from an ideal distribution of income.

The social welfare function depends on individual utilities. The best tax base under the optimal income tax approach will be the one that most closely approximates individual utility. See R. TRESCH, supra note 7, at 267-69. The argument for including the proportional component of intangible benefits along with the market value of tangible consumption in the tax base is that this approach makes taxable income a more accurate estimate of utility.

88. Existing optimal income taxation models study a wage tax. The focus is on the trade-off between distributional goals and the distorting impact on labor supply and the labor-leisure choice. See, e.g., Bankman \& Griffith, supra note 87, at 1945-55. In studying an accretion tax, a different distortion is relevant: An accretion tax increases the cost of future consumption relative to present consumption.

The disincentive effect on saving arising from this distortion was raised earlier as a reason to depart from continuous taxation and use a longer assessment period. Using a longer assessment period reduces the impact of taxation on the riskless rate. See supra note 28; text accompanying notes 24-25. Presumably, that would reduce the impact of accretion taxation on savings incentives. Sep infra note 92. To know how long to make the period, it is necessary to compare the benefits of less distortion of savings incentives against the costs of not taxing some intangible benefits.

89. Intuition might suggest that at the optimum, the welfare cost of not taxing an additional dollar of income to any given individual should be the same. At an optimum it should be true that an extra dollar given to any particular individual creates the same gain in social welfare. Otherwise a different and superior pattern of distribution is attainable by shifting income among individuals.

This intuition is logically correct but is only part of the story. In particular, it-only speaks to a distributional optimum. Taxes also create inefficiencies, and these result in social welfare costs. Generally, the higher the marginal rate the greater the inefficiencies and ensuing social welfare costs. Sep Fullerton, Shoven \& Whalley, supra note 44, at 17 (efficiency cost of tax tends to rise as square of tax rate). Optimal tax rates therefore stop short of the point of a distributional optimum. They tend to trade off distributional gains and efficiency losses most sharply at high marginal rates because that is where the marginal efficiency loss is highest. As a result, untaxed dollars for high bracket taxpayers tend to have a higher cost in terms of distributional goals. 
The accretion approach allows that component to be taxed effectively without having to measure how large it is. ${ }^{80}$

\section{b. The Cost of Deviations Under the Second Best Justification}

The second best justification for an accretion tax rests on the assumption that lowering the after-tax rate of return on investment is desirable at the margin because of its effects on wealth distribution. This assumption implies continuous taxation because it creates the greatest reduction in the after-tax rate of return.

Two steps are necessary to determine the cost of deviations under the second best justification. First, it is important to know how different tax approaches affect the distribution of wealth. Second, it is necessary to know the desirability of various wealth distributions. A measure of desirability is needed that can be used to compare distributional gains to the administrative costs of various periodicities or to the welfare losses that may result from distorting the price of future consumption relative to present consumption.

The first step involves a potentially difficult economic assessment. "General equilibrium effects," the effects of taxes on prices, ${ }^{\text {"1 }}$ may have a substantial impact on the distribution of wealth. ${ }^{92}$ No one appears to have studied the general equilibrium effect of various periodicities under accretion taxation. But studies in other areas of tax policy indicate that general

90. Sue supra note 51 ; text accompanying notes 44 \& 51 .

There is another empirical problem facing the policymaker who wishes to estimate the normative cost of deviations from continuous taxation. Departures from continuous taxation may change the distribution of wealth in a non-obvious way due to complicated effects of the tax on prices in the economy. Sit infra note 94; text accompanying notes 91-94. This shift in the distribution of wealth shifts the distribution of the intangible benefits that flow from wealth. Thus, the indirect changes in wealth distribution caused by the price effects of deviating from continuous taxation should be considered in estimating the costs of the deviations. See infra note 94 (empirical example where price effects of taxation may reverse intuitive judgments about best tax for reaching intangible benefits).

91. The impact of taxing a good on the price of that good considered in isolation is generally referred to as a "partial equilibrium effect." When the good is not considered in isolation, the impact of the tax on its price becomes a "general equilibrium effect." See Strnad, supra note 35, at 407. In this Article, I use the term "general equilibrium effects" to indicate the impact of taxes on prices. There may be some situations when analysis can be restricted to partial equilibrium effects, but I wish to convey that the price effects of taxes often are very complex.

92. The examples in this Article study periodicity with a pre-tax interest rate that is independent of the periodicity embodied in the law. See, e.g., supra note 28 . However, it is likely that the choice between periodicities will affect the pre-tax rate of return. For example, more frequent assessment lowers the after-tax rate of return. See supra note 28; text accompanying notes 24-25. This may decrease the supply of savings and cause the pre-tax rate to be bid up as businesses compete for a smaller pool of funds available for investment in tangible projects. See Strnad, supra note 46, at 1056-59.

Most of the work on detailed tax timing rules assumes that an accretion tax based on pre-tax values is the ideal tax. See, e.g., Slawson, supra note 5; Note, supra note 5. This approach may be motivated by the fact that the pre-tax world that emerges after all actors take into account the impact of the tax code is the data that must be used to administer the tax laws. An exception to the implicit or explicit reference to a fixed pre-tax world can be found in an excellent article by Professor Halperin. See Halperin, supra note 5. In this article, Professor Halperin considers how the parties would alter the pre-tax terms of transactions based on the overall impact of the tax rules. See, e.g., id. at 509-11. 
equilibrium effects can be very large and can modify or even reverse common sense conclusions about various taxes. For example, the second best justification itself rests on the presumption that accretion taxation will bring about a more equitable distribution of wealth than a cash flow income tax. ${ }^{93}$ But, based on general equilibrium studies, a strong argument can be made for precisely the opposite position. ${ }^{94}$

The second step calls for a deeper normative theory than exists at present concerning wealth distribution. Even if the economic effects of taxes on the distribution of wealth are known, a policymaker must be able to rank different wealth distributions and must know how much better one is than another. An evaluative tool such as the social welfare function in optimal tax theory is needed. ${ }^{95}$ This function ranks income distributions in terms of a normative distributive ideal. The function can be varied to accommodate the particular ideal that the policymaker finds desirable. No similar approach with respect to wealth distribution seems to exist at present. $^{\mathbf{9 6}}$

Without taking these two steps, it will not be possible to assess exactly how much is gained at the margin by more frequent taxation. But that assessment is necessary for policymakers to weigh the gains from coming closer to continuous taxation against the corresponding administrative and economic efficiency costs.

93. See supra text accompanying notes 72-82.

94. Consider three results that emerge from one prominent general equilibrium study that compares cash flow taxation to accretion taxation. Fullerton, Shoven \& Whalley, supra note 44, at 16-20. First, a cash flow tax leads to a higher level of total wealth than an accretion tax. Second, the extra wealth can be distributed to low-wealth groups. Third, the redistribution can be accomplished in a way that leaves no wealth group worse off than it was under an accretion tax. If wealth distribution is of primary concern as it is under the second best justification, these results may lead to the conclusion that the best approach is to use cash flow taxation combined with redistribution of the society-wide wealth gains to low-wealth individuals.

If this scenario is true, the cash flow tax combined with redistribution may be attractive under the intangible benefits theory as well as under the second best justification. The redistribution of wealth might "even up" the distribution of intangible benefits so that there is less need to tax them.

Studies differ in the size of the efficiency gains found to result from a shift to cash flow taxation. See, e.g., Ballard \& Goulder, Consumption Taxes, Foresight, and Welfare: A Computable General Equilibrium Analysis, in New Developments in APPlied General Equilibrium ANalysis 253, 274-75 (J. Piggott \& J. Whalley eds. 1985). Determining which study is more likely to represent reality is an important and interesting question but is beyond the scope of this Article. The point here is that general equilibrium analysis may derail the intuitive arguments under either or both wealthrelated justifications for an accretion tax.

95. See supra note 87 ; text accompanying notes $87-89$.

96. This lack of a normative approach seems clear from an examination of the many studies that focus on the choice between consumption and income taxes. These studies cannot use well-being at a particular time to evaluate alternative tax policies. A tax policy may lower a group's well-being at present but greatly increase it in the future. As a result, these studies often look at the impact of various policies on the present value of various groups' future consumption or at the "wealth equivalent" of that impact. See, e.g., A. Auerbach \& L. Kotlikoff, Dynamic Fiscal Policy 74-77 (1987); Fullerton, Shoven \& Whalley, supra note 44, at 16. This is the first step described in the text. The economic impact of a tax on the distribution of wealth is estimated. But these studies leave it up to the reader to take the second step of evaluating the normative significance of different impacts on the distribution of wealth. 


\section{c. Conclusions}

No easy method for evaluating deviations from continuous taxation emerges from either wealth-related norm. In the case of the intangible benefits justification, the inability to observe the magnitudes of the intangible benefits is a significant roadblock. In the case of the second best justification, there appears to be no well-developed theory for evaluating the desirability of various wealth distributions. In addition, it may be important to consider general equilibrium effects when studying the cost of deviations under either norm.

These problems constrain the discussion of implementation in Parts III and IV. A precise social cost cannot be assigned to the imperfect replication of continuous taxation under alternative tax rules. Nonetheless, it is possible to estimate the size of the deviation from continuous taxation under various policies in terms of ex post wealth differences with no adjustment for general equilibrium effects. ${ }^{97}$ Parts III and IV take that approach except that possible general equilibrium effects are considered in a few places. ${ }^{88} \mathrm{~A}$ fuller analysis of implementation awaits further development of the ability to assess the normative costs of deviations.

\section{B. Tax Neutrality}

Another set of justifications for accretion taxation fall under the general rubric of "tax neutrality." obtained by Professor Samuelson.

Subsection 1 describes this result using numerical examples. Subsection 2 shows that the result does not imply an ideal periodicity for accretion taxation. Instead, it requires consistent treatment for different assets. All assets must be taxed with the same frequency, or tax neutrality, as defined by Samuelson's principle, will be absent.

\section{The Samuelson Result}

Samuelson proved that the after-tax present value of market investments will be independent of the tax rate for a continuously applied accre-

97. The examples presented previously in this Article take exactly this approach. For instance, in the example discussed supra text accompanying notes 15-28, each tax treatment is reduced to an equivalent tax as of a certain time. By comparing the equivalent tax under tax treatment " $A$ " to the equivalent tax for continuous taxation, one has a measure of the deviation of treatment $A$ from continuous taxation. This measure is in ex post wealth terms since it consists of the difference in wealth that would be experienced as of a particular time after the application of the different tax treatments. Furthermore, since the example assumes that the pre-tax world is invariant to the tax system that applies, general equilibrium effects of alternative tax systems are ignored. See supra note 28.

98. Sít, e.g., infra note 213; text accompanying note 192 (considering the possible "capitalization" of tax benefits into prices).

99. The rubric itself is somewhat vague. Neutrality concepts often stand in for other unstated normative assumptions. See Andrews, supra note 2, at 948-50. This Section links tax neutrality concepts to the norm of economic efficiency. See infra note 106 and accompanying text. 
tion tax. ${ }^{100}$ The intuition behind this result is straightforward. Although taxes reduce the after-tax present value of investments, the after-tax discount rate also is reduced by taxes. These two effects exactly offset each other so that the after-tax present value of each investment is the same for a person who faces some positive marginal tax rate, $T$, as it is for the person who is not taxed on investment income.

Crucial to this result is the assumption that the after-tax discount rate is reduced the "right" amount. Samuelson assumes that the reduction is exactly that which would arise if continuous taxation were the usual tax treatment in the economy. Before discussing the implications of this assumption, it is important to strengthen the intuitions just set forth with an example.

Suppose there are three taxpayers. One is taxed at a $40 \%$ rate, one at $20 \%$ and one at $0 \%$. Suppose that, as in the example in Part I, the pre-tax interest rate in the economy is constant over time and amounts to $10 \%$ on an annual basis. If borrowing and lending transactions are taxed continuously, the three taxpayers will have after-tax discount rates on an annual basis as set out in column two of Table II. ${ }^{101}$

100. Samuelson, Tax Deductibility of Economic Depreciation to Insure Invariant Valuations, 72 J. Pol. ECon. 604 (1964).

The fact that an accretion tax will produce Samuelson's result is often cited by leading commentators as an important and valued quality of that tax. See, e.g., M. Graetz, Federal. Income TaxaTION 347 n.2 (1985); Warren, Accelerated Capital Recovery, Debt, and Tax Arbitrage, 38 TAx LAw. 549, 550 n.8 (1985); Warren \& Auerbach, Transferability of Tax Incentives and the Fiction of Safe Harbor Leasing, 95 HARv. L. REv. 1752, 1753 \& n.5 (1982).

These commentators do not claim that this tax neutrality quality is an argument for choosing accretion taxation over cash flow taxation. In fact, as demonstrated in this Section, both taxes produce the Samuelson result if applied in pure form. Nonetheless, the importance of the Samuelson result makes it worth determining the implications of the result for periodicity under an accretion tax. If using a particular periodicity approach means that the result will not hold true, this counts heavily against the approach. Furthermore, if such an approach is required to implement an accretion tax for administrative or other reasons, a pure cash flow tax begins to look more attractive in comparison since it will preserve tax neutrality in the Samuelson sense. Of course, that may be an inappropriate comparison since administrative and other constraints may mean that a pure cash flow tax is not obtainable. See Andrews, supra note 2, at 947 (comparison of two tax systems must take into account difficulties in implementing each tax); Graetz, supra note 3, at 275-76 (implementation problems for cash flow taxation must be considered in comparing that tax to the existing impure accretion tax).

101. The second half of Part III of the Appendix infra details the derivation of the rates in the table. That Part of the Appendix indicates that if borrowing and lending transactions are taxed continuously and the instantaneous rate of interest is $r$, then the after-tax borrowing and lending rate over a time period $t$ for a taxpayer with tax rate $\mathrm{T}$ is $\mathrm{e}^{\mathrm{r}(1-\mathrm{T}) \mathrm{t}}-1$. The after-tax rate at which the taxpayer can lend and borrow is the after-tax discount rate. See supra note 22; infra Appendix (Part III).

Samuelson uses precisely this after-tax discount rate in his paper. See Samuelson, supra note 100, at 604 . This rate is appropriate only in an economy where almost all borrowing and lending transactions are taxed continuously since the derivation of the rate depends on that assumption. 
Table II

$\begin{array}{rccc}\begin{array}{c}\text { taxpayer's } \\ \text { marginal } \\ \text { tax rate }\end{array} & \begin{array}{c}\text { taxpayer's } \\ \text { after-tax } \\ \text { discount rate }\end{array} & \begin{array}{c}\text { equivalent } \\ \text { time } 2 \\ \text { tax }\end{array} & \begin{array}{c}\text { after-tax } \\ \text { receipt } \\ \text { at time 2 }\end{array} \\ 0 \% & .10 & 0.00 & 144.00 \\ 20 \% & .0792 & 5.39 & 138.61 \\ 40 \% & .0589 & 10.57 & 133.43\end{array}$

Now consider the example from Part I. ${ }^{102}$ In the example, the investment yields $\$ 144$ at the end of two years. As discussed above, the market value of this investment at time 0 is $\$ 119 .{ }^{103}$ Under Samuelson's result, purchase of the investment for $\$ 119$ should have zero net present value at time 0 independent of the taxpayer's bracket. ${ }^{104}$

For the investor in the $0 \%$ bracket the result is transparent. The present value of $\$ 144$ to be received in two years under a $10 \%$ discount rate is $\$ 144 /(1.1)^{2}=\$ 119$. The time 2 taxes that are equivalent to continuous taxation for the other two investors are set out in column three of the table. ${ }^{108}$ Column four of the table reduces the $\$ 144$ return at time 2 by these equivalent taxes.

At time 2 , the investor in the $20 \%$ bracket will receive $\$ 144$ minus a tax of $\$ 5.39$. This must be discounted by the factor $(1.0792)^{2}$ to present value at time 0 . The result is $\$ 119$. Similarly, for the investor in the $40 \%$ bracket, the time 0 present value is $(\$ 144-10.57) /(1.0589)^{2}=\$ 119$. In each case the increase in taxes for the higher-rate taxpayers are exactly offset by the decrease in their after-tax discount rates.

This result has considerable meaning in terms of neutrality. All investors, independent of tax status, will pay the same price of up to $\$ 119$ in pre-tax dollars to secure the $\$ 144$ return in two years. This means that a particular investment will be undertaken by the parties who are most efficient at carrying it out rather than by the parties who have the strongest tax motivations. ${ }^{106}$

An apparent difference between investors will arise if they are able to invest less than the $\$ 119$ at time 0 to own the investment. Suppose that, as in the original example in Part I, the three investors can secure the $\$ 144$

102. See supra text accompanying notes $15-20$.

103. Se supra text accompanying notes $18-20$.

104. Samuelson's result stated in terms of after-tax value applies only to purchase of the asset at market value. If we consider purchase at $\$ 100$, a continuous tax will treat the spike increase of $\$ 19$ at time 0 differently for taxpayers in different brackets. But the essence of the Samuelson result is that all taxpayers perceive the same market value of $\$ 119$ for the asset. There is no tax motive to trade among themselves. Sep infra text accompanying notes 105-09.

105. Part IV of the Appendix describes the techniques used to compute equivalent taxes. See infra Appendix.

106. Thus, the tax neutrality idea behind the Samuelson result is grounded in a concern for efficiency. 
return in two years by paying only $\$ 100$ at time 0 . Now the net returns are as follows:

\begin{tabular}{|c|c|c|c|c|}
\hline \multicolumn{5}{|c|}{ Table III } \\
\hline $\begin{array}{c}\text { taxpayer's } \\
\text { marginal } \\
\text { tax rate }\end{array}$ & $\begin{array}{l}\text { taxpayer's } \\
\text { after-tax } \\
\text { discount rate }\end{array}$ & $\begin{array}{l}\text { equivalent } \\
\text { time } 2 \\
\operatorname{tax}\end{array}$ & $\begin{array}{l}\text { after-tax } \\
\text { net value } \\
\text { at time } 0\end{array}$ & $\begin{array}{c}\text { percent of } \\
\text { after-tax net } \\
\text { for } 0 \% \text { taxpayer }\end{array}$ \\
\hline $0 \%$ & .10 & 0.00 & 19.01 & $100 \%$ \\
\hline $20 \%$ & .0792 & 9.81 & 15.21 & $80 \%$ \\
\hline $40 \%$ & .0589 & 19.10 & 11.40 & $60 \%$ \\
\hline
\end{tabular}

The pure profit of $\$ 19$ at time 0 is taxed away at the taxpayer's marginal tax rate. At time 0 the three taxpayers have different after-tax net present values for the project. But as long as all tax rates are less than $100 \%$, all three taxpayers will undertake the same projects. Pure profits are like a windfall. Taxing part of them or even almost all of them away will not dissuade the taxpayer from making the investment.

The example in Table III is a particular instance of a more general phenomenon. When taxes are not collected continuously, different taxpayers will have different accumulated tax liabilities on any given asset. ${ }^{107}$ In these cases where after-tax value differs among taxpayers, there is a simple test for neutrality: Does the market price at which these taxpayers would be willing to buy or sell an investment differ? The market price at which any of the three taxpayers would sell the investment in Table III is $\$ 119$. For example, if the $40 \%$ investor sells at this price, the after-tax return is $\$ 11.40 .^{108}$ This is equal to the $\$ 11.40$ after-tax net value in the table. The fact that each taxpayer perceives the same market value indicates that there is no motivation for any taxpayer to trade the asset to another taxpayer based on a tax-induced difference in value. This is the core idea that Samuelson wished to capture. ${ }^{108}$

It is important to note that the Samuelson result is based on pre-tax values. No claim is made that investment incentives will be the same as in the no-tax world. ${ }^{110}$ The Samuelson result simply implies that the distor-

107. For example, column three of Table III shows the accumulated tax liability if collection of the continuous tax is delayed until the end of the two-year period.

108. The basis is the cost of $\$ 100.00$ and the amount realized is $\$ 119.00$. Sixty percent of $\$ 19.00$ is $\$ 11.40$. This is what remains of the $\$ 19.00$ gain after application of a $40 \%$ tax.

109. Samuelson explicitly linked his result to the absence of tax-motivated trading. Taxpayers in different brackets cannot deal with each other at the expense of the government since the desirability of investment is independent of the individual's tax bracket. See Samuelson, supra note 100, at 606; Fane, Neutral Taxation Under Uncertainty, 33 J. PuB. EcoN. 95, 96 (1987).

110. The desirability of investment in general may be affected by the general equilibrium impact of the tax system. Others who have studied Samuelson's work are aware of the fact that his analysis does not take general equilibrium effects into account but merely takes pre-tax prices as given. See Fane, supra note 109 , at $95-96$. The general equilibrium impact of the tax system may affect the relative desirability of investment in different assets as well as the desirability of investment in general. 
tions contained in pre-tax prices will be experienced equally by all taxpayers. The market value of $\$ 119$ in the example for a return of $\$ 144$ in two years may be distorted by general equilibrium effects from the situation in the no-tax world, but the $\$ 119$ valuation holds independent of an investor's tax rate. ${ }^{111}$

\section{Periodicity Implications of the Samuelson Result}

The previous Subsection indicated the driving force behind the Samuelson result: The decrease in after-tax discount rates offsets the loss in returns due to taxes so that investors with different tax rates value each investment the same. An important issue is whether this effect is limited to the continuous tax studied by Samuelson. It is not. Gash flow taxation and accretion taxation that is periodic rather than continuous both support the Samuelson result.

Consider cash flow taxation first using the example of a $\$ 144$ return to be received in two years. Assume that this cash flow tax is perfect in the sense that deductions take effect immediately upon cash outflows and taxes are levied at the moment of cash inflows. ${ }^{112}$ Under a cash flow tax, the after-tax discount rate will be equal to the pre-tax interest rate for all taxpayers. ${ }^{113}$ This rate is $10 \%$ in the example. For a $0 \%$ bracket taxpayer, the $\$ 144$ return will be valued at $\$ 119=\$ 144 /(1.1)^{2}$. Suppose the investor instead is subject to a tax rate, $T$. Then the after-tax return at the end of two years will be $\$ 144$ multiplied by $(1-T)$. What is the highest

111. Consider a simple example. Suppose that lowering the after-tax rate of return reduces saving and increases investment demand. As can be seen from Tables II and III, a continuous tax will tend to lower after-tax rates of return. Suppose that the no-tax world rate of return was $8 \%$. If this rate did not increase in response to the tax, most people would face an after-tax rate of return of less than $8 \%$ and would save less. Firms faced with a reduced after-tax borrowing rate (due to the greater value of the deduction for interest costs) would demand more investment funds. The pre-tax rate of return would have to increase above $8 \%$ to restore equilibrium.

Suppose that the pre-tax rate of return ends up at $10 \%$. The $2 \%$ increase over the no-tax world rate of return will mean that some investments that were viable in the no-tax world will not be viable in the tax world. Consider the investment that returns $\$ 144$ in two years. With a $10 \%$ pre-tax rate of return, investors would make this investment only if the cast is $\$ 119$ or less. But in the no-tax world the required rate of return was $8 \%$, and investors were willing to pay up to $\$ 123.46=\$ 144 /(1.08)^{2}$ to receive the return. Projects yielding $\$ 144$ in two years with costs between $\$ 119$ and $\$ 123.46$ were viable in the no-tax world but are no longer viable in the tax world. Investment has been distorted by the tax. But all investors still value the $\$ 144$ return with a common pre-tax price. That common price has changed from $\$ 123.46$ to $\$ 119$ due to the general equilibrium impact of the tax.

112. Alternatively, the government could collect taxes periodically, and taxpayers would pay or receive interest at their after-tax interest rate on taxes due or on refunds due at earlier times. Interest would begin to accrue at the moment of the actual cash inflows and outflows that generate the taxes or refunds. This scheme is similar to the approach in the example in Part I where all taxes were collected at the end of two years by applying the appropriate interest charge to taxes that were due carlier. Sie supra text accompanying notes 21-22.

For a cash flow tax, the pre-tax and after-tax riskless interest rates are equal. See supra text accompanying notes 57-58. Even if cash flows are risky, applying this riskless interest rate will result in periodic taxes that are equivalent to taxation at the time of the cash flows, unless there is a possibility that the firm can default on the future tax payments. See Fane, supra note 109, at 97-101.

113. Ser supra text accompanying notes $57-58$. 
amount that this individual will be willing to pay for the investment? The after-tax value of the investment viewed from the beginning of the two years will be $\$ 144 \times(1-T) /(1.1)^{2}=\$ 119 \times(1-T)$. So the investor would be willing to pay $\$ 119 \times(1-T)$ after-tax for the investment. This corresponds to $\$ 119$ before tax since the tax deduction of $\$ 119$ reduces the cost by $T \times 119$. Regardless of their tax bracket, investors will pay up to $\$ 119$ for this investment.

Now consider an accretion tax assessed annually. For the $0 \%$ bracket taxpayer a $\$ 144$ return to be received in two years is worth $\$ 119.01=$ $\$ 144 /(1.1)^{2}$ given a pre-tax market interest rate of $10 \%$ annually. ${ }^{114}$ Now consider whether $\$ 119.01$ would be the market price that a $40 \%$ bracket taxpayer would be willing to pay. With annual assessment, the after-tax discount rate that applies to investments that begin and end at the beginning of an assessment period is simply $10 \% \times(1-\mathrm{T}) .{ }^{115}$ For the $40 \%$ bracket taxpayer this amounts to $6 \%$. The following table records the cash flows, including tax payments and details their contribution to the investment's time 0 market value to a $40 \%$ bracket taxpayer.

\section{Table IV}

$\begin{array}{rrccc}\text { time } & \begin{array}{c}\text { amount of } \\ \text { cash flow }\end{array} & \begin{array}{c}\text { type of } \\ \text { cash flow }\end{array} & \begin{array}{c}\text { residual value } \\ \text { after } \\ \text { cash flow }\end{array} & \begin{array}{c}\text { contribution } \\ \text { of cash flow } \\ \text { to value }\end{array} \\ 0.0 & -119.01 & \text { cost } & 119.01 & -119.01 \\ 1.0 & -4.76 & \text { tax } & 130.91 & -4.49 \\ 2.0 & -5.24 & \text { tax } & 144.00 & -4.66 \\ 2.0 & 144.00 & \text { revenue } & 0.00 & 128.16\end{array}$

The last column discounts the cash flows from the second column to time 0 present value using the $6 \%$ after-tax discount rate. The figures in the last column add to zero. This indicates that $\$ 119.01$ is indeed the most that the $40 \%$ taxpayer would pay for the right to earn $\$ 144.00$ two years later. At this price, the investment earns exactly the after-tax market rate of return, which is $6 \%$ for this taxpayer. Adding a penny to the $\$ 119.01$ cost would make this investment unprofitable. Lowering the cost from $\$ 119.01$ would yield pure profit for the taxpayer. Once again the Samuelson result appears. The value of the $\$ 144$ cash flow is the same for all investors regardless of their tax brackets.

The Samuelson result breaks down, however, if not all investments are

114. Previously, the rounded value of $\$ 119$ was used in the example instead of $\$ 119.01$. See supra text accompanying notes $102-13$. The unrounded figure is used here because the analysis surrounding Table IV infra requires a greater degree of precision.

115. Consider a bond that yields the market rate of $10 \%$. For a cost of $\$ 100$, the return one year later is $\$ 110$. The $\$ 10$ in taxable income is taxed at that time, reducing the after-tax return to $\$ 10 x$ $(1-T)$. Dividing this by $\$ 100$ yields $.10 \times(1-T)$ as the after-tax rate of return. In percentage terms, this is just $10 \% \times(1-T)$. 
taxed with the same frequency. Suppose, for example, that all assets but one are taxed under a regime of continuous taxation. The one asset is the investment that yields $\$ 144$ in two years. It will be taxed under an accretion tax with assessment every two years.

In this case, taxpayers will borrow and lend using assets that are taxed continuously. As a result, after-tax discount rates will be the same as they would be under continuous taxation. The Samuelson result worked because the reduction in after-tax discount rates exactly offsets the added tax burden on revenues. ${ }^{116}$ The $\$ 144$ investment will be taxed more leniently than it would be under continuous taxation, but taxpayers will assess it using the after-tax discount rates generated by continuous taxation. One might expect that higher bracket taxpayers will value this investment more highly than lower bracket taxpayers. This is true, as the third column of the following table indicates: ${ }^{117}$

\section{Table V}

$\begin{array}{cc}\text { taxpayer's } & \text { taxpayer's } \\ \text { marginal } & \text { after-tax } \\ \text { tax rate } & \text { discount rate }\end{array}$

$\begin{array}{rl}0 \% & .10 \\ 20 \% & .0792 \\ 40 \% & .0589\end{array}$

\author{
highest amount \\ taxpayer would \\ pay at time 0
}

119.01

119.81

In sum, obtaining the Samuelson property of the invariance of investment value across different individual tax rates only requires consistent taxation. Regardless of the length of the assessment period for accretion taxation, as long as the same period is applied to all assets, the Samuelson result will apply. Furthermore, a consistently applied cash flow tax will also make investment value independent of individual tax rates. Thus, the Samuelson property does not support an accretion tax over cash flow taxation, and the property does not help in choosing the frequency of assessment under accretion taxation. ${ }^{118}$

116. See supra text accompanying notes $100-05$.

117. The calculations in the table are straightforward. At time 2 the taxpayer receives $\$ 144$ and is taxed at rate $T$ on $\$ 144$ minus the purchase price $\$ X$ of the asset. If the taxpayer's after-tax discount rate is $d$, then the highest market value the taxpayer would be willing to pay is given by solving the following equation for $\$ \mathrm{X}$ : $[144-((144-\$ \mathrm{X}) \times \mathrm{T})] /(1+\mathrm{d})^{2}=\$ \mathrm{X}$.

This equation says that the discounted present value of the $\$ 144$ in revenue minus the tax of (144 $\$ \mathrm{X}) \times \mathrm{T}$ must be equal to $\$ \mathrm{X}$, the cost of the asset. If this is true, then the investment will earn exactly the market rate of return. A higher $\$ \mathrm{X}$ will turn it into a loser, and a lower $\$ \mathrm{X}$ will result in the investment being more profitable than others available in the market. The solution to the equation is: $\$ X=[144 \times(1-T)] /\left[(1+d)^{2}-T\right]$.

118. A result related to the Samuelson theorem can be used to argue that accretion taxation has neutrality properties superior to cash flow taxation. A pure system of accretion taxation will coincide with investment neutrality even if tax rates change over time, but cash flow taxation will not. See Sandmo, A Note on the Neutrality of the Cash Flow Corporation Tax, 4 Econ. LeTTERS 173 (1979). Professor Sandmo considers only a continuous accretion tax, but the result also holds for a periodic accretion tax if tax rates are constant within periods but can change between periods. The result is 


\section{The Haig-Simons Ideal}

The legal literature often posits the Haig-Simons ideal as the normative benchmark for studying tax timing and then proceeds immediately to the level of detailed policy applications. ${ }^{119}$ Unfortunately, the Haig-Simons ideal by itself provides little guidance in choosing a period for accretion taxation. In Simons' words, "Personal income may be defined as the algebraic sum of (1) the market value of rights exercised in consumption and (2) the change in the value of the store of property rights between the beginning and the end of the period in question."120 And according to Haig, "Income is the money value of the net accretion to one's economic power between two points in time." 121 These definitions leave the issue of periodicity entirely unaddressed. What should be "the period in question" or the "two points in time" to be used in applying the ideal?122

The Haig-Simons ideal can be taken to be a definition of a type of tax

easy to explain. If tax rates change, then discount rates will change under accretion taxation. This change will offset the changes in tax paid. Under cash flow taxation, discount rates are unaffected by the tax so that these rates cannot adjust to offset the changes in taxes paid.

Invariance under tax rate changes is an important characteristic because tax rates do change frequently, and in many cases the changes can be anticipated by taxpayers. These taxpayers may accelerate or defer investments and other transactions to exploit the anticipated changes.

As Sandmo notes, however, nonneutrality under tax rate changes may be desirable. See id. Under a cash flow tax, announcing at the beginning of year one that tax rates will be lower for years two forward will cause investors to accelerate investment into year one. This yields a more valuable deduction (against income at the higher, year-one rate) combined with low rates on revenues in later years. This nonneutrality may be exactly what the government wants to accomplish. For example, the increase in year-one economic activity due to accelerating investment into that year may ameliorate a recession forecast for that year. A nonneutral tax may serve as a useful macroeconomic tool.

Suppose, nonetheless, that the goal is to maintain neutrality in the face of tax rate changes. Then the Sandmo result constrains rather than defines the optimal assessment period for accretion taxation: The period should be short enough that no tax rate changes occur within the period.

119. See, e.g., Halperin, supra note 5, at 508-09; Kiefer, The Tax Treatment of a "Reverse Investment": An Analysis of the Time Value of Money and the Appropriate Tax Treatment of Future Costs, 26 TAx Notes 925, 925-32 (1985); Note, The Tax Reform Act of 1986: Simplification and the Future Viability of Accrual Taxation, 62 NoTre Dame L. REv. 779, 785-86 (1987).

120. H. Simons, supra note 34 , at 50 .

121. Haig, The Concept of Income-Economic and Legal Aspects, in The Federal Income TAX 1, 7 ( $R$. Haig ed. 1921) (emphasis in original).

122. The author was unable to find any extensive discussion by Henry Simons concerning the appropriate period. In his major work on personal income taxation, he merely argues that the realization requirement is a practical necessity. He was aware that this policy allows deferral of gains and strategic loss taking, but, perhaps because interest rates were low at the time, he did not regard these consequences as serious. See H. Simons, supra note 34, at 99-100, 153, 157, 168-69, 207-08.

However, Simons expressed considerable ambivalence toward strict adherence to an annual period. For example, in his 1950 book on income tax reform he states:

[Good income tax accounting or] procedure must not require or presuppose sharp allocations of income among short accounting periods. ... [T]ax legislation calling for definitive annual determinations means awful complexity, difficult administration, expensive compliance, endless litigation, and bad taxpayer and Bureau morale. Like it or not, we must recognize that good income taxation is not merely a succession of events in or respecting discrete, water-tight accounting periods but is essentially process through time. Its objectives must be defined and pursued with respect to long periods, often the taxpayer's whole lifetime. . . .

....

... Income taxation has simply never faced squarely the axiom that annual-income accounting is and should be tentative and provisional.

H. Simons, Federal Tax Reform 59-60 (1950). 
treatment rather than a norm to be used in deciding what tax treatment to apply. Traditionally, many scholars have considered the Haig-Simons ideal to be just another name for accretion taxation. ${ }^{123}$

Even if one takes this view, the problem of failure to specify a period remains. As the examples in Part I indicate, accretion taxes with different assessment periods are different taxes. They have different impacts on the taxpayer's wealth position. In the transaction connected with Table I, for instance, a continuous accretion tax was $4 \%$ higher than an accretion tax assessed annually, and an accretion tax assessed annually was $4 \%$ higher than an accretion tax assessed biannually. ${ }^{124}$

There is one result that emerges as a general principle: An accretion tax treatment with assessment period $X$ will meet the Haig-Simons ideal only if that ideal is defined in terms of a period of length $X .{ }^{125}$ Thus, a continuous accretion tax will be considered excessive if the period examined is one year, two years, or indeed any noninfinitesimal period. Similarly, a one year accretion tax will appear too lenient if the HaigSimons test is applied at half-year intervals.

Consider as an example an investment that costs $\$ 100$ at the beginning of year one and yields $\$ 110$ at the end of that year. At the end of year one the taxes under different assessment periods for an individual in the $40 \%$ tax bracket will be as follows:

\section{Table VI}

assessment period

two years (biannual)

one year (annual)

continuous equivalent tax

at time 1

3.77

4.00

4.11

Applying the Haig-Simons ideal based on a one year accounting period, wealth has increased by $\$ 10$ during the year so that the individual should pay $\$ 4.00$ in tax. Biannual assessment and continuous assessment result in taxes that are too low and too high respectively.

123. The ideal is called a "norm" in much of this Article because many tax scholars use it as the explicit starting point for work on tax timing. See supra note 119 (citing sources). These scholars may have deeper norms in mind, but they do not state them. In any event, it is hard to separate "norms" from the "definitions" that they spawn. One can always challenge a norm by asking for a deeper justification. This reduces the "norm" to an operational rule on the level of a definition.

Regardless of whether one calls the Haig-Simons ideal a norm or a definition, it is clear that the ideal plays an important role in the study of accretion taxation. One leading scholar puts it this way: "The intellectual basis for accrual taxation is the Haig-Simons definition of income. . . . Commentators often use this definition in analyzing and evaluating proposals under an income tax." Shakow, supra note 5, at 1114 (Footnotes omitted).

124. See Table I, supra text accompanying notes 24-25; text accompanying note 27.

125. I have made this point in earlier work. See Strnad, supra note 35, at 400 n.34 (periodic accretion tax); Strnad, Tax Timing and the Haig-Simons Ideal: A Rejoinder to Professor Popkin, 62 IND. L.J. 73, 81 (1986) (continuous accretion tax). 
For the Haig-Simons ideal to specify the choice of tax treatment, either a particular period must be chosen and incorporated into the definition, or a tax treatment must be identified that taxes consumption plus net wealth over any accounting period. The first method simply emphasizes that the Haig-Simons ideal alone does not say anything about the choice of period. ${ }^{126}$ That choice is a normative task, and the Haig-Simons ideal does not indicate which norms should dictate the choice. ${ }^{127}$

The second route leads away from accretion taxation entirely. For any fixed set of transactions, cash flow taxation will result in Haig-Simons treatment regardless of accounting period if the impact of future taxes on present value is properly accounted for and general equilibrium effects are ignored. ${ }^{128}$ In contrast, each variant of accretion taxation meets the HaigSimons ideal only for an accounting period equal to the period of assessment under that variant. ${ }^{128}$

126. One view is that the taxpayer's lifetime is the appropriate period. The Haig-Simons ideal aims at measuring and taxing the economic power accumulated or exercised by the taxpayer. The lifetime period aggregates power exercised as consumption at all of the time periods of life with the power that remains in the form of wealth passed on to heirs. But many proponents of this view do not advocate an accretion tax with a lifetime period. Instead, they argue that a cash flow income tax combined with taxing bequests implements the Haig-Simons ideal. See, e.g., R. TRESCH, supra note 7, at 267-68; Aaron \& Galper, A Tax on Consumption, Gifts and Bequests and other Strategies for Reform, in OpTIONS FOR TAX REFORM 106, 112 (J. Pechman ed. 1984).

It is important to emphasize that a cash flow income tax combined with a tax on bequests is very different from an accretion tax with a lifetime period. A cash flow income tax tallies all receipts that are not reinvested and includes them in taxable income at the time of receipt. An accretion tax with a lifetime period would add up all receipts and delay taxation until the time of death. Thus, the cash flow income tax is not the "limit" of a series of accretion taxes as the period is extended to the taxpayer's lifetime.

127. It is possible to identify the Haig-Simons ideal with wealth-related norms. See supra text accompanying notes $31-82$. There are two problems with making this identification. First, either of the wealth-related norms may imply that a tax treatment other than accretion taxation is best. For example, if intangible benefits flow from the present value of wealth, then cash flow taxation may be a superior approach. See supra text accompanying notes 52-54. Second, when an author cites the Haig-Simons ideal as a normative starting point, it is not clear which version of the wealth-related norms is in the author's mind. Different versions may lead so different tax policy recommendations. For example, the second best wealth tax justification may imply that taxing nominal gains is desirable while the intangible benefits justification implies indexing for inflation. See supra text accompanying notes 57 \& 76-78.

In short, if the Haig-Simons ideal really "stands for" another norm, citing the ideal instead of explicitly discussing the norm can easily lead to confusion. This confusion is especially likely when considering the issue of periodicity because the Haig-Simons ideal by itself says nothing about this issue.

128. See Strnad, supra note 35, at 396-99; Strnad, supra note 125, at 75-81; Strnad, supra note 46 , at 1084-89. This result has precedents extending back at least half a century. See Strnad, supra note 35 , at 403 . Unfortunately, the result probably does not hold if general equilibrium effects are taken into account. See Strnad, supra note 125, at 87-88; Strnad, supra note 46, at 1102-03. For a numerical example illustrating the result, see supra note 35 .

The result is closely linked with the Aaron-Galper argument that cash flow taxation combined with a tax on bequests at death meets the Haig-Simons ideal if the period chosen for taxation is the lifetime of the taxpayer. See supra note 126. The length of the taxpayer's lifetime is unknown in advance. For cash flow taxation to meet the Haig-Simons ideal for a lifetime of any possible length, it must meet the ideal for any accounting period.

129. Accounting period independence is a desirable trait, and requiring it is an attractive way to resolve the failure of the Haig-Simons ideal to speak to periodicity. But accounting period independence certainly is not the end of the inquiry. Many who support an accretion tax and invoke the 
In sum, whether considered as a norm or as merely a definition, the Haig-Simons ideal is not helpful in determining the proper periodicity of an accretion tax. The ideal either offers no guidance at all on the proper period or it points toward choosing cash flow taxation over accretion taxation of any periodicity.

\section{The Normative Costs of the Accounting Period Ghoice}

Only two of the four main norms cited in favor of accretion taxation specify a desired periodicity. The two wealth-related norms suggest that continuous taxation is the most desirable frequency of taxation. The Samuelson principle merely argues for consistent treatment of all transactions. The Haig-Simons doctrine adds nothing to the periodicity debate.

This normative discussion suggests that a continuous tax applied consistently across all assets would be ideal. This Part studies the normative costs of deviating from continuous taxation and the factors that affect these costs. Section A shows that constructing a continuous tax is not easy. Most assets are risky and, as a result, the proper continuous tax depends on knowledge of the exact time path of asset value. The Section also indicates that, at least for some assets, this knowledge can be gained only at significant cost. Sections B and C show that the degree of deviation from continuous taxation depends substantially on three factors in addition to the length of the assessment period: asset riskiness, transaction costs of trading and the existence of strategic trading opportunities. Section D demonstrates that the normative costs that would result if the law left strategic trading for typical risky assets totally uncontrolled would be very large.

\section{A. Asset Path Information and Administrative Costs}

\section{Asset Path Information}

The example in Part I makes continuous assessment seem simple. ${ }^{130}$ In that example, continuous assessment was reduced to a tax at a single point. The only input data were the cash flows and the riskless interest rate. The asset cost $\$ 100$ at the beginning of the first year. It produced $\$ 144$ in revenue risklessly at the end of the second year. The riskless interest rate was constant at a $10 \%$ annual rate during the two years. Knowing these three pieces of information alone permitted the conclusion that a tax of $\$ 19.10$ at the end of the two-year period would be exactly equivalent to a continuous tax applied moment by moment during the two

Haig-Simons ideal may have other goals in mind such as implementing the wealth-related norms. If so, these norms, rather than a mere invocation of the Haig-Simons standard, should be the explicit starting point for analysis. See supra note 127.

130. Se'? supra text accompanying notes $15-28$. 
years. The mathematical computations are in fact quite straightforward, and it is possible to construct a simple computer program that will provide periodic taxes equivalent to continuous taxation for any anticipated cash flow. ${ }^{131}$ This simplicity suggests that a continuous assessment system could be administered easily even if taxes were collected periodically rather than continuously.

Unfortunately, this suggestion is mistaken. The ability to compute a continuously assessed tax on a periodic basis using only cash flow and riskless interest rate data depends crucially on the assumption that both riskless interest rates and cash flows are certain and known in advance. This assumption implies that interest rate and cash flow data will be sufficient to determine the path of asset values. ${ }^{132}$ The tax authorities do not have to observe that path. In tax policy terms, the realization requirement does no harm. The tax authorities can wait until the end of an investment and then assess a tax that is equivalent to a continuous tax.

This pleasant state of affairs vanishes if either interest rates or cash flows are uncertain. In that instance, prior to realization of the rates or flows, the value of the investment will fluctuate based on investor expectations about the future value of the rates and flows. Even knowing the ex post realizations of the cash flows and interest rates at each point in time will not allow one to reconstruct the path of asset value. That path depends on expected cash flows and not on the actual values that occur.

For an actual risky asset, risk resolution and the creation of new risk will happen frequently during the life of the asset. There will be many possible paths, and, in general, asset value will move in the "jerky" way portrayed in charts of stock prices in the newspaper. ${ }^{133}$ Knowing the initial value and final value will not determine the time path of values in between. ${ }^{134}$ The only way to specify that path exactly will be to observe it directly. ${ }^{135}$ Since the value of most assets fluctuates almost continuously,

131. The author's program consists of about 100 lines of FORTRAN code including code setting up input and output. This program could be extended easily to accommodate time varying interest rates as long as the temporal pattern of interest rates is known in advance.

132. In the example in Part $I$, this path consisted of the asset jumping in value from $\$ 100$ to $\$ 119$ at the start and then increasing exponentially from $\$ 119$ to $\$ 144$ over its two year life. See supra text accompanying notes $18-20$.

133. In fact, the leading paradigm for the motion of asset rates of return is Brownian motion: the jerky movement of small particles suspended in a liquid. See infra note 149.

134. For a simple example of a risky asset with more than one possible path between a fixed initial value and a fixed final value, see infra text accompanying notes 233-34.

135. It may be possible to make educated guesses about the path of a particular asset. One of the great contributions of modern finance is the observation that asset pricing may depend largely on a few uncertain factors in the economy. See R. Brealey \& S. MYers, supra note 77, at 140-58; Roll \& Ross, An Empirical Investigation of the Arbitrage Pricing Theory, 35 J. FIN. 1073 (1980).

For a particular asset one might estimate its asset value path in two steps. First, one would estimate how its price depends on the various market risk factors. Second, one would observe how those risk factors changed over time. In theory, the tax authorities could use this approach to estimate asset paths.

This technique would be especially valuable for assets like works of art or closely held stock where there is no series of market prices available for the particular asset. For these assets, however, the first 
almost continuous observation of asset values will be required to specify the asset value path over time. ${ }^{136}$

Unfortunately, the class of risky assets is not small. Most assets are subject to fluctuations in capital value that are not known in advance. ${ }^{137}$ These assets present the tax authorities with the problem just identified: the value path cannot be determined by simply observing the initial and final value. Nonetheless, knowing the initial and final value does make some paths more likely than others. ${ }^{138}$ Furthermore, assuming that the variance of potential asset values grows with time, more frequent observation of asset value will yield a better approximation of the actual path. ${ }^{139}$ Given continuous taxation as an ideal, choosing a period for assessment amounts to deciding how often to observe the value of each taxpayer's

step of estimating the dependence of asset price on the risk factors would be guesswork. There would be no price data available to do a statistical estimate. See R. BREALEY \& S. MYERS, supra note 77, at 187-191 (díficulties of estimating dependence of asset value on general risk factors without using asset price data).

136. For publicly traded securities, transactions that change prices are separated by very short time intervals, often less than one minute. This has prompted finance economists to use models with prices that change continuously. See Merton, On the Mathematics and Economics Assumptions of Continuous-Tme Models, in Financial. Economics: Essays in Honor of Paul Cootner 19, 20 (W. Sharpe \& C. Cootner eds. 1982).

137. Extremely short-term borrowing and lending at fixed rates where default can be ruled out may appear to be nearly riskless. In this case, cash flows are certain and the holding period is so short that there is no time for interest rate changes to affect the value of the asset. This type of investment can be held continuously despite its short term nature. For example, some money market funds hold and continually roll over extremely short-term debt. The result is that capital value remains constant, and the investor's return fluctuates with the short-term interest rate. Unanticipated changes in inflation, however, affect the real value of the capital so that short-term lending with low default risk is not a riskless investment. See supra note 78 .

Some long-term assets such as U.S. Treasury bonds have very low default risk and almost certain cash flows. But these bonds are still risky because future interest rates for riskless borrowing and lending are uncertain. The asset value will fluctuate with changes in interest rates.

For example, suppose a U.S. Treasury bond returns $\$ 110$ for certain at the end of year one and costs $\$ 100$ at the beginning of the year. The value of the bond in the middle of the year will depend on how the market at that time values riskless returns to be received in six months. Generally, the sixmonth riskless rate at mid-year is uncertain at the beginning of the year.

The uncertainty of interest rates over time means that the path of the bond's value must be $a b$ served to implement a continuous tax precisely. The value of a $\$ 100$ bond at the end of the year may be $\$ 110$. But, at the end of the year, only observation will reveal the bond's value at the middle of the year. One must either directly observe the bond's value at that time or estimate that value by observing interest rates in the middle of the year.

138. See infra text accompanying notes 146-47 (statistical information about actual path follows from knowing initial and final value).

139. Suppose that an asset has value $X(0)$ at time 0 . This value is known with certainty. From the perspective of time 0 , there will be an expected path of asset values for all later times. But the actual path is not known with certainty. That the variance of asset value grows with time means that the variance of the value $X(t)$ at time $t$ knowing only $X(0)$ is an increasing function of $t$. This means that knowing $X(0)$ provides fairly good information about what the value will be shortly after time 0 . But knowing $X(0)$ does not provide as much information about the value long in the future. Frequent observation of the value $\mathrm{X}(\mathrm{t})$ therefore provides much more information about the location of each piece of the path since each unknown value $\mathrm{X}(\mathrm{t})$ will be "near" an observed value.

The assumption that the variance of asset values increases with time is standard and has considerable empirical justification. For example, geometric Brownian motion is often used to model the movement of common stack prices. See infra note 149. The variance of the cumulative rate of return grows linearly with time for assets exhibiting geometric Brownian motion. See J. INGERSOLL, JR., ThEORY of Financial Decision Making 348, 351 (1988) (equations (6b) and (22)). 
investments and borrowings. The administrative costs of frequent observation must be weighed against the normative cost, if any, of deviating from continuous taxation.

\section{Administrative Costs}

A threshold question is whether there are cases in which the cost of observing asset paths is so high that the trade-off between administrative costs and obtaining a close approximation to continuous taxation is of serious concern. If all asset paths are observable at very low cost, then there is not much more to say. A continuous tax could be implemented easily.

In fact, the costs of observing the value paths of different assets vary widely. Publicly traded stocks are amenable to inexpensive observation of value paths. Price data is available at least on a daily basis. Using this data, it would be simple to construct a computer program that would compute an approximate continuous tax based on a very short assessment period for any publicly traded asset. The taxpayer or the government would simply enter the purchase price, sale price, date of purchase and date of sale into the computer.

At the other end of the spectrum, there are cases where it would be very difficult to assign gains and losses to a series of short assessment periods. Consider an engineer who over a period of many years develops ideas that lead to a series of projects much like the example in Part I above. ${ }^{140}$ The projects yield pure profits by earning a return that is greater than the market rate of return. Pure profits are earned because the engineer is bringing a new, more cost-effective technology to the market. The difficulty in this case is that human capital is involved. The costs of the project include the value of the time that the engineer spends thinking up new ideas. These costs are hard to observe, and the appropriate tax treatment for the costs is unclear. ${ }^{141}$

The timing issues connected with the benefit side of the projects are as difficult as those connected with the cost side. In particular, it is not clear when the earnings that flow from developing the ideas accrue to the engineer. The human capital value of the engineer clearly increases before the physical capital investment, such as the $\$ 100$ cost in the example, is made to implement the idea. In fact, some of the human capital value increase may occur many years before any observable outcomes are apparent. Undergraduate or graduate training may make profitable invention much

140. See supra text accompanying notes 15-20.

141. The standard analysis assumes that the engineer reduces work time and thus wages in order to think up the ideas. Since the forgone wages are not taxed, the engineer in effect gets an immediate deduction for the costs of developing the ideas. See Klein, Timing in Persanal Taxation, $6 \mathrm{~J}$. Legat. STuD. 461 (1977). However, the engineer might also reduce leisure time instead of work time. The value of this leisure time is already excluded from the tax base. The engineer in effect receives no deduction for forgoing leisure time. 
more likely even though the actual inventions may not become physical capital or generate cash flows until two or three decades later. ${ }^{\mathbf{1 4 2}}$

In between the easy case of publicly traded assets and the hard case of pure human capital investment ${ }^{\mathbf{1 4 3}}$ there are intermediate cases. For example, many closely-held corporations and small unincorporated businesses are similar in operation and line of business to publicly traded corporations. Valuing these closely-held corporations and unincorporated businesses is certainly theoretically possible since the market provides a valuation for comparable publicly traded entities. The catch is that the tax authorities cannot rely on freely available market data for corporations and businesses that are not publicly traded. Frequent valuation of these entities in the absence of market data might be very expensive.

It is clear that for some assets the costs of observing the exact path of value are significant. Frequent taxation will be administratively difficult

142. Returns to human capital generally are given cash flow treatment under U.S. tax law. Wages, for example, are taxed when earned. Some accretion tax advocates argue that taxation of human capital returns on a cash flow basis is acceptable as an exception because of the liberty interest in not being forced to work to pay taxes or because taxing human capacity "commoditizes" human beings. See Kelman, Personal Deductions Revisited: Why They Fit Poorly in an "Ideal" Income Tax and Why They Fit Worse in a Far from Ideal World, 31 STAN. L. REv. 831, 841-44 (1979); Warren 1980, supra note 2, at 1113-17. Other scholars have argued that it is unfair to impose a heavier tax burden on those who depend on physical capital rather than human capital. See Klein, supra note 141.

This latter position can be supported by appeal to the norms used to justify the first position. In particular, taxing human capital returns on a cash flow basis while taxing physical capital returns more heavily by using an accretion tax may reduce the physical capital stock. This would tend to reduce liberty and increase commoditization for two groups of workers: present workers with low human capital endowments who work in industries that are physical-capital intensive and all future workers. In theory, with a smaller capital stock, the marginal product and wages of future workers will be lower. See, e.g., Feldstein, Tax Incidence in a Growing Economy with Variable Factor Sup$p l y, 88$ Q.J. ECoN. 551 (1974) (The exact impact of accretion taxation on the capital stock is controversial. But some work suggests that the tax induces a substantial reduction in total capital. See Fullerton, Shoven \& Whalley, supra note 44.) Present workers with a low human capital endowment whose labor is complementary to heavy use of physical capital also might suffer since production methods using their labor would be taxed more heavily.

Both classes of laborers might have to work longer and harder to achieve the same standard of living (including leisure). This involves more commoditization and less liberty for them. It is unclear why lowering the return to labor time is any more pernicious in the case of those gifted with a large natural endowment of human capital than in the case of future laborers or of present laborers with a small endowment who work in physical-capital intensive industries.

Finally, even if one is not persuaded by these arguments, human capital is often so intertwined with physical capital that it is difficult to treat them separately. See infra note 143 . As a result, accretion tax designers will be faced with important cases where the difficulties raised by the value of human capital cannot be easily avoided. It is unlikely, for example, that most accretion tax advocates would be willing to subject the entire category of family or individual businesses to cash flow treatment simply because significant parts of the profits of many of these businesses are returns to human capital.

143. Unfortunately, human capital investment is often inextricably intertwined with other kinds of investment, even investment of the sort that we have classified as an easy case for accretion taxation. This point is made lucidly by Professor Andrews. See Andrews, supra note 2, at 953-54. Consider stock market investments. These investments seem impersonal and far away from human capital. The costs and cash flows of each investment seem clear, and there is a clear starting date for each investment. Nonetheless, people spend time deciding whether to invest in the stock market and deciding which investment vehicles are appropriate. The expertise developed through making these decisions is a human capital investment that parallels the investment in financial capital inherent in buying stock. 
for these assets. It is important to identify how harmful infrequent taxation will be in such cases. Otherwise, it will be hard to decide how much administrative effort to devote to approximating continuous taxation accurately in these cases.

\section{B. Asset Riskiness, Strategic Trading, and Transaction Costs}

The previous Section of this Part indicates that there is a trade-off between saving administrative costs by assessing infrequently and approximating a continuous tax accurately by assessing frequently. As pointed out in Part II, analyzing this trade-off is made much more difficult by the fact that it is not clear exactly how much any given deviation from exact continuous taxation matters. ${ }^{144}$ Nonetheless, some interesting, policy-relevant results are obtainable by comparing the deviations that would result from various periodicities. Larger deviations presumably are worse than smaller ones, and it is possible to identify the dependence of the amount of deviation on certain asset characteristics and on the assessment period.

Two results stand out. First, the deviation from continuous taxation is greater for riskier investments. Second, the degree of deviation for risky assets increases sharply if transaction costs are low and the taxpayer can trade strategically.

The rest of this Section demonstrates these results through a series of examples. Before presenting this series of examples in Subsection 2, Subsection 1 describes the "bridge process" technology used to generate the examples. This technology is designed to compare continuous taxation to periodic taxation from a tax administrator's viewpoint. Thus, the technology compares the two tax approaches for any given transaction based on the data an administrator will normally have concerning that transaction. ${ }^{145}$

\section{Bridge Process Technology}

Consider the problem faced by administrators of a periodic accretion tax. At the end of each assessment period there are assets with unrealized gains and losses. These assets fall into two classes. The first class have been held during the entire assessment period. This class consists of "old assets." The second class consists of "new assets" that were purchased

144. See supra text accompanying notes 83-96.

145. Since designing rules for administering the tax laws is the ultimate goal of policy studies, it is useful to study examples from an administrative perspective. But the bridge process technology introduced here may serve more important purposes than providing heuristic examples. The transactional orientation of the technology makes it potentially useful in the actual administration of an accretion tax. See infra text accompanying notes $230-45$ (potential use of bridge process approach to approximate continuous taxation or to test other methods of approximation).

Despite its potential as an administrative tool, the bridge process approach is not adequate by itself for studying the overall impact of various accretion tax approaches. A different technology is used for that purpose in Section D of this Part. See infra text accompanying notes 187-94. 
during the period and were still held by the taxpayer at the end of the period.

For both classes of assets, assume that tax administrators have three pieces of data: initial value, final value and holding period. For old assets, the initial value is the value at the beginning of the assessment period, the final value is the value of the asset at the end of the assessment period, and the holding period is equal in length to the assessment period. For new assets, the final value is the same as for old assets: the value at the end of the assessment period. However, new assets have a different initial value and holding period than old assets. For these assets, the initial value is the purchase price, and the holding period is the length of time between purchase and the end of the assessment period.

Given that an assessment period has been chosen, the periodic accretion tax is simple to compute. One subtracts initial value from final value and multiplies the difference by the tax rate. The holding period does not affect the tax. In this Section the goal is to compare this periodic tax to continuous taxation. There is an immediate problem in attempting this comparison. For a given initial value, final value and holding period, there is no single value for the continuous tax on the asset. There are many possible paths between the starting and ending value, and for each possible path there is a different continuous tax. In place of using a single determinate tax figure, all that is available is statistical information about what the path might have been. This information is summarized by "tax statistics" such as the mean and variance of the continuous tax over all the possible paths. ${ }^{148}$

In order to calculate the mean and variance, it is necessary to know the

146. A continuous tax can be calculated for each possible price path. The mean is the average tax over all possible paths. The variance measures how much the continuous taxes for the various paths tend to deviate from the average tax. If there are very high and very low continuous tax values associated with many paths, then the variance will be large.

The mean and the variance are highly significant for comparing any proposed tax treatment to the continuous tax ideal under either of the wealth-related norms. A proposed tax treatment will specify a single "proposed tax" based on three asset traits: the initial value, the final value and the holding period. If this proposed tax is less than the average continuous tax, then the proposed tax system on az'erage will undertax intangible benefits and on average will do worse than continuous taxation at reducing disparities in wealth.

Even if the proposed tax is equal to the average continuous tax, the variance of the continuous tax is of concern. This variance measures the tendency of the proposed tax to deviate from the actual continuous tax that would be due. The actual continuous tax is unknown because the asset price path between the initial and final path is not observed. If the variance is high, then the proposed tax will tend to deviate sharply from what the continuous tax would have been. As a result, the proposed $\operatorname{tax}$ will often seriously undertax or overtax intangible benefits from wealth even though the proposed tax will correctly tax intangible benefits on average. If the variance is large enough, it will be worth expending considerable resources to observe asset paths and to impose the actual continuous tax rather than to use a surrogate tax that is equivalent to the average continuous tax.

This discussion of the normative importance of the variance points to another motivation for computing the az'erage continuous tax. If a surrogate tax is designed to tax at that average level, that surrogate tax will minimize the variance between the actual continuous tax and the tax that is paid. Choosing the average of a random variable to estimate the actual value of the random variable minimizes the variance of the estimate. See infra note 231. 
probability that any particular path was the actual path. Probabilities for various paths follow from the study of a "bridge process." A "bridge process" is the probability-weighted collection of all possible paths that occur when an asset goes from a fixed initial value to a fixed final value over a given time period. ${ }^{147}$

The examples in the next Section apply a bridge process approach to a "typical" stock market asset. The asset is typical in the sense that its expected return and the standard deviation of that return reflect average performance for traded stocks during the period 1926-81. ${ }^{148}$ This asset is chosen for the examples because traded stocks are a familiar and important class of risky assets. ${ }^{149}$ In addition, some of the other important classes of assets studied in the Article will have similar risk and path characteristics. ${ }^{150}$ The rest of this Section details alternative assumptions about the availability of strategic trading and shows qualitatively how those assumptions affect the bridge process for the asset.

The potential use of strategic trading will emerge as an important factor in the size of deviations from continuous taxation. The possibility of effective strategic trading under a periodic accretion tax depends on how sales in between assessment times are treated. If the assessment period is five years for a particular kind of asset and the taxpayer sells the asset

147. This process is derived mathematically from an "unconstrained process," where an asset starts at a given initial value and moves for a fixed amount of time to some final value that is not constrained to be one particular value. For the actual mathematical derivation, see J. Strnad, supra note 14 , at 184-87, 191-98.

148. During this period the average annual nominal riskless interest rate was $3.1 \%$ while the average annual rate of return on traded stocks was $11.4 \%$. The standard deviation of that average annual rate of return on traded stocks was $21.9 \%$. See R. BREALEY \& S. MYERS, supra note 16, at 118,123 . The examples assume that riskless borrowing and lending at the pre-tax rate of $3.1 \%$ is possible.

149. The examples in this Article are based on the assumption that asset prices exhibit geometric Brownian motion. Geometric Brownian motion means that the rate of return is a constant plus a Brownian motion term. See J. INGERSolL, JR., supra note 139, at 351 (equation (22)). A constant rate of return would imply a smooth, geometrically increasing asset value path. This path would look like the path in Figure 1. See supra text accompanying notes 19-20. The Brownian motion term adds a rapidly fluctuating deviation with mean zero to the constant rate of return. Brownian motion is named after Robert Brown who observed and described the jerky and random motion of pollen particles suspended in liquid in 1827-28. See T. HidA, Brownian Motion viii (1980).

Geometric Brownian motion is the usual assumption in theoretical finance models of common stock prices. See, e.g., Merton, Optimum Consumption and Portfolio Rules in a Continuous-Time Model, 3 J. ECON. THEORY 373, 377 (1971). Recent empirical evidence casts some doube on the accuracy of the geometric Brownian motion assumption, but it is hard to come up with an obvious alternative candidate for theoretical work. See Lo \& MacKinlay, Stock Market Prices Do Not Follow Random Walks: Evidence from a Simple Specification Test, 1 J. Fin. STUd. 41 (1988).

150. Publicly traded stocks can be bought and sold at low cost, have easily observable price paths, and are volatile compared to investments such as government bonds or bank certificates of deposit. Later parts of the Article will be concerned with the taxation of volatile assets that can be traded only at high cost and that do not have readily observable price paths. See infra text accompanying notes 237-45. Closely held corporations are an example. These corporations almost surely are similar in volatility to publicly traded corporations in the same business.

The use of the average publicly traded stock in the text examples is not meant to diminish the significance of high transaction cost assets with price paths that are hard to observe. Such assets are common, and it is important to develop a policy for taxing them. 
during the first year, how will that sale be treated? If the taxpayer is taxed on the sale before the five year assessment point arrives, then taxpayer strategy with respect to when to sell the asset must be taken into account. In particular, the taxpayer may attempt to realize losses as they occur in order to accelerate the tax benefits associated with the losses.

Consider a tax system with five-year assessment for unrealized gains but where sales in any given single year are taxed at the end of that year. Suppose a taxpayer buys an asset for $\$ 100$, the asset hits a low of $\$ 80$ during the first year, and the asset reaches $\$ 125$ at the end of the five-year assessment period. If tax rates remain constant, the taxpayer would be better off selling the asset at its low point and simultaneously buying back the asset (or an asset with similar expected returns) for $\$ 80 .{ }^{151}$ This strategy results in $\$ 20$ tax loss at the end of year one followed by a tax gain that is $\$ 20$ higher ( $\$ 45$ instead of $\$ 25$ ) at the end of five years. The taxpayer obtains the deferral or "interest free loan" advantage of delaying the tax on the $\$ 20$ for four years.

Whether and to what extent a taxpayer can implement this strategy depends on transaction costs. If it is costless to buy and sell the asset and costless to monitor prices, ${ }^{\mathbf{1 6 2}}$ the taxpayer will sell the asset and repurchase a substitute whenever there is a slight decrease in value. This will guarantee that the taxpayer will sell at the lowest price reached by the asset and obtain the greatest possible deferral advantage as in the example above. ${ }^{163}$ On the other hand, transaction costs may be so high that it is not worthwhile to exploit even large decreases in value. ${ }^{154}$

151. Buying exactly the same asset back simultaneously may create a "wash sale" problem under $\S 1091$. That section disallows tax losses where purchase occurs within 30 days of sale. Sep I.R.C. $\$$ 1091 (1989). The provision is easily evaded, however, if assets available in the marketplace can serve as good substitutes. For most assets good substitutes are readily available. See infra text accompanying notes 216-17.

152. There is a large class of assets with trading and monitoring costs that are very low but not zero. This class includes stocks and bonds that are listed on a public exchange.

153. To see this point, consider the "epsilon-strategy" of trading whenever the asset falls some amount epsilon below the basis where epsilon is very small. The investor takes tax losses in units of epsilon. After each loss is taken the basis will be reduced by epsilon. This strategy will involve trading very frequently if the asset falls significantly below the original basis.

The epsilon-strategy does not allow full exploitation of early loss taking. Sometimes the asset will decline less than epsilon below the basis but will then rebound. This leaves a small, unexploited loss that is less than epsilon. Similarly, the decline to the level epsilon below the basis may take some time. Part of the total loss of epsilon dollars will have occurred earlier than the taxpayer's trade.

These small deviations from full exploitation of the opportunity to take tax losses early disappear in the limit of "cortinuous trading." This limit arises as epsilon is reduced gradually to zero. Continuous trading involves an infinite number of trades. The investor trades along the price curve whenever it declines below the basis. The basis itself continuously decreases as these trades are executed.

Continuous trading is a viable strategy when transaction costs are zero. Suppose instead that each transaction involves a fixed cost of $\$ \mathrm{X}$. No matter how small $\$ \mathrm{X}$ is, continuous trading would be infinitely costly because continuous trading requires an infinite number of transactions.

154. Family-held close corporations come to mind. The stock of such corporations generally is not traded on a market, and evaluation of the worth of the corporation may be difficult. Furthermore, the value of the company may derive largely from experienced operation by the family owners. Part of the value is therefore human capital of the family owners. This makes it difficult to transfer the company to anyone else for its full value. See infra text accompanying notes $218-22$. Selling to take a tax loss 
The value of strategic trading therefore depends on both the level of transaction costs and the legal availability of tax advantages from early loss-taking. Two cases are considered in the rest of the Article in order to gauge the influence of these two factors. In the first case, either the law postpones losses for tax purposes until the assessment period ends, or transaction costs are so high that it is not worthwhile for taxpayers to take losses early. In the second case, the law permits losses to be taken earlier than the end of the assessment period, thereby allowing taxpayers to accelerate the tax benefits associated with losses, and transaction costs are zero. Since transaction costs are zero, rational investors will take all losses at the earliest possible moment. ${ }^{155}$ This second case will be called the "strategic trading case" while the first case is one with "no strategic trading."

Which of the two cases applies affects the probabilities of asset paths and therefore alters the bridge process that will be used to compute tax statistics. This point is best explained by an example. Suppose that an asset is worth $\$ 100$ and has a basis of $\$ 99$ at the beginning of a five-year assessment period. The asset is held during the entire five years, and at the end of the five years it is worth $\$ 200$. In the strategic trading case we have even more information about the asset: Its value never fell below $\$ 99$ during the entire five-year period. The $\$ 99$ basis acts as an "absorbing barrier." All asset paths that hit and go below the barrier end there with the sale of the asset since the rational investor sells as soon as the asset crosses the barrier. ${ }^{156}$ These asset paths can be eliminated as possibilities since the taxpayer held the asset during the entire period.

The distinction between the two cases is important because eliminating all paths that cross below $\$ 99$ means that the average path that the asset took from $\$ 100$ to $\$ 200$ is liable to be substantially different. Risky assets such as the average common stock tend to move erratically up and down.

would be accompanied by the additional real loss of having to sell at a price that is substantially below value.

155. See supra note 153. A "rational investor" is one who will make all trades that increase net worth. This includes selling to take tax losses whenever that results in higher after-tax wealth.

It is assumed that the tax benefit from losses is immediate. This assumption makes mathematical analysis much easier. Generally, however, there will be some delay before the losses yield benefits. Assuming no delay gives an upper bound for the potential benefits from early loss taking. This upper bound may not be too far from the actual value of the benefits in some cases. If the taxpayer can adjust wage withholding or estimated tax payments to reflect a loss, for example, then the delay would probably be a maximum of a few weeks. See supra text accompanying note 20 and infra note 156.

156. There is a slight problem with the fifth year in reaching this conclusion. If the asset remains above $\$ 100$ for the first four years and then falls below $\$ 100$ in the fifth year, the investor may not have any tax reason to sell. The realized loss may have no tax effect until assessment occurs at the end of the fifth year. On the other hand, it may be possible to reduce taxes if there is a withholding or estimated tax system that is responsive to losses from sales but ignores unrealized gains and losses.

It would not be surprising if an estimated tax and withholding system under a periodic accretion tax did ignore unrealized losses and gains. The whole reason to tax unrealized gains and losses periodically at long intervals, rather than at short intervals or continuously, is that computing unrealized gains and losses more frequently is too costly. 
If they are only a small amount above a particular level, they are likely to cross it. Consider the example of the typical stock market asset set out above. ${ }^{167}$ If the stock is currently at $\$ 100$, the probability that it will cross below $\$ 99$ at least once during the following year is $93.3 \% .^{158}$ Paths that do not strike the $\$ 99$ level sometime during the year will tend to be those characterized by large early increases from the initial $\$ 100$ level. These early increases pull the asset price far enough away from the absorbing barrier at $\$ 99$ that the asset is unlikely to fluctuate down and strike that barrier later in the year.

The following figure illustrates this phenomenon for a one-year investment in the typical stock market asset. Take the initial value to be $\$ 100$, the final value to be $\$ 105$, and the basis to be $\$ 99$. In the figure, path 1 is composed of dots while path 2 is composed of boxes connected by lines. Path 1 is the average path with no strategic trading and path 2 is the average path with strategic trading. Path 1 is nearly exponential, ${ }^{168}$ and is similar to the riskless asset paths examined in Part I. ${ }^{160}$ Path 2 is humped. Initially, the average asset price increases sharply as is typical of the paths that are not absorbed at the $\$ 99$ barrier sometime during the year. Thus the average asset path reaches a maximum just past mid-year. Finally, it declines sharply to reach the $\$ 105$ final value.

\section{Se supra text accompanying note 148.}

The stock market asset examined here is typical in the sense that it mimics average stock market performance. See supra text accompanying note 148. It is important to note that examining this one asset understates the effects from strategic trading for individuals who hold portfolios of stocks. In any large portfolio, some losses and gains offset each other. One would want to sell the loss stocks so as to realize the tax benefits from the losses early. However, if the portfolio is traded as a single asset, only the aggregate losses on the portfolio are realized early. But it would be optimal to realize all the losses early.

158. This probability can be computed from the bridge process that describes the motion of the asset price. Sie J. Strnad, supra note 14, at 196 (Corollary 1).

15\%. It is hard to detect from the diagram that it is not exponential. Nonetheless, this path rises slightly more steeply initially than the exponential path between $\$ 100$ and $\$ 105$. It is slightly humpshaped compared to that exponential path. This can be seen from the following table:

$\begin{array}{cccc}\text { time } & \begin{array}{c}\text { value on } \\ \text { exponential } \\ \text { path }\end{array} & \begin{array}{c}\text { expected value on } \\ \text { path with no } \\ \text { strategic trading }\end{array} & \begin{array}{c}\text { expected value on } \\ \text { path with }\end{array} \\ 0.0 & 100.00 & 100.00 & 100.00 \\ 0.2 & 100.98 & 101.29 & 112.34 \\ 0.4 & 101.97 & 102.44 & 115.71 \\ 0.6 & 102.97 & 103.44 & 115.94 \\ 0.8 & 103.98 & 104.30 & 113.12 \\ 1.0 & 105.00 & 105.00 & 105.00\end{array}$

Use of the exponential path as an approximation to the path with no strategic trading is discussed infra, text accompanying notes 239-45.

160. Ser supra text accompanying notes 19-20. 


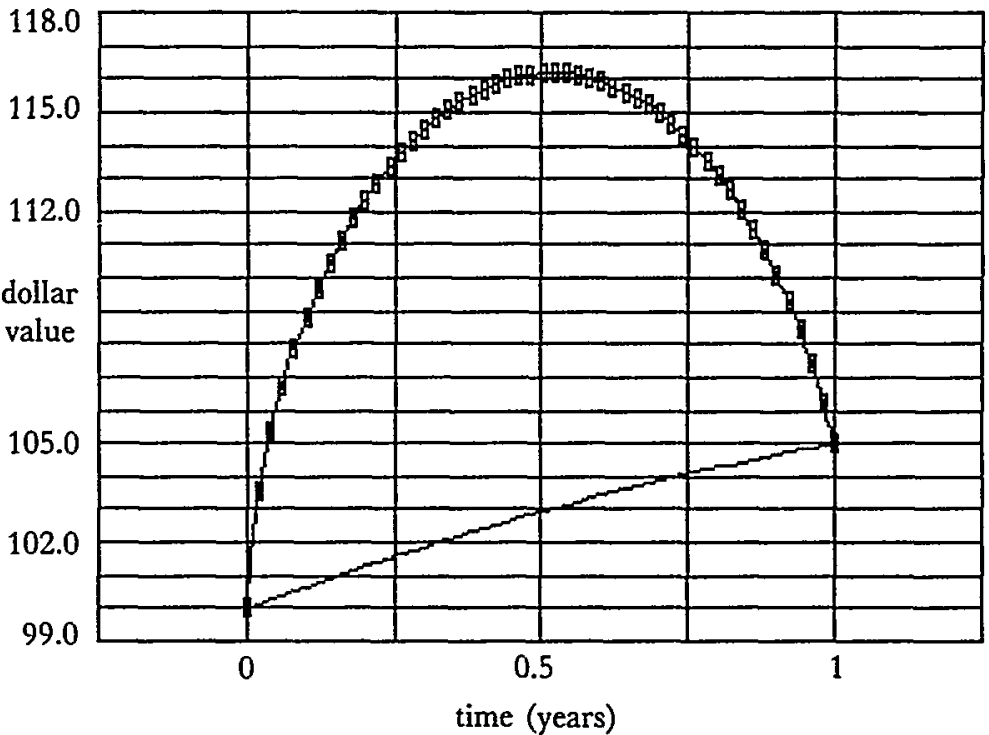

Figure 2

The implications of this phenomenon are clear under a continuous taxation standard. The fact that asset gains are likely to be clumped in the beginning of the asset's life suggests a larger tax on average than if the asset rises exponentially to its final resting point. Examples in the next Subsection verify this intuition. The average continuous tax is much higher in the strategic trading case.

\section{Riskiness and Strategic Trading}

To explore the importance of asset riskiness and strategic trading, it is instructive to compare three taxes for a typical stock market asset that begins at $\$ 100$ and increases to $\$ 105$ after one year. ${ }^{161}$ The basis of the asset is assumed to be $\$ 100$ instead of the $\$ 99$ used in the previous Subsection. ${ }^{162}$

161. The nominal riskless interest rate is assumed to be $3.1 \%$ as in the earlier examples. It is not clear what riskless interest rate would result in the most meaningful simulations. The choice of rate depends on which wealth-related norm is being examined. Under the intangible benefits justification, the riskless rate is a proxy for the proportional component of the intangible benefits from wealth that goes untaxed due to delaying taxation of gains in wealth. It is unclear how good a proxy any particular value for the riskless rate is because it is hard to observe how large that proportional component is. See supra text accompanying notes 41-42.

Under the second best justification, the accretion tax substitutes for an absent wealth tax by reducing the after-tax rate of wealth accumulation. As mentioned above, see supra text at notes $76-78$, it may be reasonable to tax the nominal riskless return under this justification. The $3.1 \%$ is the average nominal Treasury bill rate over a large number of years. See supra note 148 . Using that value for measuring deviations from continuous taxation indicates how far short the tax system falls from the reduction in the after-tax rate of wealth accumulation that would result from taxing all nominal gains the moment they occur.

162. Assuming a basis equal to the asset's fair market value is appropriate for studying periodic accretion taxation. Assets held during an entire assessment period will have a basis equal to their value at the beginning of that period. This basis reflects the fact that asset value is observed and gains 
The first tax is an accretion tax with a one year period that coincides with the one year life of the asset studied. The second is the average tax under continuous taxation with no strategic trading. The third is the average tax under continuous taxation with strategic trading. The results for a $40 \%$ bracket taxpayer are set out in Table VII. ${ }^{163}$ In the case with no strategic trading, a standard deviation for the tax is stated. ${ }^{164}$ In the case with strategic trading, an upper bound on the standard deviation is stated. $^{185}$

\section{Table VII}

type of tax

tax or standard deviation average tax or upper bound on standard deviation

one year accretion tax

With no strategic trading, the one year accretion tax will be about $1.0 \%$ lower than the average continuous tax. This error is only slightly larger than the error that would result from taxing a riskless asset costing $\$ 100$ and yielding $\$ 103.10$ after one year. In that case, the one year accretion tax would be $\$ 1.24$ while the continuous tax would be $\$ 1.25$, about $0.9 \%$ more. ${ }^{186}$ Although the error is similar for a riskless asset and a risky asset with no strategic trading, the average error increases dramatically for risky assets when strategic trading is possible. This can be seen from Table VII. In the strategic trading case, the error caused by using a one year period instead of taxing continuously is about $5 \%$ on average. That average error is about five times larger than either the error in the case with no strategic trading or the error for a riskless asset. ${ }^{\mathbf{1 6 7}}$

and losses are assessed and taxed right before the beginning of each new assessment period.

163. For a description of the method for computing the values in this table as well as in Tables VIII-IX, the tables in notes $174 \& 176$, and the third column in Table XIII, see J. Strnad, supra note 14 , at $182-210$.

164. The standard deviation is the square root of the variance. For a discussion of the normative significance of the variance, see supra note 146.

165. In the strategic trading case, computing the standard deviation involves doing a difficult multiple integration numerically. Even with the use of advanced techniques, the computation would take four days on an IBM XT with an 8087 math coprocessor. In contrast, it takes only a few minutes to compute an upper bound. See J. Strnad, supra note 14, at 199-200.

166. It is the type of path and not the lower endpoint of $\$ 103.10$ that causes this result. The riskless asset increases exponentially from $\$ 100$ to $\$ 103.10$. The continuous tax for an asset increasing exponentially from $\$ 100$ to $\$ 105$ would be 2.018 rounded to three decimal places. This makes the annually assessed tax of 2.0 about $.9 \%$ too small. This percentage deviation is about the same as in the case of the riskless asset that increases exponentially from $\$ 100$ to $\$ 103.10$.

Part II of the Appendix infra details the construction of exponential paths. The use of exponential paths as approximations to the average continuous tax in the case of no strategic trading is explored infra text accompanying notes 239-45.

167. A 5\% error may strike the reader as being rather small. However, the degree of error is a function of the pre-tax riskless interest rate and of the length of the assessment period. The degree of 
The results depend on several factors including the exact outcome at the end of the assessment period, the riskiness of the asset, the riskless interest rate and the length of the assessment period. The dependence on two of the factors, asset riskiness and asset outcome, is particularly relevant here. When strategic trading is feasible, the degree of deviation from continuous taxation increases greatly with asset riskiness. The sensitivity of the degree of deviation to asset outcome demonstrates that no simple adjustment, such as a change in the tax rate, will achieve equivalence to continuous taxation. The effect of these two factors is illustrated by extending the example.

Consider first the riskiness factor. Suppose that an individual funds half of the purchase of the typical stock market asset above by borrowing at the typical riskless rate of $3.1 \%$. An outcome of $\$ 106.90$ on a $\$ 100$ net investment of this sort corresponds to the $\$ 105.00$ outcome above. ${ }^{168}$ As Table VIII indicates, the result is that the deviation of the average tax in the strategic trading case is now seven times rather than five times as large as in the case with no strategic trading. When the asset is riskier, ${ }^{\mathbf{1 6 9}}$ the effects of allowing early loss-taking are magnified.

error increases roughly in proportion to these two factors. See infra text accompanying notes 174-76. Nominal interest rates are currently much higher than the $3.1 \%$ used to generate the example. In addition, assets are not assessed annually under current law. Instead assessment is usually not triggered until sale. Assets are often held for a much longer period than one year. A later Section shows that under the structure of current law, the potential impact of strategic trading is quantitatively quite significant. See infra text accompanying notes 187-94.

Finally, the absolute size of the effects is not relevant to one of the major points in this Article: Asset riskiness and strategic trading strongly affect the degree of deviation from continuous taxation. In the example, these factors increase the degree of deviation by a factor of five. This makes these factors much more significant in this case than the mere delay in taxation that is the motivation in most of the literature for a frequently applied accretion tax. See infra text accompanying note 223.

168. The individual borrows $\$ 100$ and pays that $\$ 100$ plus $\$ 3.10$ in interest at the end of the year. The individual invests $\$ 200$ in the typical stock market asset. Each $\$ 100$ of that investment yields $\$ 105.00$ at the end of the year for a total of $\$ 210$. The net return at the end of the year is $\$ 210$ $-\$ 103.10=\$ 106.90$. The net investment at the beginning of the year is $\$ 100$. The expected rate of return on the net investment is $19.7 \%$ and the standard deviation of the rate of return is $43.8 \%$. This compares to an expected rate of return of $11.4 \%$ and a standard deviation of the rate of return of $21.9 \%$ for an unleveraged investment in the typical stock market asset. SPe supra note 148.

169. The leveraged investment in $\$ 200$ of stock here is twice as risky as an unleveraged investment in $\$ 100$ of stock. Both of these investments amount to $\$ 100$ of net investment, since half of the leveraged investment of $\$ 200$ in stock is offset by borrowing of $\$ 100$ so that only $\$ 100$ of the investor's money is at risk.

The gains and losses from the $\$ 200$ of stock are twice as large as the gains and losses from $\$ 100$ of stock. As a result, the rate of returm fluctuates twice as much for the leveraged investment. Gains and losses are twice as large, but the net investment is the same.

The fact that the leveraged investment is twice as risky can be seen quantitatively from the fact that the standard deviation of the rate of return for that investment is $43.8 \%$, twice as large as the standard deviation of $21.9 \%$ for the unleveraged investment. See supra note 168 . 
Table VIII

type of $\operatorname{tax}$

$\begin{array}{cc}\text { tax or } & \begin{array}{c}\text { standard deviation } \\ \text { average tax } \\ \text { or upper bound on } \\ \text { standard deviation }\end{array}\end{array}$

one year accretion tax

2.760

0.000

continuous tax - no strategic trading

2.793

0.080

continuous tax - strategic trading

2.954

0.112

This result is easy to understand. A riskier investment has more extreme fluctuations. The path must move up even more quickly in the beginning to make tax losses unlikely. As a consequence, the asset path is a much taller hump than it was previously. ${ }^{170}$ This results in a higher average continuous tax.

The dependence of the results on asset outcome is illustrated in Table IX. In each case the asset begins year 1 at $\$ 100$. For each outcome, the one year accretion tax, and the average continuous tax, both with and without strategic trading, are computed. ${ }^{171}$ In parentheses following each average tax is the percentage deviation from the one year accretion tax.

\section{Table IX}

$\begin{array}{cccc}\begin{array}{c}\text { outcome at } \\ \text { end of year }\end{array} & \begin{array}{c}\text { one year } \\ \text { accretion tax }\end{array} & \begin{array}{c}\text { average } \\ \text { continuous tax } \\ \text { (no strategic } \\ \text { trading) }\end{array} & \begin{array}{c}\text { average } \\ \text { continuous tax } \\ \text { (strategic } \\ \text { trading) }\end{array} \\ 105.00 & 2.000 & 2.021(1.03) & 2.101(5.02) \\ 111.40 & 4.560 & 4.604(0.95) & 4.670(2.41) \\ 134.44 & 13.778 & 13.901(0.89) & 13.943(1.20) \\ 170.00 & 28.000 & 28.238(0.85) & 28.268(0.95)\end{array}$

Table IX indicates that as the outcome gets higher and higher, the gap between the continuous tax with no strategic trading and the continuous tax with strategic trading narrows. This is easy to explain. In the strategic trading case, all the paths that cross below basis and produce losses anytime during the assessment period are excluded. The remaining paths are likely to be paths with big gains in the beginning of the time period. ${ }^{172}$ When the outcome is low, this results in a sharply peaked hump. But a high outcome with no strategic trading also will tend to be associated with big gains in the beginning of the time period. Given that the outcome at the end of the year will be higher, fewer of the paths will ever cross into

170. Sep Figure 2 supra text accompanying notes 160-61 (plot of previous hump).

171. The outcome $\$ 111.40$ is the average outcome assuming no strategic trading. The outcome $\$ 134.44$ is the average outcome with strategic trading. This outcome is higher than the $\$ 111.40$ average outcome with no strategic trading because the paths that strike the $\$ 100$ basis have been excluded.

172. See supra text accompanying notes 156-60. 
the loss zone. Thus, the process with strategic trading will look more like the process without strategic trading, and they will have more similar continuous tax statistics. ${ }^{173}$

The figures in parentheses in the last column of Table IX indicate that the percentage deviation of the average continuous tax from the one year accretion tax varies greatly with the exact asset outcome. Increasing the tax rate of the one year accretion tax would not result in a successful simulation of continuous taxation for all outcomes.

Other factors besides asset riskiness and asset outcome influence the size of the deviations from continuous taxation inherent in a periodic accretion tax. Some of these factors are policy relevant. For example, using a $10 \%$ annual riskless interest rate instead of a $3.1 \%$ rate would increase the percentage errors from $1 \%$ and $5 \%$ in the no strategic trading and strategic trading cases to $3 \%$ and $15 \%$ respectively. ${ }^{174}$ Higher interest rates mean that infrequent assessment has higher costs when continuous taxation is the norm. ${ }^{175}$ Similarly, the percentage errors increase greatly with the length of the assessment period. Substituting a ten-year assessment period, for example, would increase the percentage errors by a factor of about five to ten. ${ }^{176}$ This increase indicates that a significant reduction in the degree

173. Numerical simulations based on J. Strnad, supra note 14 , at 191-98, indicate that after the final outcome increases enough, in this case above $\$ 120$ or so, the average path with strategic trading no longer displays a hump. However, that path still increases faster initially and is more concave than the average path without strategic trading. This results in a larger value for the average continuous tax when strategic trading is possible.

174. Replacing the $3.1 \%$ rate in Table VII with a $10 \%$ annual riskless interest rate would alter that table to read as follows:

type of tax

tax or
average $\operatorname{tax}$

$\begin{array}{ll}2.000 & 0.000 \\ 2.065 & 0.128 \\ 2.301 & 0.162\end{array}$

one year accretion tax

continuous tax - no strategic trading

continuous tax - strategic trading standard deviation or upper bound on standard deviation
0.162

175. For a discussion of the proper riskless rate for use in simulations, see supra note 161 .

176. Consider an example using a 10 year assessment period for the typical stock market asset. In this case, the asset begins at $\$ 100$, and, with no strategic trading, the expected outcome after 10 years is $\$ 411.77$. Assume that the actual outcome after 10 years turns out to be $\$ 145.00$, much lower than the expected outcome. A table similar to Table VII follows. After each average tax figure the percentage deviation from the periodic accretion tax is in parentheses.

type of $\operatorname{tax}$ tax or average tax

18.000

$19.954(10.86)$

$22.676(25.98)$ standard deviation or upper bound on standard deviation

ten year periodic accretion tax continuous tax - no strategic trading continuous tax - strategic trading

The results here are qualitatively similar to the results in Table VII for a one year time period. The periodic accretion tax in each instance deviates much more substantially from the average continuous tax in the case of strategic trading than in the case of no strategic trading. The difference is that the absolute size of the percentage errors here is much larger.

The examples are not exactly comparable. The "low" outcomes of $\$ 105$ in the one year case and $\$ 145.00$ in the 10 year case are both about one-seventh as large as the mean gain of all possible paths 
of deviation from continuous taxation is possible through use of more frequent assessment.

It is clear that factors like interest rate levels and assessment length are policy relevant. However, they do not affect the qualitative result that the impact of strategic trading depends heavily on asset riskiness, and they do not reduce the complexity introduced by the dependence of this effect on asset outcome. ${ }^{177}$

There is an important general lesson in this Section for would-be designers of an accretion tax. The conventional concern about deferral is that taxation of gains will be delayed with a resulting unjustified benefit for the taxpayer. A longer accounting period under a periodic accretion tax will increase the unjustified benefits from delayed taxation. But the errors inherent in periodic rather than continuous taxation depend importantly on three factors other than the length of the period. These factors are the riskiness of the asset, the ability under the law to realize the tax benefit of loss deductions before the end of the assessment period, and the degree to which transaction costs allow or prohibit exploitation of this ability. It is clear from the examples above that in some cases these factors induce a larger error than the delayed taxation of gains. ${ }^{178}$ Section B of Part IV discusses at length the implications of considering these factors for the design of an accretion tax.

\section{Samuelson Neutrality and the Timing Option}

The examples in the preceding Section indicate that the ability to take losses early combined with low transaction costs significantly increases the errors caused by taxing periodically instead of continuously. In the finance literature, the ability to take losses early and defer any later matching gains is called the "timing option." ${ }^{\prime 28}$ The value of a risky asset to the taxpayer holding it will depend on the value of the timing option associated with the asset, and the value of the timing option will depend on the

for the case of no strategic trading. But these outcomes may not represent the same percentile in probability distributions for those paths. The goal is to argue that the results will be qualitatively similar over different assessment periods. No attempt is made here to establish the similarity more systematically or quantitatively.

177. This is clear from the numbers for the asset riskiness effect. Increasing the interest rate from $3.1 \%$ to $10 \%$ increases the absolute size of the percentage errors, but the average percentage error for the strategic trading case is still five times as large (15\% versus $3 \%$ ) as the average percentage error for the case of no strategic trading. See supra note 174 . Similarly, the average percentage error in the strategic trading case remains several times larger than in the case with no strategic trading when a longer assessment period is used and "low" outcomes result. See supra note 176.

178. Tables VII-IX each contain examples where the average error from choosing periodic rather than continuous taxation is at least twice as large in the strategic trading case as in the case with no strategic trading. See supra text accompanying notes $165-72$. This means that allowing losses to be taken early in a low transaction cost environment more than doubles the error that arises from delay alone.

179. The phrase originates from a 1983 article by Professor Constantinides. See Constantinides, Capital Market Equilibrium with Personal Tax, 51 Econometrica 611, 611 (1983). 
taxpayer's marginal tax rate. As a result, the Samuelson principle will be violated under periodic taxation of risky assets even though it would hold if these assets were taxed continuously. ${ }^{180}$

The following example illustrates this point. An investment is made at time 0 and lasts until time 2, two years later. All the returns on the investment will be received by the taxpayer at the end of the two years. The investment consists of two lotteries. At the end of the first year, the first lottery takes place. Winning this lottery will result in receiving $\$ 500$ at the end of the two year period. Losing means having to pay $\$ 100$ at that time. These two outcomes are equally likely. The second lottery is the same except that it takes place at the end of the second year. If the investor wins both lotteries, the return is $\$ 1000$ at the end of the second year. If the investor wins one and loses the other, the return is $\$ 400$ at the end of the second year. If the investor loses both lotteries, the investor must pay $\$ 200$ at the end of the second year.

Suppose that the pre-tax interest rate is $10 \%$ per year and that investors are risk-neutral. Then the pre-tax value of the investment along the four possible paths of asset value will be as follows: ${ }^{181}$

Table X

$\begin{array}{lccc}\begin{array}{l}\text { lottery } \\ \text { outcomes }\end{array} & \begin{array}{c}\text { value at beginning } \\ \text { of year } 1\end{array} & \begin{array}{c}\text { value at end } \\ \text { of year } 1\end{array} & \begin{array}{c}\text { value at end } \\ \text { of year } 2\end{array} \\ \text { win-win } & \$ 330.58 & \$ 636.36 & \$ 1000.00 \\ \text { win-lose } & \$ 330.58 & \$ 636.36 & \$ 400.00 \\ \text { lose-win } & \$ 330.58 & \$ 90.91 & \$ 400.00 \\ \text { lose-lose } & \$ 330.58 & \$ 90.91 & -\$ 200.00\end{array}$

Now consider three possible tax systems: an accretion tax with a period of one year, an accretion tax with a period of two years, and biannual assessment with the results of any sales during the first year taxed at the end of that year. Under the third tax the end of the first year is in the middle of the biannual assessment period and will be called an "intermediate assessment point." The taxpayer may trigger taxation of first year gains and losses at this intermediate assessment point by selling and repurchasing the asset before this point in time arrives. In contrast, unrealized gains and losses will not be taxed until the end of the biannual assessment period.

Consider three taxpayers: one in the $0 \%$ bracket, one in the $20 \%$

180. Professor Fane claims that Samuelson's theorem applies to risky assets. His proof on this point is set in a discrete time framework that would seem to apply to a periodic income tax. Sof Fane, supra note 109, at 101-03. In his model, however, there is no opportunity to accelerate tax benefits by early realization of losses. His result only applies where such opportunities are not available.

181. The computation of the values in this table and in Table XI are explained infra Part V of the Appendix. 
bracket and one in the $50 \%$ bracket. Table XI indicates the after-tax value perceived by each taxpayer at time $0 .{ }^{182}$ There are only two columns for tax treatments. One column is labelled "value under pure periodic accretion tax." This column covers both the case of a one year and a two year periodic accretion tax. Only one column is needed since the results are the same for both of these taxes. ${ }^{183}$ The other column is labelled "value under accretion tax with timing option." This column is for the two year assessment period tax with an intermediate assessment point at the end of the first year.

\section{Table XI}

$\begin{array}{ccc}\begin{array}{c}\text { taxpayer's } \\ \text { marginal } \\ \text { rate }\end{array} & \begin{array}{c}\text { value under } \\ \text { pure periodic } \\ \text { accretion tax }\end{array} & \begin{array}{c}\text { value under } \\ \text { accretion tax } \\ \text { with timing option }\end{array} \\ 0.0 & 330.58 & 330.58 \\ 0.2 & 330.58 & 332.68 \\ 0.5 & 330.58 & 334.05\end{array}$

It is clear from the third column that the Samuelson result does not obtain for the accretion tax with a timing option. The value of the investment at the beginning of the first year depends on the marginal tax rate of the investor. ${ }^{184}$ The reason for this outcome is straightforward. If the investor loses the lottery the first year, the asset declines in value from its starting point. The investor will sell the asset and buy it back immediately before the end of the first year in order to realize this loss and obtain the associated tax benefit one year early. The benefit from doing this is larger the higher the taxpayer's marginal tax rate.

The outcome is also easily explained using the analysis from Section C of Part II concerning the Samuelson result. The central conclusion of that Section was that the Samuelson result, the independence of value from the investor's marginal tax rate, will hold for a periodic accretion tax if and only if all assets are taxed with the same frequency. The computations in the third column of Table XI are based on the assumption that.riskless assets will be taxed annually under an accretion tax. ${ }^{185}$ In contrast, the risky asset is taxed with a "mixed" frequency. The tax on the asset's unrealized gains and losses is biannual, but the taxpayer may accelerate

182. The computations required to generate this table are detailed infra Part $\mathrm{V}$ of the Appendix.

183. This is not surprising. Part II showed that any pure accretion tax will produce the Samuelson result of constant value across taxpayers with different marginal rates. It does not matter how frequently assessment is made under the accretion tax. As long as all assets are assessed with the same frequency, the Samuelson result will hold. See supra text accompanying notes 111-18.

184. "Value" here is the price at which the investor would buy or sell the investment. It is also the after-tax value of the investment.

185. The after-tax discount rate used to compute value in Table XI is the after-tax rate of return on riskless assets. The details of the computation are set out infra Part V of the Appendix. 
taxation of first year losses and gains to the end of the first year. The rational taxpayer will accelerate taxation of the losses but not the gains. This behavior will result in assets with first year losses being taxed annually while other assets are taxed biannually. Thus, the Samuelson result fails to hold when there is a timing option because different assets will be taxed with differing frequencies. ${ }^{186}$

\section{The Normative Costs of the Timing Option}

Sections B and C strongly suggest that strategic trading in the form of the timing option has significant normative costs. Both of these Sections, however, consist of examples constructed from a tax administrator's perspective. The organizing event is a data set facing a tax administrator: An asset moves from $\$ \mathrm{X}$ to $\$ \mathrm{Y}$ during a time period of length $\mathrm{T}$. Continuous taxation and periodic taxation are compared for various data sets.

Examples of this type do not suffice to indicate the magnitude of the normative costs induced by the timing option. For instance, in the case of strategic trading studied in Section B, loss paths are simply ignored under the bridge process approach. ${ }^{187}$ But these paths and their tax treatment affect the value of investments and should be taken into account in gauging the overall impact of the timing option on investment transactions.

This Section studies the potential total impact of the timing option. The focus is on the situation under current law except that restrictions in current law aimed at controlling the timing option are ignored. These restrictions are studied in Part IV. ${ }^{188}$ Before assessing their effectiveness, it makes sense to see what the cost will be if the timing option is left totally uncontrolled. Current law is not a periodic accretion tax. For many assets, gains and losses accumulate until the taxpayer dies. At that point, the basis in the hands of the heirs is increased or decreased to fair market value. ${ }^{189}$ Death forces realization of losses and gains, but they have no tax effect. The consequence of the potentially long delay before realization combined with the step-up in basis at death is that the timing option has considerable value to high bracket taxpayers.

The following example based on work by Professor Constantinides illustrates this point. ${ }^{180}$ Consider taxpayers who expect to live for twenty-

186. In the example, this failure is caused by the mixed frequency taxation of the risky asset and not by the choice of the one year period for taxation of riskless assets. For example, if riskless assets were taxed biannually rather than annually, the numbers in the third column of Table XI would be $330.58,335.98$ and 339.41 from top to bottom instead of $330.58,332.68$ and 334.05 as in the table. The risky asset would still be taxed under a mixed frequency, and Samuelson neutrality would still fail to hold.

187. See supra text accompanying notes 155-67.

188. The restrictions are the limitation on capital losses and the wash sales rules. See infra text accompanying notes 195-222.

189. See I.R.C. § 1014 (1989).

190. See Constantinides, supra note 179 , at $622-23$. His estimates are not in the context of a periodic accretion tax. Instead, he assumes that assets with gains are only assessed stochastically, when 
five years and hold the typical stock market asset. Assume that this asset can be traded with zero transaction costs, that marginal tax rates are fixed over the foreseeable future, and that there is a step-up in basis at death. The following table presents the proportion of asset value attributable to the timing option for taxpayers subject to different marginal rates. ${ }^{191}$

\section{Table XII}

$\begin{array}{cr}\begin{array}{c}\text { marginal } \\ \text { rate }\end{array} & \begin{array}{c}\text { proportion of as } \\ \text { attributable to tim }\end{array} \\ 0.00 & 0.0 \% \\ 0.10 & 3.2 \% \\ 0.30 & 11.0 \% \\ 0.50 & 21.1 \%\end{array}$

The table indicates that high bracket taxpayers will find the asset much more valuable than the $0 \%$ bracket taxpayer.

To the extent that the tax benefit from the timing option is not capitalized into asset prices, high bracket taxpayers will receive a benefit that is inappropriate under either of the wealth-related norms. ${ }^{192}$ On the other hand, if the tax benefits are capitalized to a large degree into asset prices, then investment incentives will be distorted significantly in favor of risky

unusual circumstances prompt the investor to sell. His model permits choice of a different tax rate at this time of assessment from the rate that applies to capital gains and losses under normal circumstances. A useful interpretation of his model for the study of current law is that the unusual circumstances are the death of the taxpayer. In order to model the step-up in basis at death under current law, the tax upon occurrence of this unusual event may be set at zero. During life, however, the taxpayer may be assumed to deduct capital losses against a non-zero rate.

191. The table is generated using equation (21) in Professor Constantinides' article. See id. at 623. The proportions in the second column of the table would be about one-third as large if unrealized gains were taxed at death. The second column would be $0.0 \%, 1.3 \%, 3.5 \%$ and $5.0 \%$ from top to bottom instead of $0.0 \%, 3.2 \%, 11.0 \%$ and $21.1 \%$. In addition, if taxing unrealized gains at death produced additional revenues and if these revenues were used to reduce tax rates, a greater reduction than two-thirds in the value of timing options would be possible.

When Constantinides computes the value of the timing option he compares the strategy of taking losses whenever possible to the strategy of holding the asset until realization is forced by death or other circumstances. This means that delaying gains that have already accrued in the form of value exceeding basis does not contribute to the value of the timing option in his calculations.

Suppose, for example, that at the beginning of year one an asset is worth $\$ 110$ and has a basis of $\$ 100$. The taxpayer dies at the end of year five, and the asset is worth $\$ 110$ at that time. Assume that the lowest value of the asset was $\$ 80$ during year two. The value of the timing option as calculated by Constantinides arises from the ability to take $\$ 20$ of loss in the first two years as the asset falls to $\$ 20$ below the original basis of $\$ 100$. This $\$ 20$ of loss is matched by $\$ 20$ of additional gain at the end of year five. But the value of the timing option does not include the value of deferring the tax on the $\$ 10$ gain existing on the asset at the beginning of year one until the end of year five. The step-up in basis at death enhances the value of the timing option because it matches $\$ 20$ of losses that reduce the investor's tax liability in early years with a later gain of $\$ 20$ that is not taxed.

Tax policy analysts have focused on the deferral of gains, such as the $\$ 10$ gain in the example just presented, as the principal drawback of the realization doctrine. The examples in this Article suggest that the timing option is a problem of the same order of magnitude. See, e.g., supra note 11 and accompanying text; supra note 178 .

192. See infra note 213 (equity and efficiency results under alternative assumptions about capitalization of tax benefits). 
investments. The size of this distortion would clearly be worrisome. For taxpayers in the $28 \%$ bracket, the value of an unconstrained timing option would be close to that of the old $10 \%$ investment tax credit. Repeal of this investment tax credit was a key feature of the attempt in the Tax Reform Act of 1986 to make taxation of capital investments neutral between investments. ${ }^{193}$ Ineffective limitation of the timing option would result in projects as risky as the typical corporate stock receiving a benefit similar to the old investment tax credit. Less risky enterprises would receive no corresponding tax benefit. ${ }^{194}$ This might cause nonneutralities that exceed those brought about by inconsistent investment tax credit and depreciation treatment of different assets under pre-1986 law.

It seems clear that an unconstrained timing option would result in large normative costs. The next Part studies current law and the general question of designing an accretion tax with those potentially large costs in mind.

\section{Policy IMPLICATIONS}

Parts II and III suggest that continuous taxation is ideal and demonstrate that the seriousness of deviations from this ideal depends heavily on the riskiness of various assets and on the ability to exercise a timing option by taking losses early and delaying gains. These results have important implications for two levels of tax policy analysis: small scale reform of current law that keeps the current structure more or less intact, and large scale reform consisting of moving closer to continuous taxation by taxing unrealized gains and losses frequently for a wide array of assets.

Section A considers small scale reform of current law. Current law attempts to limit exploitation of the timing option through the limitation on capital losses and through wash sale provisions. Subsection 1 of Section A discusses the role of the capital gains and capital loss provisions in limiting the timing option, considers reform of the capital gains provisions as a control device, and points out the weaknesses that would remain after reform. Subsection 2 discusses and critiques the use of wash sale provisions to prevent or to hinder exercise of the timing option.

Section B considers large scale reform of the tax code to bring it closer to the norm of continuous taxation of gains and losses. Unlike the current law reforms examined in Section A, this type of reform would address the conventional concern about deferral, that the taxation of gains can be delayed, as well as concern about the timing option. Section B examines two major approaches: approximation and frequent assessment. Approxi-

193. See Senate Comm. on Finance, Tax Reform Act of 1986, S. Rep. No. 313, 99th Cong., 2d Sess. 97 (1986); House Comm. on Ways and Means, Tax Reform Act of 1985, H.R. ReP. No. 426, 99th Cong., 1st Sess. 146 (1985).

194. The timing option has a value of zero for assets that increase risklessly because strategic trading is impossible if an asset cannot produce losses. See supra note 191; infra note 201. 
mation involves using a best estimate of continuous taxation based on the initial value, final value and holding period of the asset. Subsection 1 studies various approximation techniques. Subsection 2 explores frequent assessment. These Subsections detail asset categories for which one of the two approaches appears to be superior to the other. Finally, Subsection 3 proposes directions for future research.

\section{A. Timing Option Distortions: Attempts at Control Under Current Law}

\section{The Limitation on Capital Losses}

\section{a. Timing Option Distortions and the Capital Gains Provisions}

The lower rates on capital gains income provided under U.S. tax law prior to the Tax Reform Act of 1986 were a continuing problem for tax policy analysts. Lower rates were rationalized on four grounds: correcting for inflation, stimulating investment, alleviating the "lock-in" problem and alleviating higher tax rates under a progressive system when income is "bunched." As commentators have noted, ${ }^{105}$ three of these problems have more effective and simpler remedies. Inflation problems can be fixed by indexing the basis of assets and debt. Bunching of income can be addressed more easily and more effectively through income averaging provisions. Stimulation of investment is not accomplished very efficiently by capital gains treatment. More direct and more finely targeted methods are available.

"Lock in" describes the fact that a taxpayer will be unwilling to sell an asset that has unrealized gains on it. Sale accelerates taxation of the gain while holding the asset results in additional deferral. It is unclear whether the lock-in problem has any serious consequences. Professor Wetzler, for example, is skeptical about whether lock-in has significant efficiency effects. ${ }^{188}$ His skepticism seems justified. Individuals holding a locked-in asset usually can rebalance their portfolios without selling the asset, ${ }^{197}$ and there is probably enough liquidity in stock markets that lock-in has little effect on market prices. ${ }^{198}$

195. See M. GraETz, supra note 100, at 599-605; Wetzler, Capital Gains and Losses, in ComPREhensive Income TAxation 115 (J. Pechman ed. 1977).

196. Sep Wetzler, supra note 195, at 138-140.

197. The cleanest way to rebalance is by selling the locked-in asset short. If a taxpayer holds an asset and simultaneously sells it short, the short sale is treated as a separate transaction and does not trigger taxation of the gain on the long position. See I.R.C. $\$ 1233$ (a) (1989). At the same time, selling short cancels out the risk and return of the long position exactly. The proceeds from the short sale can be reinvested in any way desired. Short sales therefore provide a means of "selling" appreciated assets without realizing gains on the sales.

Even if short sales are not available because an asset is not publicly traded, portfolio rebalancing may be possible without selling the asset. In particular, the taxpayer may be able to borrow using the asset as collateral and then invest the proceeds to balance his or her portfolio.

198. The price elasticity of stocks is estimated to be very high, perhaps as high as -3000 . See $R$. BREAley \& S. MYers, supra note 77, at 297. It appears that big buyers and sellers will make the market efficient in the face of a great deal of passive holding of locked-in securities. 
Lowering the capital gains tax rate decreases the tax penalty for early sales, and thus alleviates the lock-in problem. Lowering tax rates, however, means sacrificing the goals under wealth-related norms that justify accretion taxation. Increases in accumulated wealth will be taxed at lower rates than other income. There is another approach. A high frequency accretion tax will alleviate the lock-in problem. Whenever the end of an assessment period is reached, any unrealized gains are taxed, and the basis of the asset moves up to the market value. At that moment there are no assets that are locked-in. ${ }^{199}$ This approach will be examined in Section B. 200

The four traditional rationales for establishing a separate capital gains category and subjecting this category to a lower tax rate are shaky at best. The next Subsection considers use of the capital gain category for a fifth purpose: controlling the timing option. The timing option problem is distinct from the lock-in problem because the value of the timing option arises from being able to take losses early. ${ }^{201}$ The timing option effect would be reduced by lower tax rates, ${ }^{202}$ but, as in the case of the lock-in problem, lowering tax rates sacrifices the goals of the wealth-related norms that justify accretion taxation in the first place.

Current law uses the capital gains category to address the timing option problem through the limitation on capital losses rather than through lower tax rates. The limitation operates by blocking the deduction of realized capital losses unless these losses are used to offset realized capital gains. ${ }^{203}$ The next Subsection explores the design of capital gains law assuming that control of the timing option is its primary purpose.

199. In a very clever article, Professor Alan Auerbach has devised a system of taxation that avoids the lock-in problem without requiring frequent assessment. The tax under this scheme depends only on the holding period and the final value of the asset. When the investor sells an asset for $\$ X$ after holding it for a time $t$, the gains are presumed to be equal to the gains on a riskless asset that ends up at $\$ \mathrm{X}$ after that length of time. Under this scheme investors have no incentive to retain assets merely to reduce the tax on past gains. See A. Auerbach, Retrospective Capital Gains Taxation, (National Bureau of Economic Research Working Paper No. 2792, 1988).

The problem with this scheme is that it ignores the wealth-related norms that justify choosing accretion taxation in the first place. Suppose, for example, that an investor holds risky assets and makes huge returns that far exceed the return that would have resulted from an equal investment in riskless assets. These gains will not be taxed very heavily since they will be presumed to be equal to the gains from riskless assets that would have yielded the same final value. Conversely, suppose the investor suffers large losses. This investor will be taxed as if he or she had experienced gains. In both cases, the tax system deviates very far from taxing the intangible benefits from wealth properly and from adjusting the distribution of wealth effectively. As a result, the tax scheme will not be very good at satisfying either of the two wealth-related norms.

200. See infra text accompanying notes 246-53.

201. See supra note 191. Lock-in effects would occur even for assets that increase risklessly. The taxpayer would want to defer taxes on the riskless gains by holding the assets rather than liquidating them. But for these assets the timing option has no value. There is no possibility of taking losses early because there is no possibility of ever having losses.

202. See supra text accompanying notes 183-84 and text accompanying notes 191-92 (examples in Tables XI and XII show greater distortion due to exercise of the timing option under higher tax rates).

203. Use of capital losses against ordinary income is only blocked completely for corporations. 


\section{b. Reforming the Limitation on Capital Losses and the Efficacy of the Limitation as Reformed}

If attacking the use of the timing option is the principal purpose behind the capital gain provisions, then considerable simplification of the law is possible. One difficult legal problem has been to define a "capital asset" for the purpose of determining whether particular transactions will be treated as generating capital gains or ordinary income. Since the capital gains provisions did not have a clear underlying policy rationale to support them, courts and tax administrators were faced with the task of drawing distinctions without much guidance. This often resulted in confusion if not disaster.

For example, the Supreme Court in the Corn Products case ${ }^{204}$ required a taxpayer to treat transactions in corn futures as ordinary rather than capital transactions. This decision arguably had little grounding in the statute $^{205}$ The Court's rationale for the decision was that the profits from hedging in corn futures arose from everyday business operations rather than from an investment. ${ }^{208}$ Corn Products led taxpayers to claim that loss transactions were business-connected but that gain transactions were for investment purposes. If successful, the taxpayer would get the best of all possible combinations: capital treatment of gains and ordinary treatment of losses. Some courts responded by attempting to limit the scope of the Corn Products doctrine. ${ }^{207}$ The ensuing confusion led the Supreme Court to go along with the most severe limitation proposed in the lower

Individuals may use up to $\$ 3000$ of capital losses against ordinary income. See I.R.C. $\$ 1211$ (1989).

204. Corn Products Refining Co. v. Commissioner, 350 U.S. 46 (1955).

205. See I.R.C. $\$ 117$ (1939) (now I.R.C. $\$ 1221$ (1989)). The Court itself was concerned about this. In response to the taxpayer's claim that the hedging was not within the statutory exceptions to capital gain treatment, the Court relied on its reading of legislative purpose:

Admittedly, petitioner's corn futures do not come within the literal language of the exclusions [from capital gain treatment] set out in that section [defining capital assets]. They were not stock in trade, actual inventory, property held for sale to customers or depreciable property used in a trade or business. But the capital-asset provision . . . must not be so broadly applied as to defeat rather than further the purpose of Congress. . . . Congress intended that profits and losses arising from the everyday operation of a business be considered as ordinary income or loss rather than capital gain or loss. The preferential treatment provided by [the "capital gains provisions] applies to transactions in property which are not the normal source of business income. It was intended 'to relieve the taxpayer . . . from excessive tax burdens on gains resulting from a conversion of capital investments . . . .

350 U.S. at 51-52 (citations omitted) (quoting Burnet v. Harmel, 287 U.S. 103, 108 (1932)).

206. See supra note 205.

That a court would depend heavily on the rather hazy distinction between "business" and "investment" transactions to determine whether an asset is a capital asset is not surprising. Courts know that investments like bonds and stocks are capital assets while business inventories (including bonds and stocks held by brokers or dealers) are not. This provides an analogy that can be used to decide cases. In the absence of a clear policy basis for the capital gains provisions, this analogy may be all that courts can rely on.

207. See, e.g., W. W. Windle Co. v. Commissioner, 65 T.C. 694 (1976), appeal dismissed 550 F.2d 43 (1st Cir.), cert. denied, 431 U.S. 966 (1977). The Windle court took explicit notice of this "heads-I-win, tails-you-lose" strategy in denying ordinary loss treatment where there is a mixture of business and investment motives. 
courts: Corn Products applies only to hedging transactions connected with business inventory. ${ }^{208}$

If the principal purpose of the capital gains provisions is to devalue the timing option by allowing losses only when offsetting gains are realized, then it is conceptually easy to define a category of "capital assets." This category should include all assets that may be held for long periods of time and that are risky. These are the assets that generate substantial timing option value for the taxpayer. ${ }^{209}$

Despite the conceptual ease that this definition provides, there are substantial problems with attacking the timing option problem in this way. First, taxpayers who are unlucky enough to generate net losses over long periods of time will not be able to deduct these losses until offsetting gains are secured. ${ }^{210}$ This is a more serious problem if the definition of capital assets is narrower. Suppose, for example, that the category is limited to assets that are very risky and very long-lived. It may be that a particular investor suffered large losses on these assets but has substantial gains on other assets.

Second, if the capital asset category is defined broadly to prevent harshness in net loss situations, this will make the category less effective at reducing the value of the timing option. Investors who were holding lowrisk assets outside of the capital asset category could shift to low-risk assets inside the category. The low-risk assets will produce capital gain income that will tend to free the investor from the limitation on capital losses. ${ }^{211}$

208. Arkansas Best Corp. v. Commissioner, 485 U.S. 212 (1988). Arkansas Best Corporation was a diversified holding company. It held stock in a Dallas bank. The stock was sold for a loss. The Tax Court found that there was no substantial investment purpose and therefore held that the sale should result in an ordinary loss under the Corn Products doctrine. The Eighth Circuit reversed and rejected both the customary business versus investment test from the Corn Products case and the strategic analysis approach of the Tax Court in the Windle case discussed supra note 207. Arkansas Best Corp. v. Commissioner, 800 F.2d 215 (8th Cir. 1986).

The Eighth Circuit based its holding on the fact that stock does not fall under any of the exceptions to $\S 1221$ and therefore is a capital asset. 800 F.2d at 218 . The Supreme Court agreed and specifically limited the Corn Products holding to hedging transactions connected to business inventory. The Court based its result firmly on statutory language: Hedging transactions to lock in inventory purchase prices fall under the exclusion in $\S 1221$ of business inventories from the category of capital assets. See 485 U.S. at 220-22.

209. See supra text accompanying notes 167-70 and text accompanying notes 187-94.

210. Unused capital losses can be carried forward indefinitely for individuals. The potential harshness of the limitation on capital losses in the case of the investor who has large net losses has been noted in the literature. See Wetzler, supra note 195, at 132-34. Henry Simons himself opposed a limitation on capital losses for this very reason despite being aware of the need to control strategic early loss taking. See H. Simons, supra note 34, at 157, 159-60, 212.

The potential harshness of the limitation has led a recent commentator to propose revising it. Sep Baker, Capital Loss Deduction Limits After the Tax Reform Act of 1986, 66 Tex. L. Rev. 159, 171-76, 183-87 (1987) (capital loss limitation should be applied only within a category of assets consisting of marketable securities and real estate other than the taxpayer's residences).

211. If the category demarcation is effective, then there will be either portfolio distortions or investment distortions or both. Investors will strongly prefer to invest in low risk assets that fall just barely into the capital asset category. These low risk assets have the same financial characteristics as other low risk assets but will provide a source of capital gains that alleviate the limitation on capital 
There is also another problem that would exist even under a narrow definition of the category. Investors can combine risky assets with offsetting risk characteristics in order to construct a portfolio with very little risk. ${ }^{212}$ This may be done by purchasing many individual assets so that, short of the I.R.S. hiring a slew of finance experts, it would be difficult to determine that the investor was holding a relatively riskless portfolio. Sophisticated taxpayers with large asset portfolios could evade the limitation of the capital asset category to risky assets.

Finally, the attempt to reduce the value of the timing option for high income taxpayers by limiting capital losses will fail if it is easy to convert ordinary income into capital gain income. In that case, the capital loss limitations will bind only when the taxpayer runs out of ordinary income to convert to capital gains. A taxpayer who has aggregate capital losses $\$ Y$ where $\$ Y$ is less than $\$ X$, the taxpayer's ordinary income, would simply convert $\$ \mathrm{Y}$ of ordinary income to capital gain. Thus, for taxpayers with ample ordinary income, the full potential value of timing options could be achieved on a large portfolio of investments regardless of the breadth of the "capital asset" definition. ${ }^{213}$ This final point has serious implications for current law. The effort to control conversion of ordinary income to capital gains is still very important despite the fact that capital gains rates were increased to the level of ordinary income rates by the Tax Reform Act of $1986 .{ }^{214}$ Equalization of ordinary income rates and capital gains rates means that conversion no longer directly lowers the applicable tax rate. But easy conversion would allow many taxpayers to evade the limitation on capital losses. This would leave the ability to profit from the timing option almost entirely uncontrolled under current law.

losses. That will either artificially inflate the prices of those assets, thereby distorting investment incentives, or cause investors to hold more of those assets in their portfolio than would be optimal in the absence of taxes.

212. A simple example is purchase of stock combined with sale of a call on the stock and purchase of a put against the stock. The exercise price of the put and call need to be chosen at whatever premium over the stock price generates an adequate "riskless" rate. The sale proceeds from the call and the purchase price of the put may roughly cancel each other.

213. The ineffectiveness of the capital loss limitation may result in two different polar phenomena or in a mixture of the two. First, the value of the timing option may be capitalized into asset prices. The resulting increase in these prices would distort investment. Firms would provide more of these assets than if the timing option were strictly controlled. Second, investors may gain the entire value of the timing option if asset prices remain unaffected. The precise mixture of these two phenomena that occur can only be determined by careful economic analysis. That determination is important because the distortion of investment and the inequities that arise from high income individuals being able to keep the value of the timing option may be weighted differently by policymakers. See Auerbach, Should Interest Deduclions Be Limited?, in Uneasy Compromise: Problems of a Hybrid INCOME-Consumption Tax 195 (1988); Bittker, Equity, Efficiency and Income Tax Theory: Do Misallocations Driz'e Out Inequities?, in The Economics OF TAxation 19 (J. Pechman ed. 1980).

214. For a summary of the changes to the capital gains provisions in the Tax Reform Act of 1986, see M. Graetz, Federal Income Taxation 667-68 (2d ed. 1988). 


\section{Restrictions on Losses from Wash Sales}

There is one other major provision in the law besides the limitation on deduction of capital losses that attempts to limit exercise of the timing option: the wash sale rule of section $1091 .{ }^{215}$ This rule blocks the deduction of losses when the sale of an asset is accompanied by purchase of the same asset within 30 days before or after the sale. The principal problem with this provision is that it is ineffective whenever substitute assets are readily available. This seems to be true for most publicly traded assets such as common stocks or bonds. Theoretical and empirical work in modern finance indicates that a diversified portfolio eliminates all risk except for a few common risk factors. ${ }^{216}$ This makes it easy to duplicate the undiversifiable risk in any given asset by another asset or group of assets. Furthermore, the number of assets that are necessary to obtain most of the benefits of diversification is low, typically believed to be about fifteen. ${ }^{217}$ Therefore, diversifiable risk is not a serious concern. It would seem that taxpayers would suffer little or no loss in terms of holding an optimal portfolio from selling an asset with a tax loss and substituting a different asset.

The cases where wash sale provisions are likely to be effective are the very cases where the timing option is less important. These are cases where transaction costs of sale are high or where an asset has higher value in the taxpayer's hands than in the hands of any other owner. For example, a family-owned corporation may be difficult to sell to outsiders for its full value without a costly search for buyers and a costly investigation by the potential buyers into the business. The business may also be tied up with the human capital of the family. A local restaurant or store may derive a large part of its profitability from the reputation of the owneroperators. It is unclear whether the owners would perform as well if they earned only salary with the profits flowing to someone else. ${ }^{218}$ Thus, sale of a closely held corporation may involve both high transaction costs and a real reduction in value due to the fact that the business cannot be operated as profitably by new owners.

Successfully realizing tax losses from such a business would be difficult. Since the business is more valuable in the hands of the original owners, there are no good substitute assets as in the case of marketed securities. Sale and repurchase of the business itself would probably not succeed. Even if the purchase was more than thirty days from the sale so that

215. See I.R.C. § 1091 (1989).

216. See supra note 135.

217. See R. BREALEY \& S. MYERS, supra note 77 , at 132 .

218. This is the classic agency problem discussed in Jensen \& Meckling, Theory of the Firm: Managerial Behavior, Agency Costs and Ownership Structure, 3 J. Fin. Econ. 305 (1976). Ownership of all the residual profits spurs efficient operation. Managers who own only part or none of the residual have an incentive to extract benefits from employment that reduce the residual. 
section 1091 did not apply, it is likely that the government would successfully claim that the sale-repurchase was a sham transaction. ${ }^{219}$ Furthermore, "sale" of the business within the family would fail. The law not only denies the tax loss to the seller in such a case, ${ }^{220}$ but also ensures that the buyer can only take the loss in the future to the extent that the appreciation of the asset during ownership by the buyer covers the loss. If no such appreciation occurs, the loss can never be taken. ${ }^{221}$ In contrast, the wash sale provisions simply ignore the sale and purchase so that the basis of the asset is the same as it was before the two transactions. ${ }^{222}$

\section{Conclusions}

Limiting the deduction of capital losses and disallowing losses from wash sales each have significant weaknesses as methods for controlling exercise of the timing option. The problems with these methods of control suggest that to the extent that any proposed accretion tax scheme fails to control timing option value by frequent assessment, it may be difficult for the law to control it independently. Accordingly, in discussing alternative ways to implement accretion taxation, the next Section carefully considers the impact of each design on the timing option.

\section{B. Designing an Accretion Tax}

Two major themes have been developed so far. First, accretion tax norms point to continuous taxation as ideal. In contrast, an annual periodic tax is often implicitly assumed to be ideal in the literature. A year may be a good period to use, but that choice must be justified in light of the ideal of continuous taxation.

Second, the riskiness of various assets and the ability to exercise a timing option by taking losses early and delaying gains are important considerations in accretion tax design. In contrast, the literature tends to focus exclusively or primarily on the length of the assessment period in considering design of a comprehensive accretion tax. ${ }^{223}$

These deficiencies in the literature are reflected in existing U.S. tax policy. In particular, current law ignores riskiness and timing option as-

219. A court can invoke the sham transaction doctrine to ignore the form of a transaction with "no economic substance" and treat it as something else for tax purposes. See Knetsch v. United States, 364 U.S. 361 (1960).

220. Set I.R.C. \$267(a)-(c) (1989).

221. The buyer's basis in the asset is cost, the amount paid to the seller. See I.R.C. $\$ 1012$ (1989). The seller had a higher basis. The buyer will be unable to use this higher basis to compute loss. However, the buyer can use the seller's loss to offset future gains on the asset. See I.R.C. $\$ 267$ (d) (1989). If there are no such gains, then no one will benefit from the seller's loss.

222. See I.R.C. $\S 1091$ (d) (1989). It is possible for the wash sale rules and the rules barring losses in transactions between family members to apply simultaneously. In that case, the basis provisions in $\$ 1091$ (d) override the basis rules discussed in note 221 and accompanying text for sales between family members. See I.R.C. § 267(d) (1989).

223. Ser supra note 5 (citing sources). 
pects in choosing the assets to tax most frequently. The greatest effort to implement accretion taxation by frequent assessment of unrealized gains typically involves assets that are not particularly risky. Consider the case where a bond is issued for less than its face value, the value that it will yield when it matures. In this case the increase in value represented by the difference between the face value and the issue price is economically equivalent to interest. The tax code is careful to tax this increase in value as it occurs annually. ${ }^{24}$ These bonds, however, are typically significantly less risky than other assets such as publicly traded common stocks where data is available that would make frequent taxation of unrealized gains very easy. ${ }^{225}$ Common stocks are taxed only when gains and losses are realized by sale or other disposition. ${ }^{226}$

This Section discusses design of an accretion tax in light of the continuous taxation ideal and the importance of strategic trading of risky assets. ${ }^{227}$ In the riskless environment of the example in Part I, it was possible to tax an asset only once and yet achieve a tax result equivalent to continuous taxation. No sacrifice of the goals specified by accretion tax norms was necessary in order to minimize the number of assessment and collection times for any asset. Part III, however, made clear that risky assets cannot be treated this way. ${ }^{228}$ In particular, there is not a one-toone correspondence between the asset paths and the "endpoint data" sets consisting of initial price, final price and holding period. Endpoint data conveys only partial information about the path. ${ }^{228}$

In the face of incomplete information about the path, there are two

224. The code accomplishes this under I.R.C. $\$ 1272$ (1989). The difference between issue price and face value is called "original issue discount." See I.R.C. \$1273(a)(1) (1989).

225. Several legal commentators have noted the ease with which unrealized losses and gains from such common stocks could be taxed on an annual basis and have advocated that approach. See supra note 5 (citing sources).

226. Although Congress has moved the treatment of some assets closer to a pure accretion tax, it has done so in a piecemeal fashion. The treatment of bonds issued at less than face value was arrived at in several installments in response to potential abuse by taxpayers. See Halperin, supra note 5, at 509-12. If accretion taxation is to be the standard treatment, Congress should think more comprehensively about which assets to target for frequent taxation.

227. Perhaps the most extensive and thoughtful attempt to grapple with the problems of implementing accretion taxation widely is Professor Shakow's recent article. See generally Shakow, supra note 5 . He catalogs the financial assets and liabilities currently extant in the United States and considers how each type of asset or liability might be taxed under accretion taxation. His goal generally is to assess and tax annually. Where this cannot be done, he proposes a tax at the time of sale that is equivalent to annual taxation and that is based on a linear approximation of the asset path. See infra Part II of Appendix (discussing construction of linear approximation).

The goal here is to supplement work such as Professor Shakow's by showing how asset riskiness might play an important role in the design of an accretion tax. In particular, risky assets that can be traded at low cost should be the focus of attempts to assess and tax frequently. See infra text accompanying notes 248-50. For other classes of assets it may be easy to mimic a continuous tax by periodic assessment so that infrequent assessment may not be very harmful. See infra text accompanying notes $237-45$.

228. See supra text accompanying notes 132-39.

229. The term "endpoint data" emphasizes the fact that values between the endpoints are not known. 
basic policy approaches: approximation and frequent assessment. Approximation consists of choosing the best possible tax based on the partial information inherent in the endpoint data. Frequent assessment addresses the incomplete information problem by observing more of the path.

This Section shows that which of these two approaches is best depends on the type of asset being taxed. The crucial asset trait is the level of trading costs. Frequent assessment works well for low transaction cost assets while approximation is an attractive approach for high transaction cost assets. The reason for the difference is that strategic trading is available for low transaction cost assets, and strategic trading makes approximation less accurate and more difficult.

The Section proceeds in three steps. Subsection 1 discusses approximation techniques and their limitations. Subsection 2 details the alternative approach of frequent assessment. Subsection 3 specifies some directions for future research concerning design of accretion taxation.

\section{Approximation Techniques and Their Limitations}

The challenge of approximating continuous taxation consists of using endpoint data about the asset path in the most effective possible way. An obvious candidate for use in approximation is the average continuous tax based on the bridge process approach discussed in Part III. ${ }^{230}$ Using only. endpoint data and the statistical characteristics of the asset under consideration, a bridge process is constructed: the set of all possible paths and their probabilities. Knowing this process, the approach yields a figure for the average tax over these possible paths.

The bridge process approach is attractive because it produces a best estimate of the average tax given the endpoint data that is available. But imposing an average tax in place of observing the actual asset path and imposing the corresponding continuous tax has two drawbacks. First, even using a perfect estimate of the average tax will not eliminate all of the normative costs inherent in approximation. In particular, even though using the average tax as an estimate minimizes the variance of the estimate, ${ }^{231}$ the remaining variance may be high. In this case, the average continuous tax will tend to deviate substantially from what would have been the actual continuous tax. As a result, there may be value in assessing frequently despite the fact that good estimates of the average tax are available. ${ }^{232}$ The use of frequent assessment is discussed in Subsection 2.

230. See supra note 146; text accompanying notes 144-47.

231. This point is easy to demonstrate using a little calculus. Suppose that one wants to know the true value of some random variable $X$. There are $n$ possible values, each of which is equally likely. Denote these values $x_{i}$ where $i=1,2, \ldots, n$. The variance of $X$ from some estimate $b$ is simply $V=(1 / n) \Sigma\left(x_{i}-b\right)^{2}$ where the sum is from $i=1$ to $i=n$. The second derivative of $V$ with respect to $b$ is 1 , which is positive, and the first derivative is zero when $b=(1 / n) \Sigma x_{i}$, the average value of $X$. This average value is the minimum variance estimate of $X$.

232. See supra note 146. 
A second drawback of using the average tax as a surrogate for the actual continuous tax due is that this approach will only succeed when strategic trading is not possible or is prohibitively expensive. To see why this is true, consider the following example of a risk-neutral investor investing in a risky project. ${ }^{233}$

The project is a two-year investment with returns consisting of the proceeds from two lotteries. One lottery is at the end of the first year, and the second lottery is at the end of the second year. The lottery at the end of the first year yields either $\$ 320$ or $\$ 120$ with equal probability. The outcome is announced publicly. No one has any information about which outcome will occur until the lottery itself is conducted. These two cash payments will be paid with interest at the annual market rate of $10 \%$ at the end of the two years. Therefore, the project will receive either $\$ 352$ or $\$ 132$ at the end of its two year life as a result of the first lottery. The lottery at the end of the second year yields either $\$ 110$ or $-\$ 110$ with equal probability. The outcome of the second lottery is independent of the outcome for the first lottery.

At the end of the two years, there are three possible cash outcomes from the project. With probability $25 \%$ the project will yield $\$ 22$, with probability $50 \%$ it will yield $\$ 242$, and with probability $25 \%$ it will yield $\$ 462$. The two extreme outcomes are each associated with a unique path. But the middle outcome may be reached by two different paths. These two different paths are associated with the two different possible orderings of the high and low outcomes in the lotteries, "lose-win" and "win-lose." On the lose-win path the first lottery results in a low outcome and the second in a high outcome. On the win-lose path the high outcome occurs in the first lottery and the low outcome in the second.

The lose-win path begins at $\$ 200$, increases exponentially to $\$ 220$ during the first year, drops by $\$ 100$ to $\$ 120$ after the first lottery, increases exponentially to $\$ 132$ from $\$ 120$ during the second year and finally jumps to $\$ 242$ after the second lottery. ${ }^{234}$ The continuous tax on this path brought forward to the end of the second year is $\$ 15.30$. The win-lose path begins at $\$ 200$ and increases exponentially to $\$ 220$ during the first year, increases by $\$ 100$ to $\$ 320$ after the first lottery, increases exponentially from $\$ 320$ to $\$ 352$ during the second year and then drops to $\$ 242$ after the second lottery. The continuous tax on this path brought forward

233. The Appendix infra details the methods used to derive the paths and numerical results in this example. Parts I and $V$ of the Appendix are particularly relevant to the path computation and the valuation of risky investments by a risk-neutral investor.

234. The $\$ 200$ figure is the discounted present value of the $\$ 242$ average return to be received in two years. This discounted present value increases to $\$ 220$ during the first year since the riskless interest rate is $10 \%$. Investors are assumed to be risk-neutral. These investors value risky returns by discounting the average value of the risky returns at the riskless discount rate. See infra Part V of the Appendix. Thus, the $\$ 200$ figure is the initial value of the investment.

The jumps and drops in value occur as the lottery results become known and risk is resolved. Between jumps and drops, the investment's value increases at the riskless annual rate of $10 \%$. 
to the end of the second year is $\$ 20.23$. The tax is higher on the win-lose path because it involves earlier gains and later losses than the lose-win path.

The two paths are plotted against time in Figure 3. The win-lose path consists of empty boxes connected by lines, and the lose-win path consists of pluses connected by lines. The paths coincide where there are solid boxes connected by lines: during the first year and at the end of the second year.

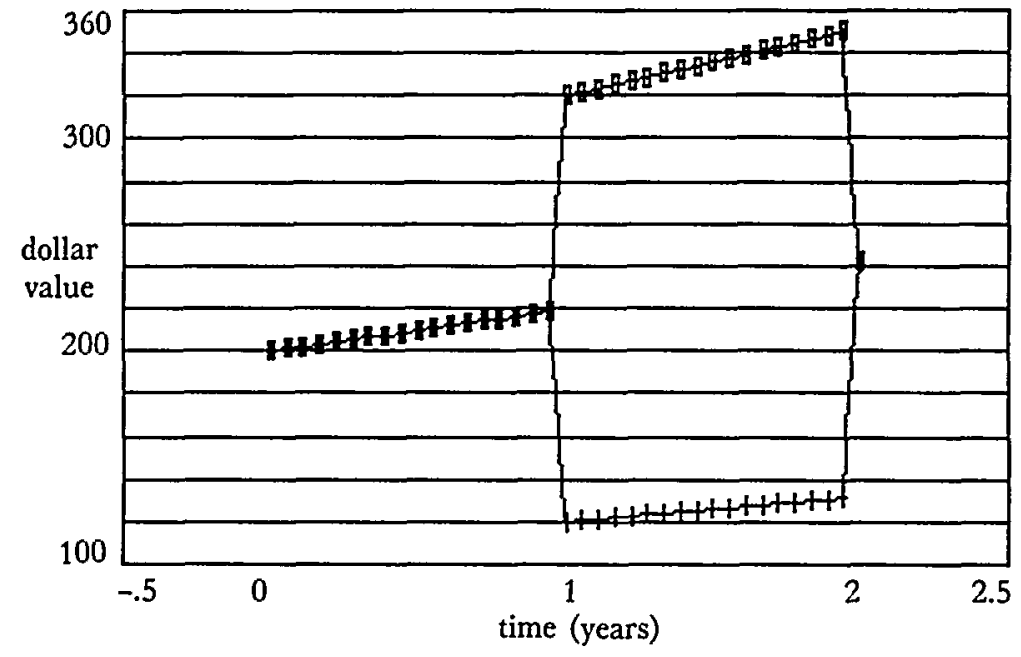

Figure 3

Suppose that the tax rule is to impose the average tax for any given ending value at time 2 . Then the tax for the outcome of $\$ 242$ will be $\$ 17.77$, the average of $\$ 20.23$ and $\$ 15.30$. But the taxpayer can now use an asset sale and purchase strategy to obtain a tax of $\$ 17.77$ in the winlose situation and a tax of $\$ 15.30$ in the lose-win situation. The strategy is to sell the project right after the first lottery if the low outcome occurs in that lottery and simultaneously buy an equivalent project. If the outcome of the second lottery is the high one, this strategy will reduce taxes from the $\$ 17.77$ average tax to the $\$ 15.30$ for the lose-win path. This result occurs because the taxpayer has replicated the lose-win path by asset sales and purchases. If the second lottery has a low outcome, the taxpayer simply pays the tax based on the final outcome of $\$ 22$ corresponding to the lose-lose path. The total tax for this path is unaffected by the sale and purchase after the first lottery. Therefore selling and repurchasing after the low outcome in the first lottery strictly dominates simply holding the project in that situation. The taxpayer will pay lower taxes in some future states of the world but will never pay a higher tax in any future state of the world.

This strategy generalizes to more complex situations. Sale combined with simultaneous repurchase splits the asset path into two pieces. The 
first piece runs from the initial time to the time of sale. The second piece runs from repurchase forward. Whenever the sum of the expected taxes from these two pieces is lower than the expected tax if the asset is simply held, the taxpayer should sell and repurchase. In essence, taxpayers will establish the actual occurrence of all paths with below average taxes but will hold the asset if the path would result in an above average tax. The result will be that the maximum tax will be the average tax over all paths, but the taxpayer will often pay less. The problem is that the average tax was computed assuming that taxpayers would not behave strategically in response to the average tax rule. The actual average tax given this behavior will differ from the average tax assumed to apply in its absence.

This problem suggests that using an average tax rule will not work well for low transaction cost assets when strategic trading is legally feasible. There are other approximation techniques that may work with these assets. Consider a "high tax approach." Under this approach an approximate tax is imposed that is much too high on average. This tax by itself would be a poor approximation of continuous taxation. However, the hope is that the taxpayer will trade to establish all the paths with lower taxes. The actual trading path then can be used instead of the high tax approximation.

In the example just presented, a perfect high tax approach would be to assume that any final outcome was reached by the path resulting in the highest tax. When $\$ 242$ is observed as the final outcome of the project in the example above, the tax would be $\$ 20.30$, the highest tax for any path leading to that outcome. With this rule, the government can rest assured that the taxpayer will establish the actual contours of any lower path by asset sales and repurchases. The tax result will always be correct. ${ }^{235}$ If the lose-win path occurs, the taxpayer will have sold the asset after the first lottery to secure this path on the tax accounts. The tax will be $\$ 15.23$. If the win-lose path occurs, the taxpayer will have held the project throughout the two years, and the tax will be the correct amount: $\$ 20.30$.

The real world implementation of this approach is more difficult than this example suggests. For many assets it is hard to establish an upper bound for the tax due on the basis of endpoint data. ${ }^{236}$ Some arbitrarily

235. There is a problem with this approach if not all taxpayers trade their assets to minimize taxes. In that case, taxpayers who do not so trade will be overtaxed. Not trading may be optimal behavior on the part of these taxpayers if they face higher transaction or planning costs than other taxpayers. Higher planning costs may arise where a taxpayer is ignorant of the proper trading strategies. Learning these strategies or discovering trustworthy agents who can do them on behalf of the taxpayer may be very costly. Furthermore, taxpayers with small portfolios may pay higher transaction costs per dollar invested.

Legal commentators have been concerned in the past about whether a taxpayer's failure to hold a portfolio that maximizes tax benefits should be an equity concern. See Bittker, supra note 213, at 22-23.

236. Consider a humped path where value starts at $\$ \mathrm{X}$, increases to some point above $\$ \mathrm{X}$, and then declines back down to $\$ \mathrm{X}$. If interest rates are positive, this generates positive tax liability. Early 
high tax could be imposed for each outcome unless the taxpayer sold and repurchased the asset with some given frequency. This approach would induce the taxpayer to produce path data for the tax authorities. That is certainly good policy if the taxpayer can plan sales and repurchases costlessly and incurs no transaction costs on those sales and repurchases. Otherwise, the planning costs and transaction costs are social costs that may make this approach undesirable. ${ }^{237}$ In that case, frequent assessment may be a better solution. This possibility is discussed in Subsection 2 .

The strategic trading problems with the average tax rule that arise for low transaction cost assets are absent if transaction costs are very high. In this case, the timing option problem is not a concern. The taxpayer will not sell to take tax losses early if selling is extremely costly. This fact makes taxing on the basis of an average path feasible. Taxpayers cannot profitably subvert the average by selling to establish below average paths for tax purposes. ${ }^{238}$

The average tax rule based on the bridge process is an attractive alternative for high transaction cost assets. But there are other approximation techniques based on endpoint data that might be used for these assets. Tax policy scholars have put forward two other techniques as possibilities. One technique is to assume an exponential path between endpoints. ${ }^{239}$ This approach envisions the asset increasing in value at a constant rate of return like the riskless assets discussed in Part I. The other technique is to assume that the path between endpoints is linear. ${ }^{240}$ Because exponential and linear path approximations fail to use all of the information on the statistical properties of asset paths inherent in the endpoint data, they may deviate significantly from the average tax indicated by bridge process analysis. ${ }^{241}$ However, using the bridge process approach requires more information than the other two approaches. It is necessary to know the pre-tax statistical properties of the assets being taxed. ${ }^{242}$ In addition, the

gains are matched with later losses to create net interest due on the taxes corresponding to each dollar of matching gain and loss. As the hump becomes infinitely high, the interest charge increases toward infinity.

237. Additional problems arise if taxpayers differ in the level of their planning or transaction costs. Sue supra note 235.

238. Cf, supra text accompanying notes 232-35 (ability of taxpayer to exploit and subvert average tax rule by strategic trading when transaction costs are low).

239. Sur, e.g., Balcer, supra note 1, at 3; Fellows, A Comprehensize Attack on Tax Deferral, 88 Mich. L. REv. 722, 742-44 (1990).

240. Sir, r.g., Shakow, supra note 5, at 1122-24; Wetzler, supra note 195, at 121-22 \& 152-53.

241. An example is a humped asset value path starting at $\$ 100$ and ending at $\$ 100$. Since gains precede equal amounts of losses on this path, a positive amount of tax usually would be due. Sep supra text accompanying note 29 . But both the exponential and linear path approximations would indicate a path that was flat at $\$ 100$. No tax would be due under either of those approximations.

242. This information is necessary because the bridge process approach operates by assigning probabilities to various paths. These probabilities are based on the statistical properties of the asset under study. Sep supra note 149; text accompanying notes 146-50. 
exponential and linear approximations are conceptually and computationally simple compared to the bridge process approach. ${ }^{243}$

It is clear that the linear and exponential approximations have some advantages over the bridge process approach. ${ }^{244}$ This raises a key question: How much is lost by the fact that these approximations do not use all the information inherent in the endpoint data? A concrete way to address that question is to examine how much these approximations would deviate from the average continuous tax computed under the bridge process for the typical stock market asset.

Consider the following table. It consists of four taxes for a typical stock market asset purchased for $\$ 100$ and held for ten years. The taxes are presented for various final outcomes at the end of the ten years. The tax rate is assumed to be .40 . The "standard tax" is simply the tax rate applied to the final value minus the initial value. The "exponential approximation" is the continuous tax that would have been due if the asset had followed an exponential path between the initial and final value. The "linear approximation" does the same assuming a linear path. The third column contains the bridge process computation of the average continuous tax as a benchmark. ${ }^{245}$ The outcome $\$ 294.34$ is the expected outcome as of the beginning of the investment.

\section{Table XIII}

\begin{tabular}{rrccc} 
outcome & $\begin{array}{c}\text { standard } \\
\operatorname{tax}\end{array}$ & $\begin{array}{c}\text { continuous } \\
\operatorname{tax} \text { (average) }\end{array}$ & $\begin{array}{c}\text { exponential } \\
\text { approximation }\end{array}$ & $\begin{array}{c}\text { linear } \\
\text { approximation }\end{array}$ \\
110.00 & 4.00 & 4.65 & 4.38 & 4.87 \\
150.00 & 20.00 & 22.13 & 21.81 & 24.35 \\
294.34 & 77.74 & 84.39 & 83.93 & 94.63 \\
500.00 & 160.00 & 172.08 & 171.48 & 194.78 \\
1000.00 & 360.00 & 384.99 & 382.38 & 438.24 \\
\hline
\end{tabular}

243. Part II of the Appendix details the mathematical construction of linear and exponential approximations based on endpoint data for asset paths. Parts III and IV of the Appendix explain how to compute the continuous tax due on an exponential path. A similar and equally elementary explanation could be given for computing the tax on a linear path. The mathematics required is high school algebra and some elementary calculus. After deriving the appropriate formulae, approximating the tax for given endpoint data involves only a few simple calculator operations. For most tax professionals these computations and the concepts that underlie them would be elementary.

In contrast, deriving the average tax due under the bridge process approach requires advanced mathematics. See generally J. Strnad, supra note 14, at 182-210 (derivation of the mean and variance continuous tax using the bridge process approach). In addition, computation of the average tax for a given set of endpoint data is difficult and must be done by computer. The bridge process approach lacks the conceptual and computational simplicity of the linear and exponential approximations.

244. Another approximation approach would be to assume that the asset fluctuated in the same way as similar assets with observable paths. This can be done systematically using modern finance theory, but that approach is most difficult precisely for the class of high transaction cost assets considered here. See supra note 135.

245. Since there is no possibility of early loss-taking in this case, the bridge process is computed for the case with no strategic trading. See supra text accompanying notes 150-60. 
The linear approximation performs poorly. It results in substantial overtaxation in every one of the five examples in the table. The picture is much brighter for the exponential approximation. Except in the case of very low outcomes, this approximation closes most of the gap between the standard tax and the average tax under continuous taxation. It seems clear that the exponential approximation method is worth considering as an alternative to computing average taxes using bridge process analysis.

\section{Frequent Assessment}

A major alternative to the approximation techniques discussed in the previous Subsection is frequent assessment. Under this approach both realized and unrealized gains and losses occurring during each assessment period would be summed and taxed at the end of the period. No attention would be paid to the timing of the gains and losses within the period. The assessment period would be chosen to be very short so that gains and losses would be assessed frequently.

This approach makes the value of the timing option zero. There is no advantage to realizing losses that occur early in an assessment period. No matter what trading an investor does during the period, only total gain or loss over the period will be taxed at the end of the period. ${ }^{246}$ Furthermore, there is no way to accelerate losses to an earlier assessment period. Losses will be taxed at the end of the period in which they occur regardless of when they are realized.

The disadvantage of this approach is the inaccuracy due to not drawing temporal distinctions within assessment periods. This inaccuracy may be minimized, however, if the assessment period is chosen to be very short. ${ }^{247}$

Since frequent assessment is likely to be costly, it would be valuable to know the gains from choosing progressively shorter assessment periods. To get an idea of the magnitudes involved, consider the following example of an asset with a riskless exponential path. The asset increases exponentially at a $10 \%$ annual rate from $\$ 100.00$ at the beginning of year one to $\$ 459.50$ at the end of sixteen years. A constant tax rate of .40 is assumed. The asset is assessed at equal intervals, and the sixteen-year period consists of an integral number of these intervals. The first column of the table specifies the number of assessments during the sixteen-year period. The

246. This approach has two other advantages. First, it eliminates the danger of overtaxing taxpayers who are unaware of how to trade their assets to minimize their taxes or taxpayers with small portfolios whose trading is circumscribed by high transaction costs per dollar invested. See supra note 235. The danger is eliminated because there is no trading strategy that will reduce taxes for anyone.

A second advantage is that the approach eliminates the need to know the statistical properties of the asset. This is true because no attempt would be made to estimate the path that the asset took during each assessment period.

247. This inaccuracy could also be alleviated by applying one of the approximation methods discussed in the previous Subsection to intraperiod fluctuations. See supra text accompanying notes $230-45$. 
second column states how long the assessment period is. The third column lists the resulting tax expressed in terms of collection at the end of the sixteen years.

\section{Table XIV}

$\begin{array}{ccc}\begin{array}{c}\text { number of } \\ \text { assessments }\end{array} & \begin{array}{c}\text { assessment } \\ \text { period }\end{array} & \begin{array}{c}\text { equivalent tax } \\ \text { end of } 16 \text { years }\end{array} \\ 1 & 16 \text { years } & \$ 143.80 \\ 2 & 8 \text { years } & \$ 175.19 \\ 4 & 4 \text { years } & \$ 192.35 \\ 8 & 2 \text { years } & \$ 201.09 \\ 16 & 1 \text { year } & \$ 205.46 \\ 32 & 6 \text { months } & \$ 207.65 \\ 64 & 3 \text { months } & \$ 208.74 \\ 192 & 1 \text { month } & \$ 209.46 \\ 832 & 1 \text { week } & \$ 209.74 \\ \text { infinity } & \text { zero } & \$ 209.83\end{array}$

The tax of $\$ 143.80$ would be the tax under the current system if none of the gains were realized until the end of the sixteen years. The tax of $\$ 209.83$ represents the "correct" result that follows from continuous taxation. A system of weekly assessment would come within $0.04 \%$ of the correct result. Annual assessment results in an error of about $2.1 \%$. Although this example was constructed for a riskless asset path, a similar qualitative result would probably apply for typical risky assets such as common stocks, given that the possibility of profiting from early loss taking has been eliminated by denying any tax effect to early realization of losses. ${ }^{248}$

Frequent assessment is an especially promising approach for low transaction cost assets. The class of assets that may be sold and purchased at low cost primarily consists of assets with well developed public markets. Daily price series are available for most of these assets. It would be possible to construct a computer program that would begin with endpoint data (date and price of purchase; date and price of assessment or sale), would construct a value path based on daily price series, and would compute tax due, with interest, for that path. It is plausible that a program of this sort could cover all publicly traded assets at a very low cost per use.

For low transaction cost assets, it is likely that frequent assessment will approximate continuous taxation more accurately and will be less costly than the approximation methods discussed in the previous Subsection. For this class of assets, approximation techniques such as the average tax rule

248. The riskless asset path used in the example is exponential. Except in the case of very low final outcomes, the tax due assuming an exponential path is a good approximation of the average continuous tax over all possible paths for a risky asset with no strategic trading. See supra text accompanying notes $244-46$. 
can be defeated by strategic trading. ${ }^{249} \mathrm{~A}$ "high tax approach" of imposing an arbitrarily high tax so that the taxpayer will establish a lower path by trading avoids the strategic trading problem. But even with low costs per trade, this approach may result in total trading costs that are much higher than the administrative costs of frequent assessment. ${ }^{250}$

Two advantages of frequent assessment over approximation techniques exist independent of the level of transaction costs for the assets being taxed. First, if assessment periods are short enough, tax rates will be constant during each period. In contrast, approximation techniques will be applied to some transactions that span many years, and the taxpayer may have been subject to many different tax rates during those years. Costly distortions will result if these different tax rates are not applied to the approximated path. ${ }^{251}$ But applying changing tax rates to the approximated path increases the complexity of using approximation methods. ${ }^{262}$

A second general advantage of frequent assessment over approximation techniques arises because of the residual variance inherent in any approximation. Even if an approximation technique accurately estimates the average tax for the set of possible asset paths, the tax for many of these paths may be substantially different from the average tax. ${ }^{263}$ Frequent assessment eliminates this problem by setting the tax due in close accord with the actual path. In effect, frequent assessment involves taking many more observations of asset values at different times so that much more information is available about the actual path.

\section{Directions for Future Research}

The previous two Subsections set out some basic trade-offs. Approximation methods allow assessment to be infrequent, thereby saving administrative costs. On the other hand, the estimates that are the heart of these methods are only estimates, and the variance of these estimates may be

249. Sur supra text accompanying notes $232-35$.

250. See supra text accompanying notes 235-37. The high tax approach also may be inequitable if taxpayers vary significantly in transaction and planning costs. See supra note 235.

251. If tax rate changes occur during assessment periods, taxpayers will shift the timing of investment to minimize taxes. This will make the tax system nonneutral. See supra note 118 . Continuous taxation avoids this result because the assessment period becomes infinitesimal in length. To achieve this result when continuous taxation is being approximated, the tax rate that would have applied at each instant should be applied along the approximated path of the asset. Furthermore, the tax adjustment necessary to convert interest rates to after-tax values will also vary as tax rates change. This will have to be taken into account in carrying the continuous tax on the approximated path forward to the time of collection.

252. Even more complexity arises if the gains or losses along the approximated path change taxable income enough in earlier periods to affect the applicable marginal tax rates during those periods. Each taxpayer would have to keep track of the impact of each gain or loss realization on earlier periods. Even if a single realization did not shift the taxpayer to a different bracket in earlier periods, a group of realizations might cause such a shift.

253. This residual variance phenomenon is detailed in the previous Subsection. See supra text accompanying notes $231-32$. 
high. In addition, some of the strongest approximation methods such as the average tax rule are not viable if strategic trading is easy.

Frequent assessment results in higher accuracy than even the best approximation methods. On the other hand, for assets that are not publicly traded, frequent assessment may be very costly.

The nature of these trade-offs suggests that approximation methods would be best for high transaction cost assets while frequent assessment would be best for low transaction cost assets. These two cases cover broad sectors of current wealth holding such as publicly marketed securities and closely held corporations. ${ }^{254}$ Clearly, however, there are "hard cases" involving assets that do not fall into either of these two categories. There is a real need to clarify the trade-offs between administrative costs, private transaction costs, and the normative costs of failing to approximate continuous taxation well. Accomplishing this task is necessary both to propose solutions in hard cases, and also to adopt with confidence the solutions that currently seem qualitatively attractive in the easy cases.

There are many possible policy approaches to the conflict between frequent taxation and minimizing the sum of private and government costs. Ghoosing an approach involves several tasks of a technical nature. First, it is important to know the compliance costs of each system. Assessment and collection of taxes involve both government and taxpayer resources. Second, and more difficult, it is necessary to measure the impact of market transaction costs on how closely a tax approximates continuous taxation. Transaction costs may deter taxpayers from strategic buying and selling that would tend to make taxes deviate from any particular desired approximation of a continuous tax. Since market transaction costs are a social cost, it is also important to know how much extra market transaction costs a given tax system induces as taxpayers attempt to respond optimally to the tax rules. Finally, there is the most difficult technical issue: What is the best method of taxation? It may end up being a "surrogate" tax such as a wealth tax on all assets not traded during the assessment period.

Developing technical models that include market transaction costs or analyze surrogate taxes is a difficult task. For example, it is no longer opimal for the taxpayer to realize all losses as soon as possible if there are transaction costs. The costs associated with sale and repurchase may exceed the expected tax benefits from realizing a particular loss early. Some scholars have succeeded in modeling this trade-off, but doing so is not particularly easy. ${ }^{255}$

Adding in complex surrogate taxes may be even harder. For risky as-

254. See Shakow, supra note 5, at 1124-26, 1185-96, for a breakdown of assets and liabilities into categories and estimates of the size of each category.

255. Models with a considerable degree of mathematical sophistication are required. See, e.g., Magill \& Constantinides, Portfolio Selection with Transactions Costs, 13 J. Econ. Theory 245 (1976); Williams, Trading and Valuing Depreciable Assets, 14 J. Fin. Econ. 283 (1985). 
sets, it is difficult enough to model simple taxes such as a tax on net gains and losses over a particular period or a tax that only is imposed on realization. ${ }^{258}$ Modeling more complex taxes probably would be much harder, and the problem of choosing an optimal tax treatment from the space of all possible tax treatments would be harder still.

Solving these technical problems would be an important step forward, but the most pressing need is to determine the normative costs associated with deviations from continuous taxation. In the absence of knowledge concerning the seriousness of any given deviation, it is hard to know how much to sacrifice in terms of compliance costs and market transaction costs to achieve any given degree of conformity with continuous taxation. This leaves tax policymakers without guidance even on such fundamental questions as whether or not annual assessment provides an adequate approximation to continuous taxation. ${ }^{267}$

\section{Conclusions}

Many accretion tax advocates prefer that method of taxation over a cash flow tax because of the impact of accretion taxation on the distribution of wealth and because the accretion tax reaches the intangible benefits derived from wealth more effectively. These wealth-related justifications suggest that the optimal assessment period under an accretion tax is zero. Taxes should be assessed continuously.

Principles of tax neutrality such as the one derived by Paul Samuelson do not imply. an optimal assessment period, but they do imply that whatever period is chosen should be applied to all assets. Statutory specification of different periods for different assets is not the only way this consistency requirement can be violated. It will also be violated if taxpayers can artificially shorten the assessment period by selling assets in order to realize losses early.

Much work needs to be done on specifying the implications of the wealth-related norms for the comparative degree of harm caused by various deviations from continuous taxation. Despite the current inability to compare the costs of various departures from continuous taxation precisely, much can be said about the optimal design of an accretion tax. Scholars have tended to focus on the length of the assessment period rather than on the riskiness of assets and on whether or not taxpayers may trade the assets strategically to accelerate tax losses. But riskiness combined with strategic trading often induce deviations from continuous

256. See, e.g., Constantinides, supra note 179.

257. In the example associated with Table XIV, see supra text accompanying notes 247-48, annual and biannual assessment result in deviations of $2.1 \%$ and $4.2 \%$ respectively from continuous taxation. To know whether the increase in administrative cost inherent in annual rather than biannual assessment is worth spending, it is necessary to know the monetary value of reducing the deviation from continuous taxation from $4.2 \%$ to $2.1 \%$. 
taxation that are as large or larger than the deviations arising from delayed assessment by itself.

There are two asset categories for which there are viable approaches to implementing or approximating continuous taxation. The first category consists of assets that are rarely traded because of high transaction costs. For these assets, a continuous tax approximation may be based on "endpoint data" alone: the initial value, final value and holding period of a given asset. Given that a continuous tax may be approximated fairly well for these assets, frequent assessment may not be necessary. A second category consists of assets that can be bought and sold with low transaction costs because the assets are traded in public markets. Frequent assessment is a good approach for these assets. This minimizes the ability of taxpayers to accelerate losses through strategic trading. The same strategic trading possibility makes it difficult to save administrative costs for these assets by assessing less frequently and using approximations based on endpoint data.

When transaction costs are a barrier but not a total bar to strategic trading and when there is no readily available price series for an asset, approximating continuous taxation is more difficult. It is technically hard to determine the best (or even a good) "surrogate tax" to use as an approximation. There is a more fundamental problem. Making the proper trade-offs between the administrative costs of frequent assessment and the normative costs of deviating from continuous taxation requires a much better idea of the structure of the normative costs. Being able to specify normative costs more clearly not only would aid in addressing difficult cases but also would provide assurance that the solutions arrived at for the easy cases are in fact good solutions.

\section{Appendix: Periodic and Continuous Taxation in a Riskless or Risk-Neutral Setting}

This Appendix provides additional detail concerning the mathematical basis for the numerical examples and figures in the text that involve a riskless or risk-neutral setting. In particular, this Appendix describes the derivation of the curves and numerical results in Figures 1 and 3, Tables I-VI, Tables X-XI, part of Table XIII and Table XIV of the text. ${ }^{258}$

Part I of this Appendix describes the pre-tax asset paths that are used in many of the numerical examples. Part II shows how linear and exponential approximations for pre-tax paths are derived. Part III describes the derivation of after-tax interest rates. Parts IV and V show how these

258. The working paper version of this Article describes the derivation of numerical results that involve the statistical properties of a continuous tax on risky assets. See J. Strnad, supra note 14, at 182-210 (Appendix B). Figure 2, Tables VII-IX, Table XII, the third column of Table XIII in the text, and the tables in footnotes 159,174 , and 176 include numbers or curves that exemplify these statistical properties. 
after-tax interest rates are used to compute "equivalent taxes" and aftertax present value. Each Part specifies the tables and figures to which it applies.

\section{The Pre-Tax Asset Paths}

Tables I-VI, X-XI and XIV are set in a world where the annualized pre-tax riskless interest rate is $10 \%$. It is assumed that all economic actors know that this rate will prevail over all future time. A riskless asset in this world will increase exponentially at a $10 \%$ annual rate.

The mathematical formula for value of an asset that grows exponentially at a constant rate is straightforward. If one dollar is invested at time 0 , this dollar will grow to $e^{\text {rt }}$ dollars after $t$ years elapse. The rate " $r$ " is the instantaneous rate of growth. In Tables I-VI, X-XI, and XIV this rate must be set so that the annual riskless interest rate is $10 \%$. A $10 \%$ annual rate means that after one year an asset purchased for a dollar must be worth $\$ 1.10$. Thus, the appropriate $\mathrm{r}$ solves the equation $\mathrm{e}^{\mathrm{r}}=$ 1.1 so that $r=\ln (1.1)=0.09531$. This value of $r$ is denoted by $r(10 \%)$.

This value of $r$ was used to calculate the two exponential paths in Figure 1. The lower path in that figure is generated by the equation $\$ 100 \mathrm{x}$ $\mathrm{e}^{\mathrm{r}(10 \%) \mathrm{t}}$ where $\mathrm{t}$ is the time in years. Except for an initial jump from $\$ 100$ to $\$ 119$, the upper path in the same figure is generated by the equation $\$ 119 \times \mathrm{e}^{\mathrm{r}(10 \%) \mathrm{t}}$. The upper path is the pre-tax asset path that serves as a basis for the simulations in Tables I-V in the text. Figure 3 involves similar exponential increases (at a 10\% annual rate) punctuated by jumps when risk is resolved. Finally, the simulations in Table XIV are based on a pre-tax asset path that obeys the equation $\$ 100 \times \mathrm{e}^{\mathrm{r}(10 \%) t}$.

\section{Linear and Exponential Approximations for Pre-Tax PATHS}

Part IV of the text explores the situation where a continuous tax should be applied but all that is known is the initial value of the asset, the final value of the asset and the holding period. Let the initial value be $\$ X$, let the final value be $\$ Y$ and let the holding period be $T$ years. Part IV of the text, particularly the numerical simulation contained in Table XIII, considers the possibility of basing the continuous tax on either a "linear approximation" or an "exponential approximation" of the actual pre-tax path of asset value.

These approximations are derived as follows. For the linear approximation the path will be $\$ \mathrm{X}+\mathrm{bt}$ where $\mathrm{t}$ is time and $\mathrm{b}$ is a constant equal to $(\$ Y-\$ X) / T$. The constant $b$ is the linear rate of change that would describe a straight line asset path between $\$ \mathrm{X}$ at time 0 and $\$ \mathrm{Y}$ at time $\mathrm{T}$. For the exponential approximation the path will be $\$ \mathrm{X} \mathrm{x} \mathrm{e}^{\mathrm{ct}}$ where $\mathrm{c}$ is a constant equal to $(1 / \mathrm{T}) \times \ln (\mathrm{Y} / \mathrm{X})$. The number $c$ is the constant expo- 
nential rate of change that yields $\$ Y$ starting from $\$ X$ after $T$ years elapses. The last two columns of Table XIII contain the continuous taxes that would result from these approximate paths. These taxes (as well as the approximate paths) are a function of the "outcome" in the first column of the table. This outcome is the final value of the asset, denoted here as $\$ Y$.

\section{After-Tax INTERest Rates}

The numerical simulations in the text list or employ two kinds of aftertax interest rates: rates that apply for a continuous tax and rates that apply for a periodic tax. The after-tax interest rate for a given taxpayer is also called the "after-tax discount rate" for that taxpayer since this is the rate that the taxpayer will use to discount riskless investments to present value. Tables I-III and $\mathrm{V}$ have a column consisting of the after-tax discount rate for various taxpayers under a continuous tax regime. The next Part describes how after-tax discount rates are used to compute the "equivalent tax" as of a certain time which occurs in many of the text tables. This Part focuses on how the after-tax discount rates themselves are derived.

The annualized after-tax discount rate is the annual after-tax rate of return that would be earned on a riskless investment. As discussed in the previous Part, the text examples envision that a one dollar investment in a riskless asset will grow to $\mathrm{e}^{\mathrm{r}(10 \%) \mathrm{t}}$ after time $\mathrm{t}$ where $\mathrm{r}(10 \%)=0.9531$ is the instantaneous rate of return that results in a 10\% pre-tax annual rate of return on the riskless asset.

Now suppose that the tax rate is $\theta$ and that a periodic tax is imposed every $\mathrm{n}$ years. One dollar invested at the beginning of year one will grow to $\mathrm{e}^{\mathrm{r}(10 \%) \mathrm{n}}$ dollars after $\mathrm{n}$ years. The gain at the end of the $\mathrm{n}$ years on the dollar investment is simply $\left[\mathrm{e}^{\mathrm{r}(10 \%) \mathrm{n}}-1\right]$ and the tax on that gain is $\theta\left[\mathrm{e}^{\mathrm{r}(10 \%) \mathrm{n}}-1\right]$. The after-tax return on the one dollar investment is $\mathrm{e}^{\mathrm{r}(10 \%) \mathrm{n}}$ $-\theta\left[\mathrm{e}^{\mathrm{r}(10 \%) \mathrm{n}}-1\right]$. Raising this to the power $(1 / \mathrm{n})$ annualizes the after-tax rate of return and subtracting one from this annualized return gives the annual rate of return. So the annualized rate of return under a tax with period $\mathrm{n}$ is

$$
\operatorname{ATDR}(\mathrm{n})=\left[\mathrm{e}^{\mathrm{r}(10 \%) \mathrm{n}}-\theta\left[\mathrm{e}^{\mathrm{r}(10 \%) \mathrm{n}}-1\right]\right]^{(1 / \mathrm{n})}-1
$$

where $\operatorname{ATDR}(\mathrm{n})$ stands for the after-tax discount rate under a tax of period $n$ and (A1) labels the equation for future reference. ATDR(n) can be converted to a percentage by multiplying by 100 .

As an example, consider the first number in the final column of Table I. This is the annualized after-tax discount rate for a taxpayer in the $40 \%$ bracket when the period for taxation is two years. The $6.11 \%$ figure is computed by first computing ATDR(2) using (A1) with $\mathrm{n}=2, \mathrm{r}(10 \%)$ $=0.09531$ and $\theta=.40$. This yields .061132 . This number is multiplied 
by 100 and rounded to two decimal places to obtain the $6.11 \%$ figure in Table I.

Computing the after-tax discount rate under a continuous tax regime is similar conceptually, but computing the tax due requires the use of calculus. Suppose that at time 0 one dollar is invested risklessly at a $10 \%$ annual rate as in the text examples. As shown in the previous Part, at time $t$ the dollar will have grown to $V(t)=e^{r(10 \%) t}$ in value. During each instantaneous interval $\mathrm{dt}$, the asset increases in value by $\mathrm{r}(10 \%) \times \mathrm{e}^{\mathrm{r}(10 \%) t}$ $x \mathrm{dt}$ using the fact that the time derivative of the asset value is $\mathrm{dV} / \mathrm{dt}=$ $\mathrm{r}(10 \%) \times \mathrm{e}^{\mathrm{r}(10 \%) \mathrm{t}}$. Under a continuous tax, the proportion $\theta$ of this instantaneous gain is taxed away leaving $(1-\theta) \times \mathrm{r}(10 \%) \times \mathrm{e}^{\mathrm{r}(10 \%) t} \mathrm{x} d \mathrm{~d}$ as the amount kept by the taxpayer. A continuous tax therefore reduces the instantaneous rate of return from a constant rate of $\mathrm{r}(10 \%)$ to a constant rate of $(1-\theta) \times \mathrm{r}(10 \%)$. Thus, the after-tax return from a one dollar riskless investment under a continuous tax is $\mathrm{e}^{(1-\theta) \mathrm{r}(10 \%) t}$, and the annual after-tax interest rate is

$\operatorname{ATDR}(0)=\mathrm{e}^{(1-\theta) r(10 \%)}-1$

The notation "ATDR $(0)$ " signifies the after-tax discount rate for a tax with a period of zero, that is, for a continuous tax.

As an example, consider the case of a $20 \%$ taxpayer. Setting $\theta=.20$ and $r(10 \%)=0.09531$ in (A2) yields $\operatorname{ATDR}(0)=0.0792$. This is the number that appears in the second column of Tables II, III and V as the after-tax discount rate for the taxpayer.

\section{Computing the Equivalent Tax at a Given Time}

The central results in Tables I-III, VI and XIV are equivalent taxes at a given time. The concept of the "equivalent tax at time $t$ " is used to compare taxes of different periodicities. Thus, in Table 1, the equivalent tax at time 2 is computed for a continuous tax, for a tax of period one, and for a tax of period two. To obtain these equivalent taxes, taxes at times other than time 2 are translated to taxes at time 2 using the aftertax interest rates calculated in the previous Part. These taxes are then added to the actual tax at time 2 (if any) to yield "the equivalent tax at time 2." Since the taxpayer's after-tax interest rate has been used to derive the equivalent tax, the taxpayer will be indifferent between paying this tax at time 2 and paying the stream of taxes used to calculate the equivalent tax.

As an example, consider the equivalent tax at time 2 for annual assessment in Table I. This tax is $\$ 18.34$. Annual assessment will occur twice during the two years between time 0 and time 2. The asset studied in Table I exhibits a gain of $\$ 30.91$ between time 0 and time 1 and a gain of $\$ 13.09$ between times 1 and 2 . The tax rate is taken to be $\theta=.40$ in computing Table I. The tax at time 1 would be $0.4 \times \$ 30.91=\$ 12.36$. 
Using (A1) with $\mathrm{n}=1$ and $\mathrm{r}(10 \%)=0.09531$, the after-tax discount rate is $\operatorname{ATDR}(1)=0.06$. The time 1 tax of $\$ 12.36$ therefore translates to a tax of $\$ 12.36 \times(1.06)=\$ 13.10$ at time 2 . There is also an actual tax at time 2 on the gain of $\$ 13.09$ that occurs between times 1 and 2 . This $\operatorname{tax}$ is $0.4 \times \$ 13.09=\$ 5.24$. The sum of $\$ 13.10$ and $\$ 5.24$ is the $\$ 18.34$ "equivalent tax at time 2" presented in Table I.

For continuous taxation, the computation is similar. The asset represented in Table I jumps from $\$ 100$ to $\$ 119$ at time 0 and then increases at the constant instantaneous rate of $\mathrm{r}(10 \%)$ for two years. Translating the continuous increase from $\$ 119$ to $\$ 144$ over the two years to an equivalent tax at the end of year two is particularly easy: This tax is equal to the pre-tax gain of $\$ 25(=\$ 144-\$ 119)$ minus the after-tax gain during the two-year period. This after-tax gain occurs at the constant instantaneous rate of $(1-\theta) \times \mathrm{r}(10 \%)$ and is therefore equal to [\$119 $\left.\mathrm{e}^{(1-\theta) \mathrm{r}(10 \%) 2}\right]$ $\$ 119$. The table is based on $\theta=.40$. Using this value along with the fact that $\mathrm{r}(10 \%)=0.9531$ yields $\$ 14.42$ for the after-tax gain. Subtracting this from $\$ 25$ yields $\$ 10.58$ as the time 2 equivalent of the tax on the constant exponential growth from $\$ 119$ to $\$ 144$ during the two years. The instantaneous gain of $\$ 19$ at time 0 will be taxed at that time by a continuous tax. Using $\operatorname{ATDR}(0)=0.0589$ based on a tax rate of $\theta=.40$ the tax of $0.4 \times \$ 19$ at time 0 translates to a tax of $0.4 \times \$ 19 \times(1.0589)^{2}=$ $\$ 8.52$ at time 2. The total equivalent tax at time 2 is therefore $\$ 10.58+$ $\$ 8.52=\$ 19.10$, as appears in column two of Table I.

The equivalent taxes in Tables II, III, VI and XIV are calculated using the same approach as in these examples. ${ }^{268}$

259. Calculating the first entry in the second column of Table VI is a bit tricky. This entry is the tax at time 1 that is equivalent to taxation with a period of two years on the one year gain of $\$ 10$ from an asset that starts at $\$ 100$ and grows at a constant $10 \%$ annual rate. The $\$ 10$ gain will result in $\$ 4.00$ of tax at the end of year two. The after-tax discount rate for a tax with period two is ATDR(2) $=0.0611$ so that the $\$ 4.00$ tax at time 2 is equivalent to a tax of $\$ 4.00 /(1.0611)=\$ 3.77$ at time 1 .

This $\$ 3.77$ is the figure that appears in Table VI as the first entry in the second column.

Table XIV involves some computations that are so lengthy that use of a computer is advisable. That table studies taxation of an asset that grows risklessly for 16 years at a constant annual rate of $10 \%$. The table computes an equivalent tax at the end of the 16 years for accretion taxes with 10 different periodicities. The ten tax periods include one week, one month, three months, six months, one year, two years, four years, eight years, and sixteen years as well as continuous taxation.

To see why it is desirable to use a computer to do some of the computations, consider the case of a weekly period. A "week" is taken to be exactly $1 / 52$ years. There are exactly $832(=16 \times 52$ ) of these weeks in 16 years. During each week, the asset will increase in value a certain amount. The tax on this amount is computed by multiplying by .4 , the tax rate used in the example. This tax must be brought forward with interest to the end of the 16 years. The proper interest rate is the after-tax discount rate for a tax with a weekly period. Using equation (A1), this rate is 0.058875 on an annualized basis. (The corresponding rate for continuous taxation is only slightly lower: 0.058853 .) The tax due at the end of week $n$ must be multiplied by 1.058875 raised to the power $(832-n) / 52$ to translate that tax with interest to the end of the 16 year period. The sum of all 832 translated taxes is the equivalent tax that is desired. 


\section{Computing After-Tax Present Value}

Column four of Table III, column five of Table IV, column three of Table $\mathrm{V}$, columns two and three of Table $\mathrm{X}$ and columns two and three of Table XI consist of after-tax present values. The method for computing after-tax present value is closely related to the method for calculating equivalent taxes detailed in the previous Part. In particular, choosing the appropriate after-tax discount rate is the crucial step in computing both after-tax present value and equivalent taxes.

Consider, for example, the results in column three of Table V. The algebra used to reach these results is set out in footnote 117. As indicated in that footnote, the values $\$ \mathrm{X}$ in column three are computed according to the formula:

$$
\$ \mathrm{X}=[144 \mathrm{x}(1-\theta)] /\left[(1+\mathrm{d})^{2}-\theta\right]
$$

where $d$ is the after-tax discount rate. The setting for the computations in this table is a world where all transactions are subject to continuous taxation except the one analyzed in the table. Since the taxpayer can borrow and lend only at the after-tax rate that applies under a continuous tax, $\$ \mathrm{X}$ should be computed using ATDR(0), the after-tax discount rate for a continuous tax. The value of $d$ used in equation (A3) should therefore be $\operatorname{ATDR}(0)$ computed according to equation (A2) for each particular value of $\theta$.

There are two examples that involve a slightly different kind of present value computation. The first of these examples is expressed in Tables $\mathrm{X}$ and XI. The second includes the asset path plots in. Figure 3 and the surrounding discussion. These examples are different because the investment being valued is risky. In both examples, investors are assumed to be risk-neutral.

A risk-neutral investor does not care about risk and therefore does not require any risk premium in excess of the riskless rate to invest in risky assets. If there is a risky cash flow that will be paid at some future time, the risk-neutral investor values this cash flow by computing the average cash payment at that time and by discounting this average payment to present value using the riskless rate. An average payment is computed by multiplying each possible payment outcome by its probability and adding up all the resulting numbers.

To show how the computations work for a risk neutral investor investing in a risky asset, the following discussion focuses on the example set out in Tables X and XI. The computations for the other example, the one that is expressed in Figure 3 and the surrounding discussion, are similar. The only significant difference is that the Figure 3 example requires computation of a continuous tax rather than a periodic tax. The methods for computing a continuous tax have already been detailed in Part III of this Appendix. 
In the example that generates Tables $\mathrm{X}$ and $\mathrm{XI}$, one lottery will occur after one year and another after two years. Each lottery has two possible equally likely outcomes of 500 or -100 , and both lotteries pay off at the end of year two even though the outcome of lottery one is revealed at the end of year one. Thus, the sequences win-win, win-lose, lose-win and lose-lose result in payoffs of $\$ 1000, \$ 400, \$ 400$ and $-\$ 200$ respectively at the end of year two.

Table $\mathrm{X}$ lists the pre-tax values of the asset at times 0,1 , and 2 under each of the paths. These pre-tax values are calculated using the pre-tax interest rate of $10 \%$. Thus, the value of the asset at time 0 is the discounted value of each of the four outcomes multiplied by $1 / 4$ and summed. This is $.25 \times(\$ 1000+\$ 400+\$ 400-\$ 200) /(1.1)^{2}=\$ 330.58$. This number fills the second column of Table $X$.

If the investor learns at the end of the first year that $\$ 500$ is the outcome of the first lottery, then the investor faces an equal probability of ending up with $\$ 400$ or $\$ 1000$ at the end of year two. These two possibilities are simply the sum of the $\$ 500$ result of the first lottery and the equally likely outcomes of $-\$ 100$ and $\$ 500$ in the second lottery. The present value of the investment (at the end of year one) is therefore $1 / 2 \mathrm{x}$ $(\$ 1000+\$ 400) /(1.1)=\$ 636.36$. This is the result in the first two entries in column three of Table X. The remaining entries in that column are calculated similarly. These entries stem from the situation where the first lottery results in the low outcome of $-\$ 100$. The present value of the investment is then $\$ 90.91$. This represents a loss of $\$ 239.67$ from the initial value of $\$ 330.58$.

Table XI calculates the after-tax value of the investment at time 0 under different tax rates. The second column assumes annual assessment for the investment. The third column assumes that there is no tax until the cash out at the end of year two but that the taxpayer can exercise a timing option by selling and realizing any loss that occurs at the end of year one. A loss of $\$ 239.67$ will occur at time 1 if the first lottery results in the low outcome of $-\$ 100$. This loss will have a value at time 1 equal to the tax rate times the $\$ 239.67$ loss. The taxpayer then repurchases the asset at the $\$ 90.91$ price.

For a risk-neutral individual, the after-tax value of the investment at time 0 is $1 / 4$ times the after-tax present value of each of the four equally likely outcomes. It is assumed that riskless assets are taxed annually so that the appropriate discount rate is ATDR(1) from equation (A1) in the previous Part. This discount rate depends on the tax rate that applies.

As an example, consider the case of a $20 \%$ bracket taxpayer under the timing option case in the third column of Table XI. For this tax rate, $\operatorname{ATDR}(1)=.08$. Let ATDF $=1 /(1.08)$ be the discount factor. The after-tax values of the four outcomes are computed as follows: 
win-win: There are no cash flows or taxes after the first year. At the end of the second year, the taxpayer receives $\$ 1000$ in cash and has taxable income of $(\$ 1000-\$ 330.58)=\$ 669.42$. Twenty percent of this $\$ 669.42$, or $\$ 133.88$, is paid in tax. The after-tax cash flow at the end of the second year is $(\$ 1000-\$ 133.88)=\$ 866.12$. The time 0 present value of this outcome is $\$ 866.12 \times \mathrm{ATDF}^{2}=$ $\$ 742.56$.

win-lose: The present value of this outcome is computed in exactly the same way as the win-win outcome. The only difference is that $\$ 400$ is substituted for $\$ 1000$ as the terminal cash flow. The present value of this outcome is $\$ 331.03$.

lose-win: This outcome involves a tax benefit at the end of year one. The asset falls from $\$ 330.58$ in value to $\$ 90.91$ at the end of year one. The asset is sold at that time, and the loss of $\$ 239.67$ results in a tax benefit worth $\$ 239.67 \times .2=\$ 47.93$. The time 0 present value of this tax benefit is $\$ 44.38$. The asset is repurchased for $\$ 90.91$, and at the end of year two yields $\$ 400$ in cash less the tax liability of $.2 \times(\$ 400-\$ 90.91)=\$ 61.82$. The time 0 present value of this $(\$ 400-\$ 61.82)=\$ 338.18$ is $\$ 338.18 \times$ ATDF $^{2}=$ $\$ 289.94$. Adding $\$ 289.94$ and $\$ 44.38$ yields the total time 0 present value of $\$ 334.32$.

lose-lose: The time 0 present value of this outcome is computed in exactly the same way as the lose-win outcome except that the final cash flow is $-\$ 200$ instead of $\$ 400$. The time 0 present value of this outcome is $-\$ 77.21$.

The four outcomes have time 0 present values of $\$ 742.56, \$ 331.03$, $\$ 334.32$ and $-\$ 77.21$. Since these outcomes are equally likely, a risk-neutral individual will add them up and divide by four to obtain the overall value of the investment. The result is $\$ 332.68$. This is the value reported as the second number in the third column of Table XI. The other values reported in columns two and three of that table are computed in a similar fashion. 
